Portland State University

PDXScholar

7-17-1996

\title{
An Exploratory Evaluation of Language and Culture Contact by Japanese Sojourners in a Short-term US Academic Program
}

Elizabeth Anna Harley

Portland State University

Follow this and additional works at: https://pdxscholar.library.pdx.edu/open_access_etds

Part of the Bilingual, Multilingual, and Multicultural Education Commons Let us know how access to this document benefits you.

\section{Recommended Citation}

Harley, Elizabeth Anna, "An Exploratory Evaluation of Language and Culture Contact by Japanese Sojourners in a Short-term US Academic Program" (1996). Dissertations and Theses. Paper 5168. https://doi.org/10.15760/etd.7044

This Thesis is brought to you for free and open access. It has been accepted for inclusion in Dissertations and Theses by an authorized administrator of PDXScholar. Please contact us if we can make this document more accessible: pdxscholar@pdx.edu. 
THESIS APPROVAL

The abstract and thesis of Elizabeth Anna Hartley for the Master of Arts in TESOL were presented July 17, 1996, and accepted by the thesis committee and the department. COMMITTEE APPROVALS :
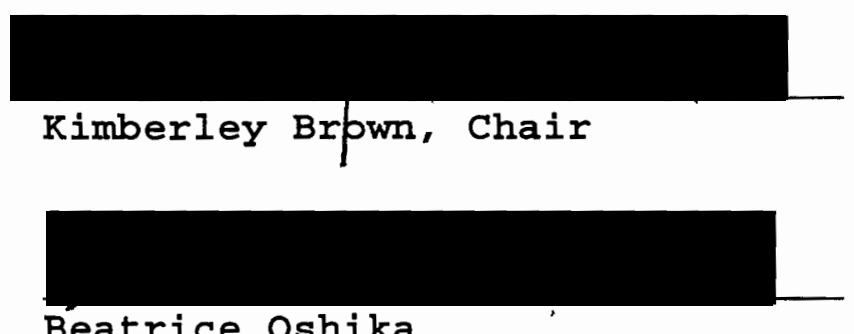

Beatrice Oshika

DEPARTMENT APPROVAL:
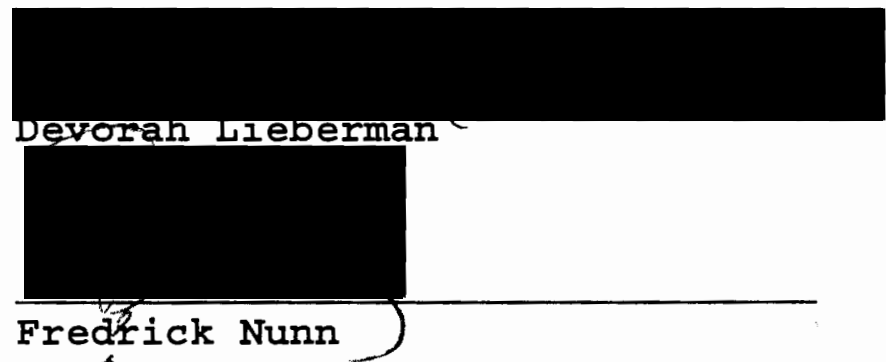

Representative of the office of Graduate Studies

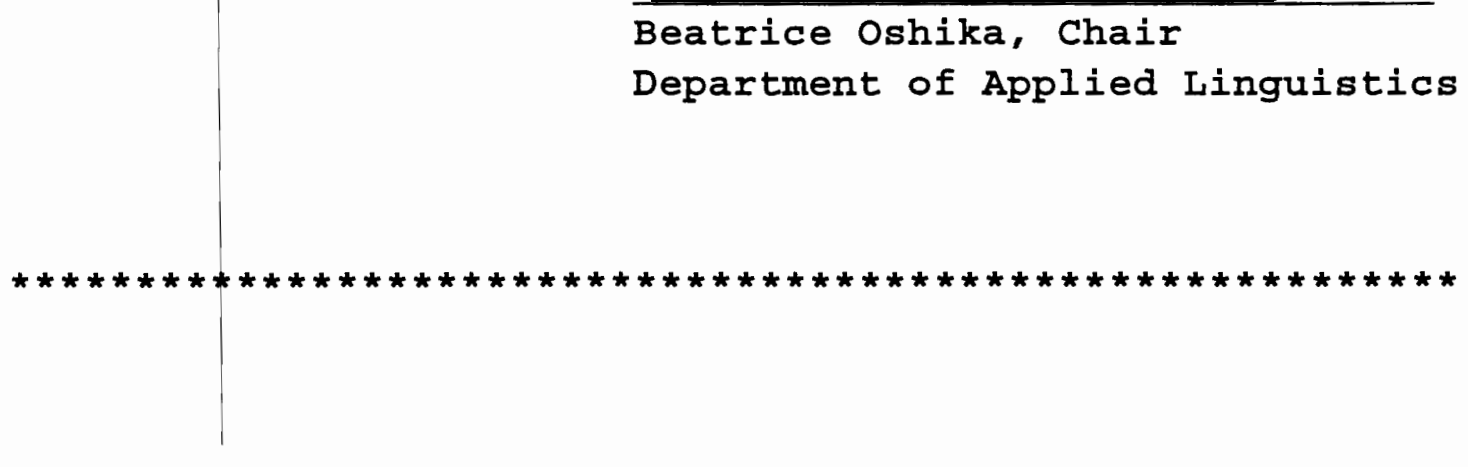

ACCEPTED FOR PORTLAND STATE UNIVERSITY BY THE LIBRARY by on

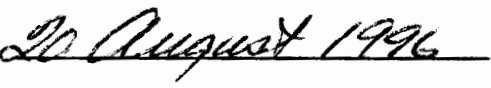




\section{ABSTRACT}

An abstract of the thesis of Elizabeth Anna Hartley for the Master of Arts in TESOL presented July 17, 1996.

Title: An Exploratory Evaluation of Language and Culture Contact by Japanese Sojourners in a Short-term US Academic Program.

Short-term intercultural exchange programs provide a wealth of information and experiences for participants. Participants are given the opportunity to travel out of their native country and are exposed to new languages and cultures.

This case study looks at the Japanese sojourners in the Northwest/ Pacific Rim (NWPR) summer program. The purpose was to examine the language use of the Japanese sojourners throughout the course of the NWPR program. This case study sought to determine when the Japanese sojourners used English and/or Japanese, in which 
situations, what strategies the Japanese sojourners employed and who initiated contact with whom.

All of the data was gathered from a participant observer who also employed various ethnographic methods. The Japanese sojourners were observed informally and six were interviewed formally. All four of the ESL teachers were also formally interviewed to provide as wide a range of information as possible.

The results showed that the Japanese sojourners did, in general, have a positive experience in the NWPR program but they did not learn as much English and intercultural sensitivity as they could have. Although this case study was focused on the language use of the Japanese sojourners aspects of program evaluation inevitable infiltrated in. 


\title{
AN EXPLORATORY EVALUATION OF LANGUAGE AND CULTURE CONTACT BY JAPANESE SOJOURNERS IN A SHORT-TERM US ACADEMIC PROGRAM
}

by

ELIZABETH ANNA HARTLEY

A thesis submitted in partial fulfillment of the requirements for the degree of

\author{
MASTER OF ARTS \\ in \\ TESOL \\ Portland State University \\ 1996
}




\section{DEDICATION}

To my parents, who gave me life and provided me with vast amounts of love and guidance, I dedicate this thesis. 


\section{ACKNOWLEDGMENTS}

This is it I have finished another stage of my life. I am no longer a student. That feels strange to me since that is all I have known for the last nineteen years of my life. I am now moving into the working world. I will start my adventures in Ecuador and only destiny knows where I will go from there. As I look at what I have accomplished I have to admit that I feel very proud of myself but I also feel gratitude to all those that have helped me along the way.

It took me three years to be able to finish my masters degree and in this time I was forced to make many life changes. The second term of my graduate studies will always remain clear in my mind because it was during that term that my dear dear father became dreadfully ill. It was determined that he had a gran mal tumor in the center of his brain and a month later he was dead. I was shocked and heart broken. I considered dropping out of school to be able to spend more time with him before he passed away 
but he would not hear of it. "Stay in school", he told me and so as I graduate with my masters I hope that he is watching me and I hope that he will be proud of what I have accomplished. He was so courageous until his last day and I can only hope to be so courageous in my life. I must also mention my mother who is in fact my idol. She has demonstrated how a strong will and determination lead to success. I love her with all my heart and there is no way that I could have made it this far with out her as an example, confidant, friend and mother. She is my inspiration and I hope that in my life he will be proud of the choices that I have made and the accomplishes that I have accrued. She gave me the gift of life and the gift of finding wonder in even the smallest most insignificant of things.

I would also like to mention my dear "little" brother. He is the sweetest man I have ever met. I hope that he will have a successful life and realize that he can conquer anything with a little smile, a little love and a lot of hard work. 
My many friends that have stood by me through thick and thin are also in my thoughts. Arie, my inseparable other half, helped my learn how to make a chart on the computer and also made sure to encourage me along the way. She never lost faith in the fact that I would be able to finish this thesis. She is a very strong woman and I have learned a lot from her. There are others who also deserve to be mentioned; Jian Li Zhao, my beautiful first college friend who will always have a special place in my heart; Alejandro, who understood and listened and always knew the perfect time to bring flowers; Jennifer, who's editing made all the difference, ; Vidya, who helped me through the final chapter; and to everyone else who has helped and supported me. Thank you and remember to

Take a deep breath

Life is what you make it and Anything is Possible 


\section{TABLE OF CONTENTS}

LIST OF FIGURES.....................

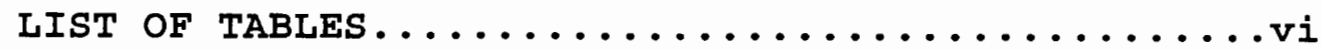

I INTRODUCTION.......................

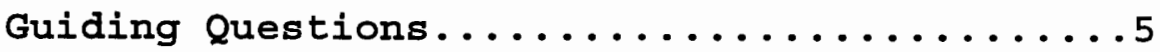

The First Few Days..................

The Outdoor Wilderness Trip...............

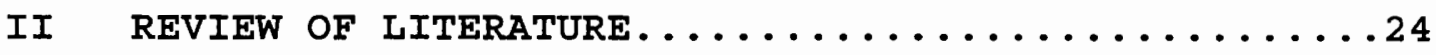

Introduction......................24

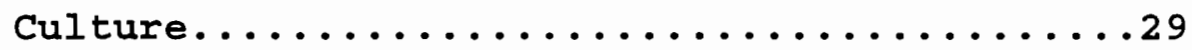

Exchange Program/ Study Abroad............... 31

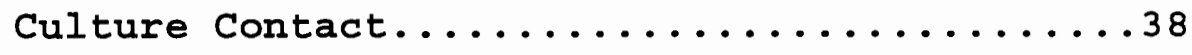

Intercultural Adjustment (Adaptation)...39

Culture shock.................43

Language Learning................... 45 
Content-Based Instruction............47

Successful Culture Contact............49

summary...........................

III METHODS...........................

Introduction.......................

The Researcher....................... 54

Gaining Entry......................

subjects........................... 55

Length........................... 57

Case study........................ 58

Ethnography...................... 61

Participant Observation..............69

Program Evaluation....................

Procedures.........................

Limitations.......................

IV $\quad$ RESULTS..............................

Introduction........................

A Typical Day....................... 81 
Outside the Formal Setting of the Classroom..86 Daily Activities...............86 Conversations.................. 89

The Results of the Formal Interviews....92

strategies......................116

summary......................118

Inside the Formal Setting of the Classroom...118

ESL Classes...................119

Content Classes.................130

Colloquiums...................139

v DISCUSSION AND CONCLUSION...................

Discussion.........................

Additional Pertinent Information......158

Suggestions........................

Conclusion..........................

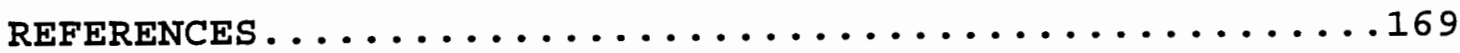


APPENDICES
A THE 1995 NWPR SUMMER PROGRAM CALENDAR......174
B THE ALMOST DAILY SHINBUN.................. 191

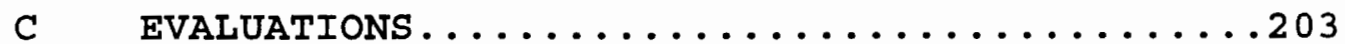

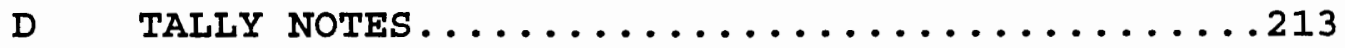


LIST OF FIGURES

1 Yumiko's Communication Chart.............994

2 Satoko's Communication Chart............95

3 Yoko's Communication Chart..............97

4 Koichi's Communication Chart............98

5 Satoshi's Communication Chart............102

6 Usamu's Communication Chart..................

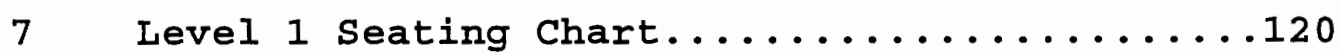

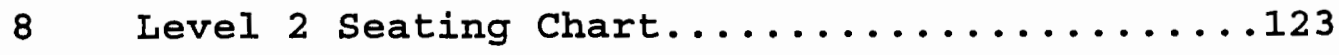

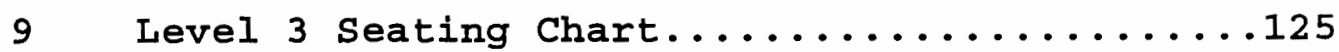

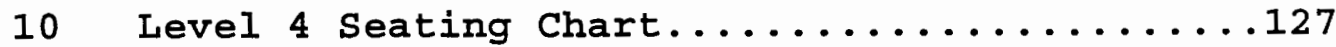

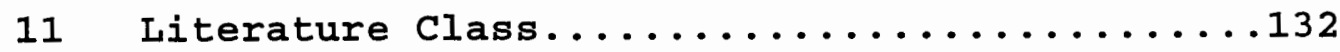

12 History/Culture Class........................ 


\section{LIST OF TABLES}

TABLES PAGE

1 Summary of Communication Charts of the

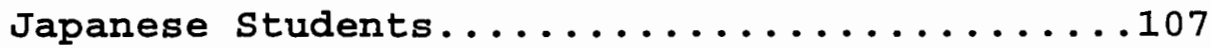

2 Students Participation: Voluntary verses Non-voluntary Answers in the Literature

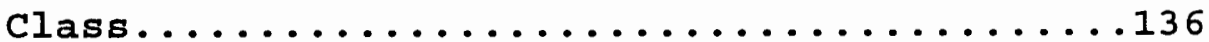

3 Students Participation: Voluntary versus Non-voluntary Answers in the History/Culture Class.................137 
CHAPTER I

\section{Introduction}

The best way to learn about a new culture and language is to experience it first hand; one way to do this is by participating in an exchange program. For the past four years there has been a cross-cultural exchange program sponsored by a coalition of $\mathrm{NW}$ universities and a very influential Pacific Rim university housed at a NW college in the US. This program, for Japanese sojourners and American students, claims to be a highly innovative program that provides intercultural educational exchange opportunities. The students all live together in a dorm and are in constant contact with each other in and outside of the content and language classes that are offered.

The Northwest/Pacific Rim (NWPR) program is a product that was years in the making. Since 1988, administrators and educators from the Pacific Rim University and academic, governmental, business and community leaders in 
Oregon have been involved in the development of this experimental intercultural concept. "The program is based upon a concept of education transcending national and institutional borders and barriers" (student Bulletin, p. 1). The hope and expectations of the organizers are that "an assessment of the current program will further demonstrate that it is a significant directional sign on the road to a permanent cooperative program based in a metropolitan city" (Student Bulletin, p. 1). The goal is to create a relationship that will last and benefit all who participate. Throughout this study pseudonyms were used to protect the identity of informants and institutions.

The designers of this program were trying to form an environment where American students (from various states) are brought together with students from the Pacific Rim University and given the opportunity to learn about each other's cultures. The unifying belief is that education can cross borders and unify people. It is important that the program work and that the students have the most positive experience possible. 
However, teachers have commented on the lack of equality between the Japanese sojourners and the American students and the less than desirable organization of the classes. This lack of equality and organization arises for various reasons. The lack of equality is a result of the fact that the content classes are all taught in English. The Japanese sojourners' level of English proficiency is not always adequate enough for comprehension of the presented information.

Although the Japanese sojourners attend a prestigious university in Japan and are some of the best students from their university, they are at an immediate disadvantage when they start this program. The American students are doing all their reading in English without being slowed down while the Japanese sojourners are slowed down considerably. Due to this inequality and disadvantage, the Japanese sojourners do not always perform at the level that has been expected of them or that they expected of themselves. Since all the content classes are in English and since the Japanese sojourners have frequently had difficulty understanding the readings and some of the 
lectures, it is very possible that they may be deprived of various intercultural experiences because they have to spend so much time in their rooms reading and, ultimately, simply translating their assignments.

The ESL teachers made comments and suggestions concerning the ways that the ESL classes and the content classes were organized in relation to each other. Almost all of the cross-cultural contact and learning took place outside of the classroom. The classes contributed very little to the facilitation of the cross-cultural aspect of the program due to the lack of understanding on the Japanese students' part and the amount of topics covered in the content classes.

This case study describes the nature of the crosscultural contact of the Japanese sojourners in formal and informal settings through the use of ethnography, participant observation and program evaluation. This case study will also be looking at what constitutes success for the students, the ESL teachers and the program administrators. In a qualitative, descriptive manner I will also look at possible causes of success or failure. 
Guiding Questions

These are the guiding questions that formed the basis of the research. The questions are aimed at understanding and identifying the intercultural contact dimensions of the program.

1) What is the nature of the cross-cultural contact between the Japanese sojourners and American students?

a) Within the formal structure of the classroom:

i) In what contexts do the Japanese sojourners use English? Who are the interlocutors who are involved when the second language is used?

ii) What are the contexts in which the Japanese sojourners' first language is used? Does this change throughout the course of the program?

iii) What strategies are the Japanese sojourners using to get their ideas across?

iv) Who initiates contact and with whom?

b) Outside the formal structure of the classroom:

i) In what contexts do the Japanese sojourners use English? Who are the interlocutors who are involved when the second language is used? 
ii) What are the contexts in which the Japanese sojourners' first language is used? Does this change throughout the course of the program?

iii) What strategies are the Japanese sojourners using to get their ideas across?

iv) Who initiates contact and with whom?

Kramsch (1989) clearly states what actually happens when one decides to expand one's views and learn other languages and other cultures:

Foreign language learning is educational. It offers the opportunity for emancipation from the confines of learners' native habitat and culture, with the development of new perceptions and insights into foreign and native cultures alike. It is an experience whose complexity is only partly captured by accounts of teaching grammar, reading foreign literature, visiting foreign countries on academic exchanges, studying foreign political systems, social issues and historical trends. It is all of these intellectual endeavors, but also the emotional experience of abandoning one's own language, cultural and ethnic identity, leaving home and country literally and metaphorically and becoming deeply involved with exotic people, places, food, life style and all that makes a culture as a way of life. It is, finally, the opportunity to reflect upon oneself and one's own culture from the archimedean standpoint of another language and culture, and the acquisition of new insight into self and native surrounds which are fundamental to the notion of education. (p. 15) 
Kramsch (1989) shows that there are many factors to consider when organizing and developing an exchange program. On the surface it may appear to be a simple and beneficial way for countries to strengthen their political and social ties, but kramsch (1989) reminds us that things are not always as simple as they may appear. All the issues mentioned in the quote by Kramsch (1989) have come up in this program. Experienced professionals need to be on hand to show the processes and choices of language and culture learning to the students.

The following is a twelve page narrative about the first eight days in the NWPR program including the three day outdoor wilderness trip in which all students were required to participate. I, a participant observer, need you, the reader, to be able to see this program as a whole. I want you to receive the same information, knowledge and experiences that we, the students, received. In order to understand my conclusions, it is necessary to step into the program with me.

As you read you will see two groups of students from very different cultures come together, start to break down 
language and cultural barriers and begin the process of forming friendships. Take notice of the preparation and the intercultural training that the American students receive and any activities that address cross-cultural issues. The narrative consists of two sections: the first few days and the outdoor wilderness trip.

The First Few Days

It is the first day at the NWPR program and all the American students are arriving. There are American students from Oregon (Portland, Eugene, Corvallis, etc.), Washington (Seattle, Tacoma, etc.), California (L.A., etc.), Utah, Hawaii, one from Korea and one from Germany. As we arrive one of the four Resident Hall Assistants (RAs) meet us and take us to our rooms. The rooms are bigger than the dorm rooms that I am familiar with. My room has a set of bunk beds, a single bed, three desks, and two closets. The room is pleasant and bright due to the big window that takes up most of the outer-facing wall. In each room there are keys, towels and a folder with important information for us. There is also a three 
inch thick, three ring binder that contains the readings for the content classes. Each student will take two of the three content classes offered. As I walk around and slowly get to know the other American students, it comes to my attention that all of the American students have taken the single beds in their rooms. I am the only exception, having chosen the bottom bunk out of personal preference.

It is rather quiet in the hall and most people have their doors closed. There is tension due to expectations as to what will happen in the next six weeks. We all seem to have certain ideas about Japanese culture and these ideas may or may not be based on actual experiences gathered first hand. I am wondering if what I presume to know about Japanese people and Japanese culture will be supported or destroyed. I have always thought that Japanese people are very polite, quiet, studious, considerate and reluctant to answer negatively to questions. As I talk with the other American students I realize that they also have similar views on Japanese people and culture. The American students are together 
for three days before the Japanese students arrive. There are many speculations as to what it will be like to live with Japanese students and what they will be like. Some are wondering what conflicts may arise. I am wondering how I will know if my roommates are having a problem or if they disagree with me. Some of the other American students are wondering how they will be dividing the two closets between three people. Will the Japanese students really be as polite and considerate as they appear to be in brief contact?

Now that I am in this program I realize that even though I have only moved fifteen minutes from my home and have remained in familiar surroundings I am now going to be in a different atmosphere and subculture. I have left what I know very well and now I will be in close contact with people who are from the other side of the world. These people speak a language that I do not understand and they have a culture that is unknown to me. I am nervous about sharing my day-to-day life with them and yet I also welcome the challenge to open my eyes and see the world through different and unimagined perspectives. I can not 
help thinking that six weeks is a long time and I hope that I will enjoy the time.

There are varying degrees of contact and experience with Japanese culture and language. A few students have just returned from Japan; some have visited or studied there; some have lived with Japanese people here in the United States; some have studied the Japanese language; and others have had little to no contact with Japanese culture or language. Despite all these differences, everyone appears to be interested in learning and eager to be open minded.

All of the students will live in the same dorm, the women on the second floor and the men on the first floor. We are in constant contact with one another. Each American student has either one or two Japanese roommates. We all compare and practice our roommates' names. I feel so comfortable living alone in my room and am nervous about my Japanese roommates' arrival, and yet I am very excited and cannot wait to meet them. I am a graduate student and I have lived alone for four years. I fear that it will be difficult for me to live with and be able 
to share my personal space with other people. I am also nervous about the fact that my roommates will be a few years younger than me.

Day two and three consist of program orientation. Many students comment that the orientation is long and not very helpful. The orientation consists of various activities: orientation meetings to the program, previews of the content classes, excursions to interesting spots downtown, movies and visits to local people's homes.

The content classes that are offered will be cotaught by a Japanese teacher and an American teacher. The American teachers are here to give a preview of the classes and to explain how the theme of the program, Equality and Inequality, will be integrated into the class topics. The American teachers comment that they are really eager to work with their Japanese counterparts. They will enjoy seeing a new perspective on the issues and topics that will be discussed. As we all sit in the class and listen to the previews of the content classes, it is easy to see that we are all extremely hot. Various people 
fan themselves with handouts while many others gaze forward with blank looks on their faces.

In addition to the previews of the content classes, meetings give us an opportunity to introduce ourselves to each other. We try to memorize everyone else's name. We have an opportunity to talk to some former NWPR program students. This is the only chance the program provides for us to learn about Japanese culture, what we should be aware of and what to look out for before the Japanese students arrive. I want to have an idea of how the Japanese students may express themselves, problems that previous students have had, areas where communication breakdowns may occur, difficulties with living in such close contact with others, etc...

Finally the day has come for the Japanese students to arrive. We feel so excited and no one wants to leave to explore Portland for fear that the Japanese students will come while we are gone. When the Japanese students arrive we are eating lunch in the cafeteria. One of the RAs runs in the cafeteria yelling, "They are here!!" We quickly put away our trays and run outside to welcome them, 
introduce ourselves, and show them to their rooms. As the Japanese students get off the buses, a very eager crowd of American students searches almost desperately for their roommates. The Japanese students wear name tags so the identification process is somewhat easier. You can hear us saying, "Where are my roommates?" "Do you see them?" "Mary, here is one of yours." After the initial scramble most of us are in our rooms starting the introduction process.

I have two roommates, Yuka and Kaya. They seem nice from my first impression. They are talkative and I am surprised at how high their level of English is. I notice that one of the women is more fluent than the other and appears to communicate with more ease.

Then the American students have another preview of a content class and the Japanese students are given an opportunity to get settled in, unpack, take naps, or whatever else they decide to do.

The next day is spent shopping since hardly any of the Japanese students brought any clothes with them. There are many van loads of students driven to the mall 
where a frenzy of shopping takes place. I go twice, first without my roommates and then with them. I help the Japanese and American students find the stores that will have what they are looking for. We arrive late for two meetings that day because once people enter the mall they are almost impossible to find again. As we all walk around the mall we are feeling more comfortable and we laugh and joke. I expect the Japanese students to not be very concerned with the amount of money that they spend, and this stereotype is soon broken. Some of the students do not seem willing to spend very much and wait until they find items at acceptable prices.

In the evening we have our welcoming dinner. For this formal occasion all of the students dress up in suits and dresses. We wait a long time before the food is served because all the important guests give their speeches first. At a later date I questioned the director as to why the welcoming dinner was not a fun event such as a barbecue. He said that it is very important for the Japanese people to have a formal opening and closing of the program to make it more official and respected. 
Before the speakers begin to talk there is a frenzy of picture taking by all of the students, Japanese and American. I am beginning to feel like I am on vacation. Then all the students sit down and the speakers begin. The president of the NW College, Jered Vojt, and various Pacific Rim administrators speak about their hopes and aspirations for the program.

The Outdoor Wilderness Trip

All of the students have been randomly divided into three groups. I am not with either of my roommates but there are students who are with their roommates. Each group will rotate between three activities which include rafting, hiking and rock climbing. There are 26 students in my group. There are four American women, four American men and eighteen Japanese. My group rafts first. My roommates and I do most of our packing the evening before we leave, but at seven o'clock in the morning we are still packing some last minute items. It is very hard to get up so early. The night before most of the students in the 
program went to a night club downtown and got home very late so they are especially tired and slow getting ready.

The American students and the Japanese students continue to get to know each other everyday. They feel so curious about us and we feel so curious about them. We continually ask questions and try to remember everyone's name. Before the Japanese students came all the American students had all the names of the people in the program memorized. Now that there are 45 new students with foreign names we are finding it difficult to remember them all.

The first thing that comes to my attention is that the minute the Japanese students are in a moving vehicle they immediately fall asleep. Their eyes ever so slowly get heavy and finally close as they drift into oblivion. Now when I fall asleep in a moving vehicle I become limp and fall on whatever happens to be near me. That may be a wall, a part of a seat or another human being. I know that when I am falling asleep I need to brace myself so that I will not make a fool of myself and end up drooling on someone. 
The Japanese students, on the other hand, remain in an upright position when they sleep. The van we were in was full, so each seat had three people and there was very little room to get comfortable. The Japanese students would just sit in an upright position and sway with the movements of the van. As I watch them I am sure that they will fall on each other at the next big curve and yet somehow they remain in the same positions and never touch their neighbors and never fall over. We are amazed at their ability to sleep. They are professional sleepers. We are also tired and eventually most of us are sleeping. The amount of sleeping makes traveling very quiet unlike a van full of American students which would most likely be very loud and out-of-control.

Once again picture taking goes on at all times. I have never seen people take so many pictures. After a while we are right there alongside the Japanese students. I think that the picture taking mania rubbed off on us. The picture taking starts before the welcoming dinner and never stops until the program ends. I think it takes us twice as long to do everything because we stop and take 
pictures so often. Mind you if we stop because one student wants to take a picture, inevitably everyone wants a picture in the same spot with their own camera.

The first day of the outdoor wilderness trip we are scheduled to raft. When we arrive, at the spot where we enter the river, everyone gets very excited. I am reluctant to go but everyone encourages me and are so supportive that I decide to try it despite my great fear of rafting. The other students and the guides say that they would watch out for me and that I should try because it will be really fun. Some people have rafted before and I make sure to be in a boat with them. People are constantly helping each other. Before we go into the water we apply suntan lotion to shoulders and backs. Every one helps each other reach the hard-to-get places. Suddenly I become aware of the fact that in a short time we have formed such close and supportive relationships. We met only a few days ago and already we talk, laugh, and joke around like old friends.

On the first night we camp outside without any tents. As soon as we arrive at the camp site people break into 
groups, some play Frisbee, some walk around, some climb a nearby hill, some sit, talk or help cook and prepare the dinner. In the evening we all sleep huddled together on tarps on the ground. Some people talk all night while others are so exhausted they fall asleep immediately. I find it difficult to sleep because I am not comfortable without a tent. I fear that bugs and night animals will crawl on my face and bite me.

In the middle of the night I feel something pinching my face so I brush it off. Then I realize what I did and I wake up and frantically search, with my flashlight for whatever I just brushed off my face. I see nothing. I decide to go back to sleep. Since the sleeping bags are loaned to us, I am inside a sheet inside the sleeping bag. All of this makes moving very difficult. I am about to fall asleep when I hear a noise between my ear and the ground. My heart stops beating as I grab whatever it is in the sheet. As I repeat, "Oh my god, oh my god!!!" I shine the flashlight on the thing. I do not know what it is. By now several people wake up. After a few minutes I gather enough courage to hurl the thing towards my feet 
and off the tarp. It turns out to be the biggest, black bug I have ever seen in my life. In a normal bed I would have screamed bloody murder, thrown the sheets off and ran. In a mummy bag running away is not an option because it is impossible. This experience shows me that I can handle situations in a different way and still make it through. Regardless, I sleep very little that night. Starting with the first meal, the men and women end up sitting at separate tables or in separate circles to eat. One or two of the American males come to sit with the women a couple of times but not that often. Some of the female American students notice this phenomenon and comment on it but the situation remains unchanged. A bit more mixing occurs in the sleeping situations but not that much more.

The Japanese students speak Japanese amongst themselves a majority of the time and only a few frequently speak English to the American students. The Japanese students understand a lot more English then they are able to produce. Of the American students who speak some Japanese, none of them has spoken in Japanese. 
The second day we hike on Mt. Hood and that night we sleep in tents. On this day it is possible to see evidence of the bonding that is taking place. Everyone treats each other very respectfully. For example the trail is difficult, wet, steep and slippery at times and people help each other at these places. Everyone is also willing to take breaks often to give people a chance to catch their breath. At night one group of American and Japanese students stay up almost all night talking and having a good time. The third day we rock climb. Everyone works together so well that we have a very successful day of rock climbing. We even have enough time for a quick swim in the lake before we head home. As we drive back people talk about eating, taking a nice hot shower and putting on clean clothes. We end the day with a pizza feast in downtown Portland. We are all famished and inhale many pizzas without even realizing it.

By the time we return to the dorms everyone is exhausted. We slept very little the last three days and we engaged in fairly demanding physical activities. The most important thing for me at the moment is to get home, 
take a shower and put on some clean clothes. Despite the exhaustion everyone is very happy. I am glad to see my roommates and we ask each other about our experiences and adventures. We enjoyed ourselves and in the end, friendships were beginning to form before we realized it. The previous narrative attempted to draw a picture of the beginning of a short-term exchange program. The next chapter, Review of Literature, will address some of the most important theoretical issues that are relevant to this program. These issues start with a definition of culture and then move on to discuss the following: exchange programs/study abroad, culture contact, intercultural adjustment(adaptation), culture shock, language learning, content-based instruction and successful culture contact. 
Chapter II

REVIEW OF LITERATURE

Introduction

This review of literature looks at the components involved in this case study starting with large general components and moving to the smaller sub-components. The chapter starts by presenting various definitions of culture.

Culture is not a superficial concept; it is not merely a definitive of particular foods, flags and festivals. Because culture is so deeply embedded in people's lives, this case study would be remiss to neglect a discussion of it. In order to understand all that was involved in the complete design of this program, an examination of the various definitions of "culture" is necessary, beginning with a bedrock definition that will serve as a starting point. 
After discussing culture, which encompasses all aspects of this study, the next step down is a discussion of exchange programs/study abroad. There are certain aspects inevitably involved in exchange programs, and in theory, there are recommended ways of conducting an exchange program so that the participants will receive adequate preparation beforehand, adequate support during and some sort of debriefing at the end of the program. After the section on exchange programs/study abroad, there is a review of three issues that result when two cultures come together in a cross-cultural exchange experience. This discussion starts with a brief look at culture contact. Culture contact is then further divided into intercultural adjustment(adaptation) and culture shock. These two issues are unavoidable results of culture contact.

Besides culture contact, exchange programs/study abroad involve language learning. Most programs involve going to new countries where a new language is spoken. Even if some of the participants are already familiar with the new language they will have to learn to use it in the 
sub-community in which they will be living. Language learning is included because it is one of the important components. In fact, it is so obvious it is commonly overlooked or simply not given enough attention.

The third component of the exchange program/study abroad that is included is content-based instruction. This section is especially relevant to the program under investigation in which the Japanese students are enrolled in ESL classes and content classes. This section highlights important issues in content-based instruction.

The last section to be introduced talks about successful culture contact which should be one of the main goals of exchange programs. Successful culture contact is affected by participants' individual characteristics and by the way that exchange programs are organized.

This chapter will give the reader a sense of the issues that presented themselves throughout the course of this study; in the end, it should be apparent how much is actually involved in exchange programs. On the surface they may simply look fun and educational, which they are, but under the surface there are many other issues that 
affect participants that should not be ignored. Before each component is addressed individually, there will be a brief introduction to all of them.

Many avenues exist whereby a person can encounter some form of cross-cultural experience, whether marginally or via complete submersion. Relative to the latter option, the most effective format is the exchange program, otherwise known as "study abroad". Offered by an array of organizations, this type of program frequently places the individual with a "host" family in a different country for a specified amount of time. The goal is to expand the individual's awareness and world view, thereby slowly creating a peaceful and unified global community (Bochner, 1982 \& Paige, 1986). In exchange programs, a person is taken out of the familiar surroundings of home and placed in an environment where new rules and behaviors must be learned; participants are given the opportunity to see the world from a different cultural angle. In the NWPR exchange program, the Japanese participants were submersed in American culture and, therefore, had the chance to 
assess the world from a different vantage point as well as share information from their own country.

Though the American participants did not have the experience of an "exchange" the way the Japanese participants did the mere act of "culture contact" provided cross-cultural exposure for both groups. Through daily interactions, everyone continually encountered an unfamiliar culture, and the need to assess both native and foreign cultures surfaced throughout the course of the program. Internal adjustment (an individual's acceptance and incorporation of new methods of communication) and culture shock were inherent and expected components of the program and served as the vehicles of personal growth.

Language learning is another facet of cross-cultural exposure. As a language is learned, speakers practice different methods and tactics of communicating. Speakers can learn the style and vernacular of their immediate environment. For example, while in the United states, the Japanese students had a chance to learn how American college students talk to each other on a daily basis. In effect, they were able to learn English by what is known 
as "content-based instruction", a strategy that focuses on exposing people to the reality of language use as opposed to its formality (Adamson, 1993 \& Koester et al, 1991).

In the NWRR program, the Japanese students were fortunate to be surrounded by peers who, knowingly or not, practiced content-based instruction by correcting English mistakes and clarifying misunderstood responses and behavior. In this way, they provided the tools which the Japanese could then use to better understand American culture.

\section{Culture}

Most researchers agree on certain aspects with respect to a definition of "culture": culture is most likely to emerge in adaptive interactions, consists of shared elements, and can be transmitted across time periods and generations (Triandis, 1994). Its constituents are the intangibles that guide people's lives (beliefs, teachings, faiths, traditions, and customs), passed down, consciously and unconsciously, from generation to generation. Each society has its own 
cultural values which govern the daily routines and views of its people. Triandis(1994) suggests:

One useful way to think about culture is to think of unstated assumptions, standard operating procedures, ways of doing things that have been internalized to an extent that people do not argue about them... Another way to think about culture is that it includes ideas and behavior patterns that are "obviously valid" for the members of the culture and that need not be debated. (p. 16)

Generally, people do not question or deliberate their cultural perspectives unless there is an instance where their natural responses to a given situation are challenged by another person's natural responses in the same situation.

Spradley (1980) believes that culture:

... is acquired knowledge people use to interpret experiences and generate behavior. Cultural knowledge is hidden from view yet it is fundamentally important because we use it constantly to generate behavior and interpret experiences. (p. 6)

When studying culture, a researcher looks at what people do (cultural behavior), what people know (cultural knowledge), and what people make and use (cultural artifacts) (Spradley, 1980). Culture is learned, reused, 
maintained, and defined by people interacting on a daily basis. It provides a way of seeing, categorizing, encoding and defining the world, including assumptions about the nature of reality and values concerning what is good, true and believable (Spradley, 1980). Culture encompasses people's lives to the extent that it may even imprison them. People can become culture-bound and oblivious to it until their view of the world is challenged by imposition from another culture.

\section{Exchange Programs/ Study Abroad}

"The principal goal of intercultural training should be to reduce the severity and shorten the duration of the newcomer's passage through the adjustment cycle" (Paige 1986, p. 6). M. Bennett (1986) believes that developmental models should be organized, the key organizing denominator of these models being a focus on the concept of "difference". Models should be designed that allow students to experience "difference", and then provide strategies that aid in comprehension of those particular differences. Developmental models can guide 
the sequencing of concepts and techniques to match the development of the individual students.

In Exchange Program developmental models, the focus is on "intercultural sensitivity" and how people view cultural differences and the experiences that led to these views. It is assumed that the cultural differences an individual focuses on will vary systematically as the person's perception of the new culture develops and changes (Bennett, 1986). This concept of "difference" is a central issue in the field of intercultural communication.

Bennett's (1986) model also includes increasing awareness and expanding understanding. Students pass through stages on their way to developing an understanding of other cultures, beginning with ethnocentrism and moving towards ethnorelativism. These stages are outlined in the model below.

Bennett's Developmental Model of Intercultural Sensitivity

The Ethnocentric states and their stages

I. Denial
A. Isolation
B. Separation

II. Defense 

A. Denigration
B. Superiority
C. Reversal

III. Minimization

A. Physical Universalism

B. Transcendent Universalism

The Ethnorelative states and their stages

IV. Acceptance
A. Behavioral Relativism
B. Value Relativism

V. Adaptation
A. Empathy
B. Pluralism

VI. Integration

A. Contextual Evaluation

B. Constructive Marginality

(Bennett, 1986, p. 32)

In the above model outline, ethnocentrism is defined as the assumption that one's world view, according to one's own culture, is central to all reality. In contrast, ethnorelativism is defined as the understanding that one's existence is not necessarily central to the reality perceived by all others.

This model lays out a map of the many issues and stages participants may go through. Before intercultural contact people naturally start out leaning towards ethnocentrism. What they know to be true naturally forms 
their reality. The model shows the stages people are likely to move through as they move away from ethnocentrism and towards ethnorelativism.

Cross-cultural orientation refers to those intercultural programs that are designed to prepare specific groups of learners to reside in specific target cultures for specific purposes. This includes reentry into one's own culture after sojourning abroad. (Paige, 1986, p. 2)

The history of cross-cultural orientation suggests that practitioners have been far too willing to experiment with new program ideas and have, thus, neglected to identify any conceptual and theoretical foundations (Kramsch, 1987). In order to have a successful program ideally there should be cross-cultural training for the participants.

Education and training in intercultural communication asks people to change their natural behavior. They are asked to transcend their traditional ethnocentristic characteristics and explore relationships across cultural boundaries. (Bennett, 1986, p. 27)

Bennett (1986) reminds us that intercultural contact asks people to look at many issues that they may have never even been aware of. People are asked to change what comes 
naturally to them and may be out of their level of awareness.

Kauffmann et al. (1992) state that the multitude of differences among students and the programs in which they participate can result in many different oulcomes. Perhaps the ideal description of a study abroad experience is "hard but good": a sojourner must work hard to find the good aspects in the experience. Being lonely, feeling foolish, stumbling over mispronounced words, letting go of stereotypes are a few common and hard components of living abroad. During such uncomfortable moments, inaccurate conclusions can be formulated if sojourners use their own culture as criteria to investigate other cultures (Kauffmann et al, 1992). Care must be taken to avoid falling into habitual negativity and, thus, missing out on the many positive experiences.

Intellectual development is the principal goal of academic programs abroad. Exchange program are meant to expand sojourners' horizons, but they should also learn the new language and culture of their host culture. Greater language acquisition can be expected abroad then 
at home. The amount of language learning increases with greater immersion in the foreign culture and less contact with fellow patriots (Martin, 1989). Sojourners show an increased knowledge of foreign countries where they study relative to their interest in reflective thought, systematic thinking, and in their familiarity with different schools of thought (Paige, 1986).

What method of language study works best abroad? The method that works best is one that incorporates what the foreign setting has to offer in the way of instances, practices and evaluations of the local environments (Kauffmann et al, 1992).

Success in language learning does not correlate with the amount of language studied before the sojourn. Even if the sojourners have studied the language extensively, they are often ill-equipped when expected to perform in a foreign school, for example (Paige, 1986). This was the case in the NWPR summer program. AIl of the students had received high scores on the TOEFL exam, and yet the majority of them could not understand what was happening in the content classes. The ESL instructors spent most of 
their time trying to help Japanese students understand the content courses.

Study abroad influences sojourners' international perspective (Kauffmann et al, 1992). Sojourners are more likely to develop positive attitudes toward the host culture if they start out with realistic expectations, spend a significant amount of time in the host culture (six months or more) and experience a high degree of immersion in the host culture (Bennett, 1986). An increased appreciation of the host culture can be accompanied by more critical views of the home culture and if these new ideas, values, and attitudes conflict with the home culture (Kauffmann et al, 1992). "Sojourners should develop a global understanding which involves an awareness of, interest in, concern for international events and issues" (Kauffmann et al., 1992, p. 74). study abroad is the prototype for a new perspective in education, a new approach to learning that is holistic and multifaceted. 


\section{Culture Contact}

Intercultural sensitivity is not part of our primate past nor has it characterized most of human history. Cross-cultural contact has been accomplished by bloodshed, oppression, or genocide. The continuation of this pattern in today's world of unimaginable interdependence is not just immoral or unprofitable it is self-destructive. Yet in seeking a different way, we inherit no model from history to guide us. (Paige, 1993, p. 21)

It is easy for negative feelings and impressions to develop when there is culture contact. These tendencies should be taken into account when teaching about or actually encountering culture contact. Trying to respond differently can be challenging. Students who experience intercultural contact are being asked to transcend their traditional ethnocentrism (Paige, 1993) and explore new ideas and views of the world as they cross cultural boundaries. It can take a great deal of dedication and perseverance to be able to change what one does naturally without thinking. 
Intercultural Adjustment (Adaptation)

As students come in contact with new cultures, they should be able to adjust and adapt to the ways of the other culture. According to Kim (1988), intercultural adjustment is defined as follows:

...the process of change over time that takes place within individuals who have completed their primary socialization process in one culture and then come into continuous, prolonged firsthand contact with a new and unfamiliar culture. (pp. 37-38)

The degree to which a sojourner will adapt to a new culture depends on the following: the desire of the sojourner to understand the new culture, the duration of the stay, the character of the sojourner, and the expectations the sojourner has of the host culture. The duration of the stay will affect both the sojourner's and the host's desires for adjustment and adaptation. Brislin (1981) distinguishes hosts' expectations between shortand long-term adjustment and adaptation of sojourners as follows :

During short-term sojourns, hosts frequently do not expect culturally appropriate behavior in all situations; mistakes are forgiven as long as the sojourner seems sincerely interested in learning about the culture. Over a longer time period, on the 
other hand, hosts expect greater sophistication and may react negatively if sojourners have not learned appropriate behaviors. (p. 271)

All of the above mentioned factors influence each other. A sojourner then has to go through a transition process; all sojourners go through this process in their own way. Adler (1975) has developed a model of transitional experiences based on the notion that:

...specific psychological, social, and cultural dynamics occur when new cultures are encouraged and...these behavioral dynamics are, in a large part, a function of perceptions of similarities and differences as well as changed emotional states. ( $p$. 15)

Adler (1975) explains that the transitional

experience is "a movement from a state of low self and cultural awareness to a state of high self and cultural awareness" (p. 15). He introduces his model by representing five stages: contact, disintegration, reintegration, autonomy and independence. As sojourners go through the transition process, they pass through these stages and hopefully are able to reach the last stage. 
Problems arise when sojourners remain in one stage for too long and are unable to move on.

Hall (1959) defines Japanese culture as a highcontext culture:

A high-context communication measure is one in which most of the information is either in the physical context or internalized in the person, while very little is in the coded, explicit, transmitted part of the message. (p. 79)

In other words, Japanese-style communication does not require that the message sender have as much responsibility in communication as does the message receiver. In the NWPR summer program, a few American students expressed that they had difficulties understanding whether a Japanese student's response to a yes/no question was affirmative or negative. This problem could have been a result of the Japanese style of communication -- since they were the "speakers", they were under no obligation to help the "hearers" understand what was being said. They assumed that if the hearers were uncertain, they would ask for clarification. Hall's (1959) theory may also explain the interesting fact that 
the Japanese students did not sense the presence of any communication difficulties with yes/no questions. If they did not understand the speaker, their normal, cultural reaction was to ask for clarification.

De Mente (1987) describes the different communication styles between Americans and Japanese as follows:

The primary purpose of communicating in the US is to convey information and understanding. The first purpose of communication in Japan is to convey moods and feelings... Communication in Japan tends toward imprecise words and nonverbal signals. (pp. 96-97)

Japanese people say, "I'm sorry," for many occasions only as a formality; they actually feel little regret. Japanese also use this phrase in situations where an American would never think to use it. A Japanese student's smile can also be interpreted differently by Americans.

In this short-term exchange program participants had to make many internal adjustments. These internal adjustments were complicated by the cultural differences between the Japanese and American students. All of this 
changing could certainly lead to some forms of culture shock.

\section{Culture shock}

When people come into contact with other languages and cultures, there is always the possibility that they will experience various stages of culture shock. Culture shock is responsible for many unsettling emotions. Paige (1993) explains that people can develop a sense of helplessness and hopelessness rendering them powerless and debilitated in certain situations. He believes that people need to be aware of what happens when there is a communication break- down. Many times, negative feelings will surface when a person is not able to communicate effectively. Paige (1993) points out that it can be very frustrating for people not to be able to communicate. If they do not understand the cause of this anguish, they may not be able to develop coping strategies or alternate their ways of behavior. It is also likely that they will lose their sense of control, relegated to reacting rather than acting. 
Culture shock is a possible result when encountering another culture and is therefore one of the issues that could have effected the Japanese sojourners. However, not everyone experiences culture shock. Culture shock is a condition of psychological maladjustment resulting from mutual disagreement or discomfort from an interaction through which unconscious cultural values are challenged and unfamiliar ways are encountered (Kondo, 1987). There are in fact many instances that can cause culture shock. When a person is in another country he/she has more sensitivity to differences which can sometimes be overwhelming, especially when these differences cause a person to completely reevaluate ways of thinking about the world. Kondo (1987) mentions three definitions of culture shock :

1. The shock when people fail to realize the other cultures logically, or when they do not know how to decode received messages.

2. The shock when people fail to make others understand them, or when their communication partner cannot decode their messages.

3. The shock when people encounter a situation in which they doubt the propriety of norms which they have considered appropriate, or when they fail to have intrapersonal communication. (pp. 70-71) 
Culture shock has the potential to cause difficult problems. In order to reduce the severity of possible culture shock exchange programs/study abroad should provide intercultural training and a sort of intercultural counseling throughout the program or at least at the beginning and the end. Kondo's definitions illustrate highly tension producing instances where stereotypes can be found and barriers can be raised when they should be lowered.

Culture shock and internal adjustment (adaptation) are sub-components of culture contact which is in turn a sub-component of exchange programs/study abroad. The next sub-component of exchange programs/study abroad to be discussed is language learning.

\section{Language Learning}

"Language is a system that relates what is being talked about (content) and the means used to talk about it (expression)" (Mohan, 1986, p. 1). It is very easy for educators to overlook the importance of language as a medium of learning, as a means for everyday interaction, 
and playing a role in education, work, and social interactions.

In early theories, language proficiency was equated with knowledge of grammar (Bachman et al, 1986). In more recent theories there is the realization that other kinds of knowledge are involved in language proficiency. These other kind of knowledge involve content information. Mohan (1986) believes that language learning should take place not only in the language classroom but also in content classes. He explains that using foreign language in content classes increases the language proficiency by giving it a context for use. Each of the classes, language and content classes, can reinforce each other, thereby giving the students the most useful information for communication and a place to apply it. There are certain steps Mohan (1986) suggests that can be taken to help students learn language that will be useful to them. An organizing framework should be developed that provides language and thinking skills that apply across curricula. This framework should help students develop skills that will allow them to connect 
what they learn in classes and also learn how to understand independently of others. Students should definitely be helped to improve communication in the subject matter at hand. Mohan (1986) emphasizes the fact that the teacher should try to find strategies that will help the students develop the thinking skills that they will need to be successful language learners. One suggestion is content-based instruction.

\section{Content-Based instruction}

Adamson (1993) believes that ESL students need higher levels of competence in English grammar to be able to learn content material. He says that there are specific school-related skills and knowledge that are important and useful for ESL students to use in their daily lives. Adamson (1993) found that students who are able to infer the meanings of unknown words that exist in their native language will most likely be able to do the same in the new language they learn. There are some aspects that should not be forgotten when teaching students. First, in the ESL classroom, vocabulary that will be used in content 
classes needs to be taught. A caution however: verbal recitation should not be practiced because it can actually hinder learning by causing too much tension for a student. Adamson (1993) emphasizes the idea that teachers should attempt to put less emphasis on grammar and more emphasis on communicating real information; they should not depend on social relationships between students to develop English skills. Along the same lines, it is very helpful for students to use their second language to discuss what they're learning with others. Basically in order for students to succeed in mainstream courses, they need a general proficiency in English plus a background knowledge of the content material and effective study skills (Kramsch, 1982 \& Swain, 1988).

Kauffmann et al. (1992) reminds us that languages are more than different codes to communicate similar ideas. They are conveyers of culture integrated in world views. Genuine communication comes from the use of language from real communication in an environment where language is indigenous to the culture. 
Students experiences with culture contact, language learning and content-based instruction affect whether the student will have successful culture contact. There are also many other aspects of successful culture contact that affect this important and desirable outcome of an exchange program/study abroad. The following section will examine what is involved in successful culture contact.

\section{Successful Culture Contact}

Researchers continue to debate over which characteristics will make a person a successful intercultural communicator and traveler. Although there are many different ideas, most of the characteristics have certain common aspects. Triandis (1994) has put together a list that contains some of the general characteristics. These include:

- Cultural flexibility (the ability to substitute activities in the host culture for own culture valued activities)

- Social orientation (the ability to establish new intercultural relationships)

- Willingness to communicate (e.g., use the host language without fear of making mistakes) 
- Skills in conflict resolution (collaborative style)

- Patience (the ability to suspend judgment)

- Intercultural sensitivity (a willingness to search for possible cultural differences that may explain behavior that is not understood)

- Tolerance for differences among people (finding differences interesting)

- A sense of humor (the ability to laugh when things go wrong)

(p. 272)

One must remember that simply because a person possesses all these traits, there is no guarantee that she/he will be successful in a cross-cultural contact situation. Despite the similarities, each situation has its own unique challenges; people must learn to ask questions rather than make assumptions (Kramsch, 1986 \& Nieto, $1992)$.

Ethnocentrism is a concept that greatly affects the quality of an intercultural contact. Ethnocentrism is using one's own culture as a standard for judging other cultures, and it is difficult to change because it comes 
naturally (Triandis, 1994). To reduce ethnocentrism, we must learn to appreciate the best that people have produced in their lives and in their countries. The more contact there is between groups, the more accurate stereotypes that will be formed (Triandis, 1994).

The above mentioned characteristics provide the tools for an intercultural communicator to use, not the answers for every situation. In the NWPR program, students have the chance to find out what it might be like to be American or Japanese without making assumptions based on false information.

Research has identified certain personal characteristics that will help people have successful intercultural experiences: awareness of self and culture, awareness of implications of cultural differences, interpersonal flexibility, and the ability to facilitate communication.

Many scholars have tried to identify competencies that are necessary for an individual to function effectively in intercultural contexts and the variables that influence those competencies (Martin, 1986). In 
cross-cultural contact, it is important to avoid stereotyping people and to attempt to differentiate among members of other cultures (Triandis, 1994). For example, some may be apt to react negatively to cultures whose people express emotions differently. It is important to remember that emotional experiences are universal, but the manner in which emotions are expressed varies widely across cultures. Expression of emotions is culture specific (Triandis, 1994)

\section{Summary}

This chapter mapped out some of the important and relevant pieces of an exchange program/study abroad. These pieces formed a base from which to work, giving guidance as to what aspects of this case study to focus on and what the guiding questions should address. The following chapter looks at the methods used to collect data. 
CHAPTER III

METHODS

Introduction

This chapter starts out by providing my background as a researcher/participant observer and then how $I$, as a researcher and participant observer, gained entry to the NWPR program. This is followed by a description of the subjects and the length of the NWPR program. The methods that I employed are then reviewed. They include: case study, ethnography, participant observation, and program evaluation. There is then a detailed description of the procedures that I used for the actual data collection. The final section mentions some of the limitations of this study. 
The Researcher

Before moving on to Chapter III it is necessary to provide a picture of my assumptions, education and background. Since in my course work, I have taken many classes regarding the design and delivery of ESL instruction I started the NWPR program with certain ideas about what I expected to see and what I thought needed to be included to make the program successful. I have also participated in various exchange program and studied various languages so I have formed many opinions about language and culture learning. These opinions and conclusions no doubt influenced my data gathering and the conclusions that I made. I was however aware of this possibility and when looking at the data and formulating hypotheses, searched for confirmation from more than two sources whenever possible. For example, I drew upon my quantitative classroom observations and the ESL teachers comments and concerns about the Japanese students when making statements about Japanese student use of English. 


\section{Gaining Entry}

Gaining entry to the NWPR summer program involved requesting admission and being accepted after the application process. In the required essay for the application, I requested and was given permission from the directors to gather data for my thesis. Being a participant in the NWPR summer program and being in close contact with the other students allowed me to gain their confidence and trust.

At the beginning of the program I told the students in my content classes that I was a graduate student and that I was collecting data for my thesis. I also answered questions about my data collection throughout the program. I indicated that if any students were uncomfortable being observed that they could indicate that to me and I would not include them in my study. I also reassured them that their names would not be used.

\section{Subjects}

In the NWPR summer program, there were a total of 73 students; of these, 45 were Japanese and 28 were 
Americans. The subjects for this study were divided into two groups: one that was informally involved and another that was formally involved. In the informal group, participants were seen as part of the whole and analyzed as a group, not as individuals. For the formal study, the subjects were selected according to the following parameters: nationality (they needed to be Japanese), gender, degree of introversion/extroversion as measured by my observations and members of the history/culture and literature class. As I observed the students in various situations I became aware of the students that were constantly out if their rooms communicating and interacting with others these students were seen as more extrovert. The students that appeared to need time alone in their room to recuperate and be alone were seen as leaning toward introversion. This classification was based on my observations and biases.

For the formal interviews, an equal number of men and women were used, and there was an attempt to have an equal number of introverts and extroverts. Six Japanese subjects were chosen, and they were each individually 
interviewed at least once. These interviews were taped, and all of the subjects were asked the same questions with variations occurring when a topic of interest came up. In addition to interviewing some of the students, I also chose to interview all of the ESL teachers since they had a great deal of contact with the Japanese students. I interviewed one of the history teachers about his drastic change in lecture style initiated by issues concerning the Japanese students' comprehension level.

As opposed to the formal group, I was in constant contact with the informal group. I asked them questions and discussed their opinions and feelings, regarding the classes and the program in general, on a daily basis.

\section{Length}

The data gathering lasted from July 18 to August 27, 1995. The American students began the program three days earlier than the Pacific Rim students, and the Pacific Rim students stayed one day longer than the Americans. Before the Japanese students arrived, the first three days were dedicated to orientation for the American students, 
followed by a day of orientation for the Japanese students the day they arrived, and then the three-day outdoor wilderness trip. The rest of the time was dedicated to study, field trips and getting acquainted.

I was an actual participant in the NWPR program and was treated the same as all the other students. I was expected to go to class, to interact with the other students, to participate in activities and to complete required work.

The NWPR program takes place annually at a NW college. The students live collectively in a dorm (women on the second floor and the men on the ground floor), eat together in the cafeteria and have access to all the facilities on the NW college campus.

\section{Case study}

This study is in fact a case study and in the literature concerned with case studies, there is a range of definitions and descriptions. Despite this, there are a few unifying aspects of case studies that will be discussed here. Nunan (1992) believes that a case study, 
"utilizes a range of methods for collecting and analyzing data" (p. 74). In this study, I used many methods to collect data: interviews, observations, participant observations, program evaluations, etc..

In general, a case study is when a researcher selects "one instance from a class of objects and phenomena and only looks at that instance and how it functions in context" (Nunan, 1992, p.75). The case study is therefore limited in scope and only looks at one case. In my research, the instance was represented by the Japanese students; I looked at how they functioned in the context of the NWPR summer program.

Nunan (1992) concludes that a case study involves a detailed description and analysis of an individual subject, particular organization, or event. This case study is based on a particular organization: the NWPR summer program.

Several research methods involve manipulation of the subject by the researcher or involve the asking of standardized questions to a sample of representative individuals. A case study researcher, on the other hand, 
simply "...observes the characteristics of an individual unit - a child, a clique, a class, a school, or a community" (Nunan, 1992, p.77). This technique results in a deep probe and analysis of the phenomena that constitute the life of the subject or the community. The results that are gathered can be generalized to include a wider community. In this case study, the researcher did not manipulate any of the subjects. All of the collected data were from observations and formal interviews. The hope is that the information gathered will be useful to future groups of students who participate in the NWPR summer program.

Nunan (1992) asserts that case studies examine a particular aspect or facet of the culture or subculture under investigation. That is, there is an attempt to provide a portrait of what is going on in a particular setting. A case study must provide more than just objective reporting of the particular culture. It must encapsulate the pertinent information of a point of view so that readers can draw conclusions other than those written by the researcher. Nunan (1992) adds that one of 
the key issues for case studies is the extent to which the insights generated by the study can be applied to other cases.

This case study examined what I feel was a small subculture that was formed for six weeks in the summer. As a participant observer I gathered descriptive data of certain aspects of the program. One of my hopes was that if I found particular aspects that could be improved I could in turn make this information available so that the NWPR program would have the option of using it.

\section{Ethnography}

Ethnographic elements are employed in this study. Ethnography yields empirical evidence which contributes to both description and explanation of regularities and variations in human social behavior and tells about the lives of people in specific situations (Spradley, 1980). A general ethnographic focus aims at discovering the cultural knowledge people are using to organize their behavior and interpret their experiences (Spradley, 1980). 
This case study looked at the experiences and opinions of Japanese students in the NWPR summer program. I explored Japanese students' opinions and feelings about their experiences and the amount of English they understood and learned in six weeks. This exploration involved formal and informal ethnographic interviews. Spradley reminds us that:

...ethnographic interviewing...begins with the assumption that the question-answer sequence is a single element in human thinking. Questions always imply answers. Statements of any kind always imply questions. This is true even when the questions and answers remain unstated. (Spradley, 1979, 83-4)

Spradley draws our attention to an unconscious reality that greatly affects the information a researcher collects. Unless the researcher gains enough confidence of the informants and enough knowledge of their lives and situations the researcher will not know what questions to ask or at times what questions are already being answered. I kept spradley's quote in mind while conducting my formal interviews with the Japanese students.

The Japanese students' opinions and feelings were explored through formal interviews which involved 
developing rapport and eliciting information. The two processes are complimentary: rapport encourages information to be shared and eliciting information leads to the development of rapport. The formal interviews followed Spradley's (1979) guidelines for ethnographic interviews. These guidelines are laid out in the following chart:

A. Forming a Rapport

a-i. Apprehension

a-ii. Exploration

a-iii. Cooperation

a-iv. Participation

B. Descriptive Questions b-i. Grand Tour Questions

1. Typical Grand Tour Questions

2. Specific Grand Tour Questions

3. Task-related Grand Tour Questions b-ii. Mini Tour Questions

1. Typical Grand Tour Questions

2. Specific Grand Tour Questions

3. Task-related Grand Tour Questions

b-iii. Example Questions

b-iv. Experience Questions (Spradley, 1979, p. 78-79\&86)

The chart shows that there are various parts and subparts involved in ethnographic interviews. The guidelines begin with forming a rapport between the interviewer and the informants. I was in almost constant contact with the 
subjects and formed a friendly and open rapport before the actual interviews took place. Spradley (1979) describes four stages in the process of forming a rapport: apprehension, exploration, cooperation, and participation. In the beginning, there is apprehension. There was indeed apprehension in the NWPR summer program the day when the American students met the Japanese students. Many American students expressed their concerns about meeting, living with, and getting to know people from another culture. At first it was quiet, and the American students did most of the talking and questioning before the Japanese students finally joined in. There was a noticeable increase in the amount of conversation between the students as they became more and more comfortable with each other.

The second stage is exploration, and the students in the NWPR program definitely experienced this stage. In this stage, people try to figure out what others are like and what they want from relationships (Spradley, 1980). The students in this case study were constantly asking questions and trying to get to know each other. 
Questioning started before the Japanese students even arrived and continued up to the very last day of the program. There was a very open and welcome atmosphere for questioning.

Cooperation is the third stage, where people are now willing to help each other without being asked. American students asked Japanese students yes/no questions about their culture, and the Japanese students answered yes or no and then slowly, voluntarily elaborated on their answers.

The final stage in establishing rapport is participation. In this stage all the students participate together in the exchange of information in relaxed and open situations. In a surprisingly short amount of time the participants in the NWPR summer program reached a point where they were able to interact freely with one another.

Besides establishing rapport with informants, ethnographic interviews also involve using descriptive questions to elicit information. The goal is to stimulate conversation by encouraging informants to talk about 
particular cultural scenes. Descriptive questions form the backbone of all ethnographic interviews. An example in this case study might be asking the participants to talk about a typical day in the NWPR summer program. There are various types of descriptive questions including grand tour, mini tour, example, and experience questions (Spradley, 1979) .

Grand tour questions are designed to provoke rich descriptions from the informants. Whether asking about the political arena or a simple object, the end result is the same: a comprehensive verbal description of the cultural scene in question. There are three types of grand tour questions: typical, specific, and task-related (Spradley, 1979). Typical grand tour questions ask the informant to generalize and talk about patterns of events. In this study, I asked the participants questions about who they talked to and how frequently.

Specific grand tour questions inquire about a recent day, a series of events, or a locale most familiar to the informant. That is, the informant's description is aimed at a particular topic. In the present case study, the 
questions dealt with what the participants were experiencing at the time of the interview. They answered questions about specific times and places. For example, I asked who they talked to in class and if they ever talked to any of the teachers.

The last type are task-related questions which ask the informants to perform a simple task that will aid them in their descriptions (Spradley, 1979). For example, the participants in the current case study were asked to fill out communication charts illustrating their patterns of contact with others.

The flip side of grand tour questions are known as mini tour questions. These questions offer almost unlimited opportunities to investigate smaller aspects of the informant's experiences (Spradley, 1979). In general, mini tour questions are analogous to grand tour questions but on a smaller scale. Mini tour questions have the same three types of questions: typical, specific, and taskrelated. An example of a typical grand tour question asked the informants about who they talked to and how frequently. The mini tour questions would then go in and 
ask about each person that the informants had mentioned on their communication charts. When talking about students content classes the mini tour questions asked about the questions the informants asked in class or specific questions about the informants notes.

The third type of descriptive question in an ethnographic interview is the example question (Spradley, 1979). These questions are more specific than either grand or mini tour questions. Informants are asked to give examples of a single event or activity. The type of example questions asked in this case study urged the participants to give examples, on their communication charts, of the topics that would be covered in certain situations and the type of language that would be used. Students were also asked to show an example of their notes and explain how much they understood that day and if they copied their notes from the board or wrote down what the teacher was saying.

Experience questions are the last type of descriptive questions. These ask informants about experiences in particular situations or settings. Of all the descriptive 
question types, experience questions are the most open ended and may be difficult for informants to answer; often, the interviewer builds up to these questions during the interview. In this case study, experience questions were used to prompt discussion about specific situations in certain classes, in the dorms, in the rooms, and at leisure time.

\section{Participant Observation}

Participant observation is used to answer the six information questions: who, what, where, when, why, and how (Jorgensen, 1989). For example, a participant observation describes who was involved, what event occurred, where and when the event took place, why the event took place as it did, and how the event occurred (from the standpoint of the participant) (Jorgensen, 1989). My goal in this case study was to answer all of the information questions in the data that were collected. Since I was also a participant in the program, I had the benefit of first-hand experience and was able to take notes on who or what was involved and when and where 
particular events took place. I was also able to have a fairly accurate idea as to why particular events unfolded in specific ways.

Participant observations are good for studying relationships between people and events, the organization of people and events, patterns, processes, and immediate social contexts in which human existence is enfolded (Jorgensen, 1989). Besides looking at events that took place, I also focused on the stages through which the students journeyed, making note of the multitude of relationships that were forming among the students.

In general I feel it can be said that participant observation enters the world of the subject in the attempt to see the world through the eyes of the subject. Participant observation can be an extension of a case study when it is employed through systematic, unbiased reporting and classification of facts. In order to obtain complete information, the researcher must both ask questions and observe events. In the NWPR program, I observed many events that aided in understanding the processes at work. As a participant, I was immediately 
involved with the students-- talking, studying, helping, laughing, lamenting, and bonding.

\section{Program Evaluation}

Nunan(1992) proposes that the data resulting from a program evaluation should assist in decision making and problem solving for the program in question. The evaluation should show if a program needs to be modified or altered to achieve objectives more effectively. If learners are not achieving the goals and objectives the program sets, the evaluation should help determine why that is so. In the end, the evaluation should also provide ideas as to what can be done to remedy any problems or shortcomings. It is, however, important to remember that an evaluation is not simply a process of obtaining information; it also involves making decisions. Therefore, a researcher who conducts a program evaluation does not only have to assemble information but also has the job of interpreting that information and making value judgments. An evaluation's purpose is to identify shortcomings in information gathering procedures so that 
next time something different will be done to obtain better results (Nunan, 1992).

The purpose of this case study is not to provide a detailed program evaluation, but rather to look at issues that concerned the Japanese students participating in the program. Inadvertently, in the process of data collection, evaluations of the program were formed based on my own knowledge and experiences as well as on other students' experiences.

Hudson (1989) believes that the key to program evaluation is the measurement of students' performances by concentrating on the outcomes of the learning process rather then on the process itself. However, the end product of six weeks in an intercultural educational program was examined with a focus on the processes. Contrary to what Hudson said, I believe that it is important to assess the processes that lead to particular results in order to explain the outcomes. As I examined the speech patterns of the Japanese students, it was useful to look at the opportunities that the program 
provided in which the students could use new language or communicate with one another.

\section{Procedures}

A variety of procedures were used in the collection of data: observing, note taking, informal conversing, questioning, and formal interviews. A majority of the data were collected through continual observations of students and the general atmosphere, inside and outside of the classrooms. In addition, I conversed with students, casually asking their opinions on various topics in order to assess the general sentiments and impressions participants had about the program and their experiences in it.

Almost every evening, I deliberated over the day's events and the notes that had been taken. Commonly, there was inadequate time during the day to take thorough notes; these couple of hours allowed for contemplation and recording of what had happened. At one point, I joined a group of Japanese students who were chatting in the cafeteria with their English teachers. Since I became 
involved in the conversations and did not want students to feel nervous, very few notes were taken. Later, I reflected on which students had been there, what had been said, who had done the talking, and what language had been used. During those nightly hours of rumination and recall, I also had a chance to go over what was already written, cut out repeated information and relate new information to that previously gathered. As the program progressed and patterns began to develop, they were mirrored in the data. From this, I was able to generate questions that would fill in gaps or formulate/support hypotheses.

Besides observing and talking to the students, various formal interviews were conducted and tape recorded. The taping was used as an aid in analyzing the information at a later date. Before the program started I spoke to one of the ESL teachers from the previous year. My thesis advisor had been on the planning committee, the faculty interviewing committee and a direct supervisor of two of the ESI teachers. She was very familiar with the program and she describe problems based on her 
experiences. I was influenced by this in my initial generalizations based on the realities of the program related to by my advisor and two ESL instructors.

The questions asked during the interviews were decided upon and formulated on a daily basis. During the course of the interviews, additional impromptu questions often surfaced and were incorporated. The formal interviews included six student interviews and five teacher interviews. All of the English teachers were interviewed along with the American teacher for the history/culture class.

The ESL teachers were interviewed because of the amount of contact that they had with the subjects. They were able to provide insights that I was not aware of. The history/culture teacher was interviewed in the first half of the program after it became obvious that a drastic change had been made in his lecture style. The teacher's normal speaking rate slowed dramatically and abundant writing on the chalkboard was used as a backup for what was being taught. I was curious if this change was due to the teacher's perception regarding the Japanese students 
and their level of comprehension in the classes or another issue.

In addition to interviewing the history/culture teacher, I also interviewed each of the ESL teachers. All were very receptive to the interviews and shared opinions and ideas as well as their suggestions for program improvements. They were quite concerned about finding the best method to teach their classes that would promote the highest level of understanding and, consequently, help the Japanese students be successful. All of the ESI teachers seemed to have the welfare of the students in mind and voluntarily observed a majority of the content classes in order to be able to aid their students in comprehension of the topics being discussed.

Six students were interviewed formally. Questions were formulated by looking at the guiding questions and by issues and topics that became apparent on a daily basis in the program. As an example, in the content classes some of the teachers would randomly translate words or short phrases into Japanese. I was curious to find out if this aided the Japanese students in comprehension of the 
lectures. The formal interviews lasted almost an hour or so, and each Japanese student was only interviewed once. Throughout the program, I talked to those Japanese students who had been interviewed formally to update and elaborate upon information that had been gathered in the formal interviews.

\section{Limitations}

As researcher and participant, I cannot ignore the fact that the observations and conclusions of this case study are not free from bias regardless of my intention to remain objective. All the information gathered was interpreted through my perspective and was thus influenced by my numerous intercultural experiences as well as interactions with my own ESI students. Particular ideas and opinions undoubtedly filtered their way into the assessment of this program and it must, therefore, be noted that any other participant with a different background could, in fact, formulate a divergent point of view. 
Yet another limitation has to do with the amount of time that I was able to spend with the students. Since there were 73 students in the program and a multitude of activities going on at any moment I was unable to be with all of them at all times. Some of the opinions and conclusions were drawn from a small sampling. The final results are therefore a general statement of what happened and are limited to my observations and those of the people that I spoke with and observed. 
CHAPTER IV

\section{RESULTS}

Introduction

This chapter will provide a description of the data that was collected during the NWPR summer program. The presentation will start with a narrative of a typical day in the NWPR program to give the reader a peak inside the program. This narrative is aimed at capturing the sights, sounds, smells and general atmosphere of the program after the initial eight days that were covered in the narrative in Chapter I. The students are now getting to know each other and have been interacting with one another and slowly forming relationships. They have started classes and have gone on various field trips and excursions together.

The narrative is then followed by a more specific look at the daily activities outside of the classroom, on 
a daily basis and in group conversations. Then the results of the formal interviews with the Japanese students are laid out in detail.

The following section, concerned with the formal setting of the classrooms, begins with the ESL classes and looks at what took place between the Japanese students and between the Japanese students and the teachers. This is followed by descriptions of two content classes, literature and history/culture, and charts that show how often students participated in these classes. This section finishes by assessing the weekly colloquiums that were mandatory for all the participants.

The data were gathered in a variety of ways including interactive and non-interactive observations, casual/informal conversations, and formal interviews. In the classroom, I was part of the group being observed; at other times, I observed from a distance and had no involvement with the group I was watching. The information gathered from casual conversations and formal interviews detailed the Japanese students' views of their 
English skills and provided insight to their interpretation of their experiences.

\section{A Typical Day}

With the exception of weekends, there was a daily routine that students followed. Mornings were very quiet, and people slowly roused at seven o'clock to prepare for 8:30 classes. There were usually people still getting up at $8: 15$. People stumbled into the bathroom to wash their faces, take showers, put in contacts and brush their teeth and hair. The closer it got to $8: 30$ the faster people moved. My roommates were usually among the last students to wake up and always had to get ready in a frenzy.

The Japanese students greeted everyone who entered the bathroom. They greeted their Japanese counterparts in Japanese and the American students in English. Even if their eyes were still half closed from sleep, they managed to greet any newcomer with a heartfelt and singsong "Good Morning!" Many students were chatty and, though conversations in both languages could always be heard, the 
Japanese students and the American students spoke to each other only in English.

If people got up early enough, they had time to eat breakfast before literally running to class. In the cafeteria, Japanese and English could be heard. People would greet each other and talk about what they would be doing that day ("Koichi, do you want to play tennis later on?" "Hey Claudia, did you run this morning? I didn't because I couldn't wake up." "Are you guys going to the gym tonight?"), ask who finished the homework ("Did you finish the homework?" "What homework?"), copy homework from others, finish their homework while eating, practice for a Japanese or English test, try to wake up, laugh, shout, etc..

While classes were in session, the dorms were quiet. During the day the Residents Assistants (RAs) kept busy posting notices of upcoming events and field trips on the board and passing out the updated bi-weekly schedules (see Appendix A) and copies of The Almost Daily Shinbun (newsletter) (see Appendix B). 
On Mondays, Wednesdays, and Fridays, classes finished at 4:00 p.m. On Tuesdays and Thursdays, classes were finished at 10:30 am. However, finishing classes early did not mean the students had nothing to do. The afternoons were filled with field trips, movies, shopping and additional study sessions.

After the day's classes were finished, people usually spent their time outside swimming, playing volleyball, tennis, basketball, running, talking, taking walks, shopping or just lying on the grass. The participants in these activities were randomly mixed, sometimes everyone involved was Japanese or American; other times it was mixed.

Twice weekly, a conversation group, composed of five to ten Japanese students and two or three ESL teachers, met in the cafeteria for a few hours. The noticeably relaxed atmosphere of these meetings was undoubtedly beneficial to the students' language proficiency. The meetings were held entirely in English and none of the students switched to Japanese at any point. They were 
eager to ask questions about culture and language that were not covered in classes.

From 5:00 p.m. to 6:30 p.m., everyone ate dinner. The situation at dinner was similar to that of breakfast and Iunch. Mixed tables and a variety of activities were taking place simultaneously. At dinner (as well as lunch), there were usually other people eating in the cafeteria with us: a young boys' basketball camp, a conference for families with ill or afflicted children, NW college RA training for fall term, etc... Many people were milling around, talking and shouting and, compared to the breakfast scene, it was evident that an increased amount of communication was going on.

After dinner, most returned to the dorm and, as darkness fell, the noise level started to rise. The later it got, the more people there were running down the halls calling for their friends or sitting and having long conversations in the hallways or in someone's room. Sometimes a group of Japanese students would be in a room speaking Japanese and if an American joined the group, the students would speak in English and Japanese. Some 
American students tried to speak Japanese but it was more common for the American students who had prior knowledge of Japanese to be listening and conversing in Japanese. Many people left their doors open. In my room the door was usually open and I could hear people talking, laughing and running by yelling for others. There were also many people studying in their rooms, in the lounge, in empty rooms or in the computer lab in the basement of the dorm. Most people did not go to bed until very late at night. My roommates, for example, usually went to bed around five or six in the morning. From what I heard there were other students retiring around the same time. Occasionally people did not even sleep at all.

There was a great deal of drinking going on. At least four nights a week a particular group of students, Japanese and American, drank in the lounge, in an empty room, or at a bar. Small groups of students, Japanese and American, also went to night clubs and bars on Friday and Saturday nights. For many of the Japanese students this was their first time away from home and their parents and, in effect, their first experience "cutting loose." 
Activities were usually planned for both weekend days (trips to Kahneeta, the beach, a play in downtown Portland, movies) but occasionally one of the days was designated a "free day." The Japanese took advantage of the free days to do some shopping downtown or at near by mall. The dorms were nearly deserted on weekends; those American students who had cars and lived close by would take fellow students home with them, and other groups would go out somewhere. There was always something to do whether it was academic or just for fun.

Outside the Formal setting of the Classroom Daily Activities

In general, the students used their native languages to speak to members of their culture and English to communicate between cultures. Though a few American students did speak varying degrees of Japanese, none seemed eager to use the skill. I spoke to one of the American students and she indicated that she had studies Japanese fro four years in high school and college. From what I observed I found her to be very reluctant to use 
her Japanese skills. It was only near the end of the NWPR program that I actually observed her communicating in Japanese just for fun. Previously I had seen her only using Japanese when she was completing an assignment for her language class.

Due to this shortcoming on the American students' part, the Japanese students were given no choice but to always speak English to the Americans. English could be heard more than Japanese.

In the beginning of the program, the students appeared reluctant to mix. Homogenous groups of Japanese and Americans stood out conspicuously. As the program progressed and the cultures spent more time together, this changed. Some American and Japanese roommates became good friends and as the program drew to a close, it was apparent that the students had accomplished a great deal of integration.

In the evenings, the American and Japanese students would meet to study, help each other, and just talk. On these occasions, I observed that both English and Japanese were used depending on the subject being discussed and the 
people involved in the discussion. Japanese students helped each other in Japanese and the Americans would explain class topics to them in English. Although there were academic discussions, most of the conversations I remember were simply chatting about fun topics.

It has already been established that the Japanese participants were required, by necessity, to speak English to the Americans if they wanted to communicate. However, there were also a few formal occasions where the Japanese students were required to speak English. One of these occasions was Japan Day, presented by the Japanese students the third week of the program. The American students and all of the teachers attended. On this day, the Japanese students were speaking a great deal of English. They had to explain their exhibits and hands-on activities. For example, some Japanese students taught us how to make origami figures; others wrote names in Japanese characters with special brushes and let the American students write their own names; there were Japanese children's games being played; the Japanese relaxation practice of burning incense was demonstrated; 
and still others were involved in a tea ceremony that the American students were welcome to join. Japan day lasted two hours and seemed to be a success. Some of the Americans had their Japanese characters hanging on their walls, and the origami figures appeared throughout the program.

Group conversations

Besides the daily contact between the Japanese and American students, there were also specific group activities/conversations that took place. For instance, the previously mentioned twice-weekly cafeteria conversations were formed because a Japanese student asked his ESL teacher if it would be possible to have stressfree conversations outside of class whereby they could practice English. All of the students sat around a big table and the ESL teachers were mixed in with the students so that they did not represent or assume a leadership role.

I took part in five of these conversations. On average, there were eight Japanese students and two ESL 
teachers. Most students rocked back in their chairs and only a few wrote down new words. They volunteered questions and answers and appeared eager to get some answers or clarifications. They had many questions about American slang, culture, and customs and frequently expressed concern that they were having trouble understanding English at the native speaker rate. The ESL teachers addressed their questions and some of the common things that Americans say, such as "Whachagonnado?" or "Whachawannado?"

Many of the Japanese students commented that they had to spend too much of their time studying and did not have enough opportunities to practice English with the American students. The group conversations were quite helpful to them because, as many of them mentioned, they learned more about how to speak and understand English the way it is really spoken by Americans. Information about the group conversations was gathered by observing and participating. I also asked students various questions in a casual manner to elicit more specific information. 
One of the other group activities that took place outside of the formal classroom setting were the Kyogen play groups. In the literature class, students learned about an old Japanese style of presenting plays on stage, Kyogen. The students were divided into groups and the assignment was to write, direct, and perform their own Kyogen play. The writing, directing and practicing all took place outside of the classroom.

My group consisted of two Japanese students, Yoko and Susumu, and three American students, Tom, James, and me. These are all pseudonyms. James was fluent in Japanese, and Tom and I spoke no Japanese. In the first group meeting, everyone started out speaking English. Susumu wanted to be the playwright, but he was having difficulty explaining his idea in English so he changed to Japanese and directed his speech to James. At first James translated the Japanese into English, but somehow all translation came to a halt and only James, Susumu, and Yoko were figuring out the play while Tom and I waited for a translation. There was nothing for us to do but wait. Finally, the other three did explain their idea and in the 
end, Susumu wrote the play with the help of James, and Tom was the director. All of the plays were in English with a few Japanese words or phrases.

In summary it is important to note that the information gathered for the previous section was a result of informal conversations with the Japanese students on a daily basis. I was in contact with the students seven days a week and took the opportunity to write down many of my observations and feelings and the opinions and comments of the Japanese students.

The Results of the Formal Interviews

In addition to the information that was collected on a daily basis, I also conducted six formal interviews, one with each of six Japanese students. There were three females (Yumiko, Satoko, and Yoko) and three males (Koichi, Satoshi, and Usamu). Pseudonyms are being used for all of the students mentioned by name in this case study. The interviews lasted 45 minutes to an hour and a half. Each student had one main interview near the beginning of the program; however, throughout the rest of 
the program I frequently checked in with the Japanese students to ask them more questions and elicit opinions and then I would write down what they had said. The information reflected each Japanese student's perspective of the program and thus, was a representative sample of the Japanese students' feelings and reactions.

At the beginning of each interview, the Japanese students filled out a communication chart that reflected his/her perceptions of the daily interactions with others. These charts indicated who the student spoke to the majority of the time, which language was primarily used, and who initiated the contact. In some interviews, the Japanese student was willing to elaborate upon the situations where either English or Japanese was used.

These communication charts gave me a clear perspective of the Japanese students point of view of the communication that was taking place in the program. I was able to compare the observation and conclusions I came to with the information that they presented to me on their communication charts. It is well known that self reporting is not as accurate as it may appear and yet I 


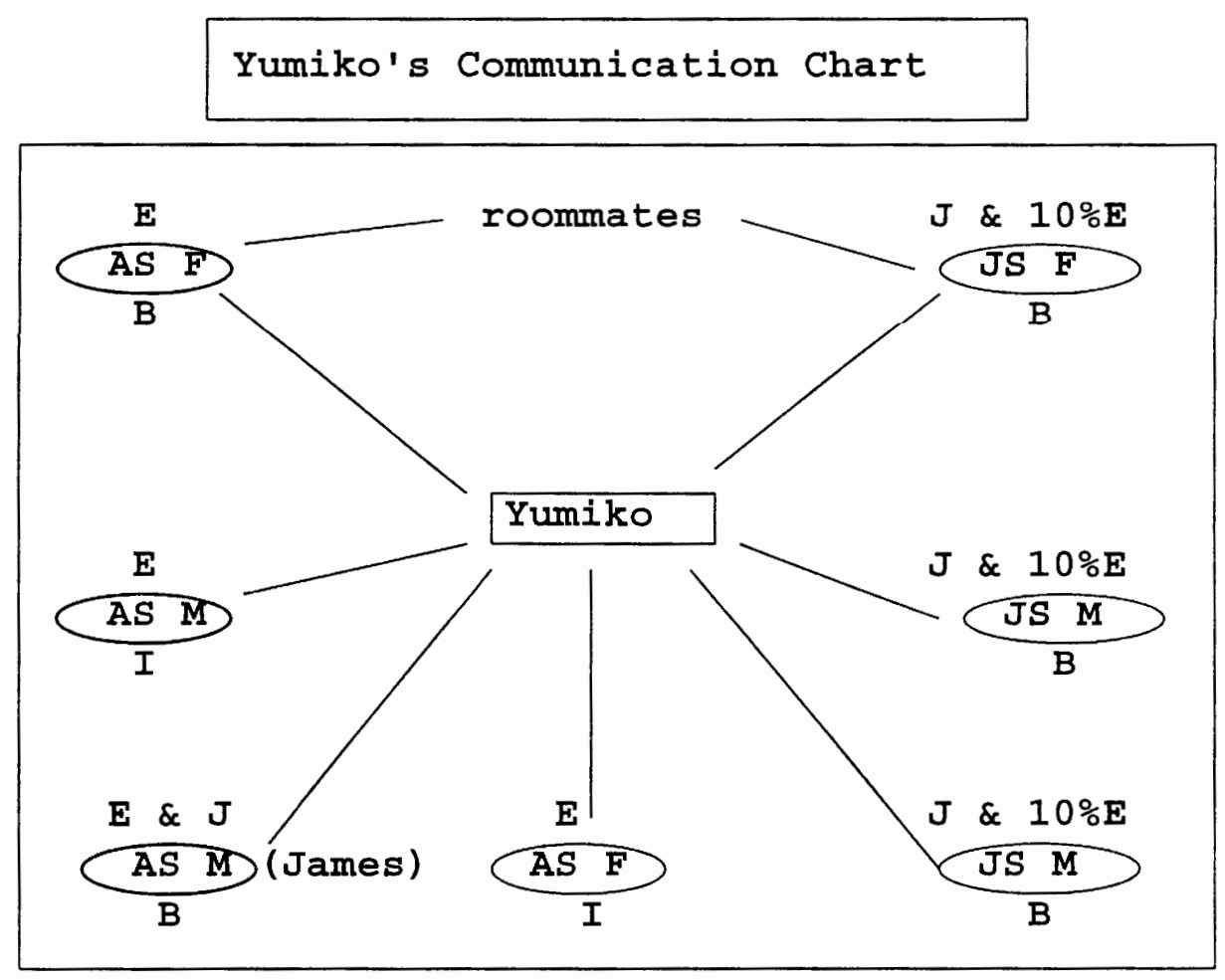

Legend

$\begin{array}{rlrl}\mathbf{J} & =\text { Japanese } & & \mathbf{F}=\text { female } \\ \mathbf{E} & =\text { English } & \mathbf{M}=\text { male } \\ \mathrm{JS} & =\text { Japanese student } & \mathbf{B}=\text { both initiate } \\ \text { AS } & =\text { American student } & \mathbf{I}=\text { Initiator }\end{array}$

Figure 1 


\section{Satoko's Communication Chart}

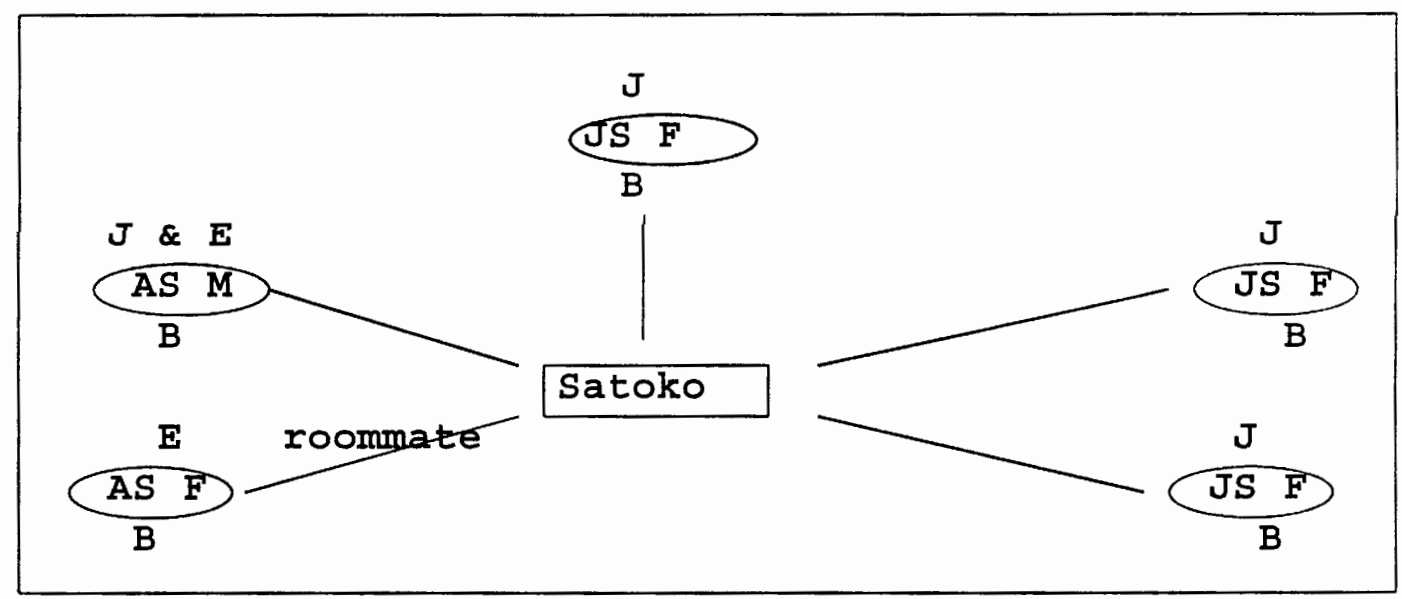

Legend

\begin{tabular}{|lll}
$\mathrm{J}$ & $=$ Japanese & $\mathrm{F}=$ female \\
$\mathrm{E}$ & $=$ English & $\mathrm{M}=$ male \\
$\mathrm{JS}$ & $=$ Japanese student & $\mathrm{B}=$ both initiate \\
$\mathrm{AS}$ & $=$ American student & $\mathrm{I}=$ Initiator
\end{tabular}

Figure 2 
needed to see how the Japanese students saw themselves. These charts are not meant to be absolute indications of the communication that was taking place in the program at all times. They are provided simply to reinforce other descriptive data and to indicate tendencies or patterns among students' language use.

The first to be interviewed was Yumiko (see Figure 1). Yumiko was a very outgoing person who could rarely be found in her room; she was always out talking to people, playing sports, or just having fun. Her communication chart indicated that she conversed with both Japanese and American students. Yumiko said that she always used English with her American roommate and all the other American students except one, James, who was fluent in Japanese. With him, she spoke English half of the time and Japanese the other half. As for communication with other Japanese students, she stated that English was used only when Americans were also involved in the conversation, approximately 10 percent of the time. She would speak English so as not to exclude anyone. With the Japanese students, Yumiko felt that she initiated about 


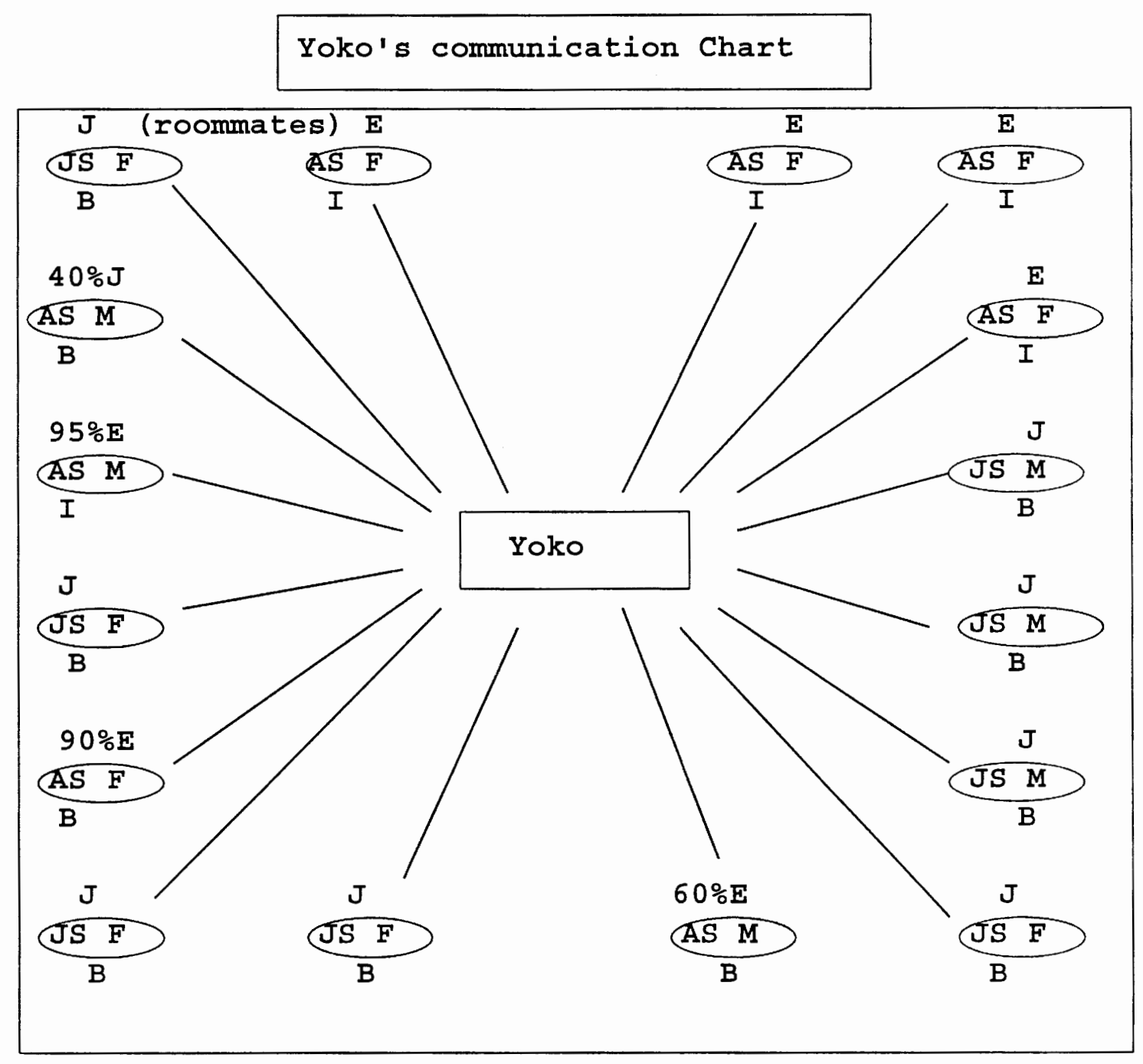

Legend

$\begin{aligned} \mathrm{J} & =\text { Japanese } & \mathrm{F}=\text { female } \\ \mathbf{E} & =\text { English } & \mathrm{M}=\text { male } \\ \mathrm{JS} & =\text { Japanese student } & \mathrm{B}=\text { both initiate } \\ \text { AS } & =\text { American student } & \mathrm{I}=\text { Initiator }\end{aligned}$

Figure 3 


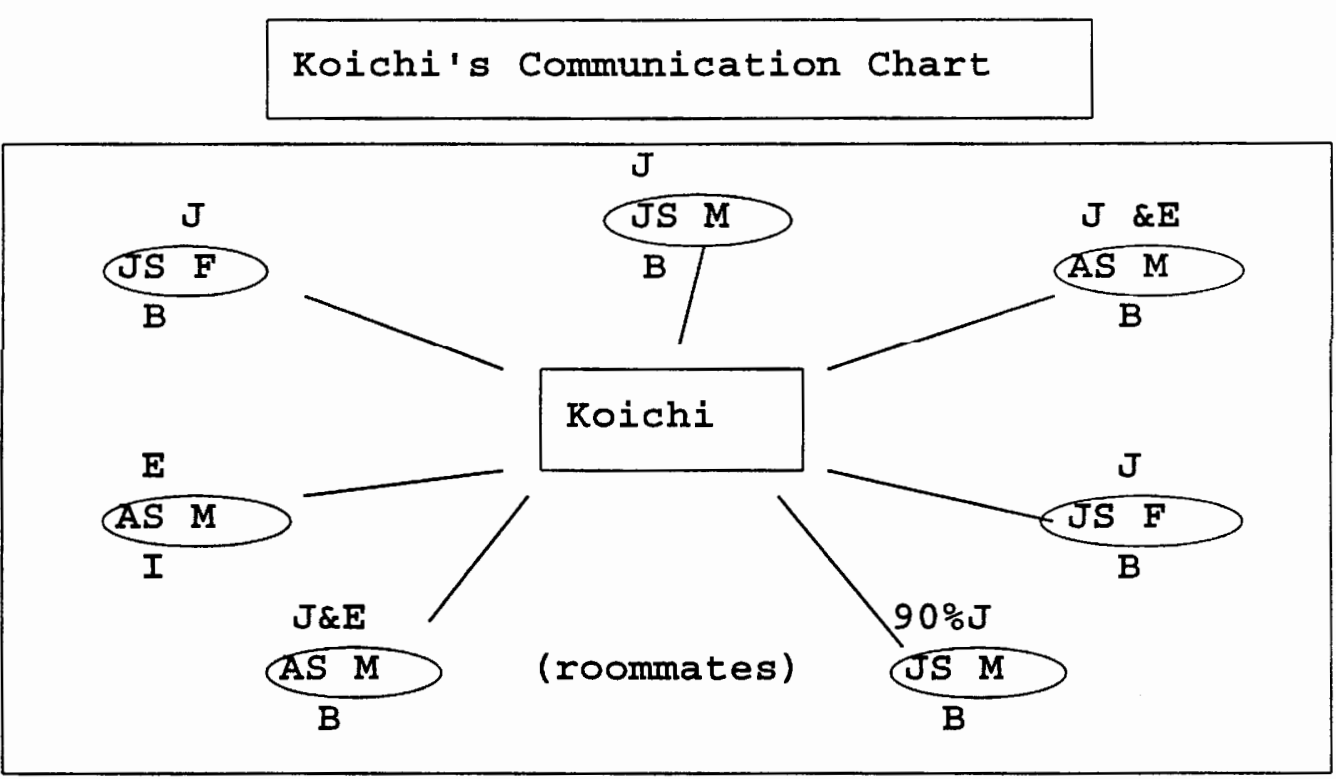

Legend

$\begin{array}{rlrl}\mathbf{J} & =\text { Japanese } & & \mathbf{F}=\text { female } \\ \mathbf{E} & =\text { English } & \mathbf{M}=\text { male } \\ \mathrm{JS} & =\text { Japanese student } & \mathrm{B} & =\text { both initiate } \\ \text { AS } & =\text { American student } & & \mathbf{I}=\text { Initiator }\end{array}$

Figure 4 
half of the conversations and they initiated the other half. This was also true for her American roommate and James. However, she pointed out that the American students initiated contact with her a majority of the time.

Unlike Yumiko, Satoko spent a lot of time closed up in her room studying. As indicated on her communication chart (see Figure 2), she spoke primarily to Japanese students. Of the American students with whom she regularly communicated, Satoko spoke half English and half Japanese. They talked about their backgrounds, compared cultures and had short conversations. With her roommate, she always used English. She spoke Japanese with the other Japanese students, unless she was practicing English. Satoko speculated that she did not practice enough and she was disappointed with her English skills and wished she had learned and spoken more English during the program. Regarding her interaction with students, she felt that she and the people she communicated with initiated conversation equally. 
The third female to be interviewed was Yoko. She categorically fell somewhere between Yumiko's extremely outgoing personality and satoko's rather shy personality. Yoko did, however, include a lot more people on her communication chart (see Figure 3) than did the other two. She talked to equal numbers of American students and Japanese students speaking Japanese only with those Americans who had a fairly good command of the language. Yoko used only Japanese with the Japanese students. The only exception was a Japanese male in her ESL class with whom she practiced English. Yoko perceived that there were equal initiations of conversations but admitted that there were a few American students who consistently initiated the majority of their repartee. Relative to personality, Koichi was Yoko's counterpart. He was outgoing yet also studious. He indicated (see Figure 4) that he talked to more Japanese students than he did American students. With the exception of his Japanese roommate, Koichi spoke Japanese with every Japanese student on his chart; he and his Japanese roommate spoke English to each other only during 
conversations with their other roommate, an American. However, Koichi indicated that he spoke both Japanese and English with his American roommate; using Japanese to discuss homework, personal topics and people, and English to discuss American slang, theme classes, their feelings and personal topics.

There were two American students on Koichi's chart who had previously lived in Japan, with whom Koichi attempted to speak both English and Japanese. One of the students could comfortably converse in Japanese, he and Koichi talked about the weather, classes and their feelings. They used English to clarify classroom lecture material and homework. Koichi used only English with the second American student, because the one time he used Japanese there was a miscommunication and the student did not understand. Thus, he preferred to use English to avoid problems. The American students initiated conversations with Koichi the majority of the time while all of the Japanese students and his roommate only initiated half of the time. 


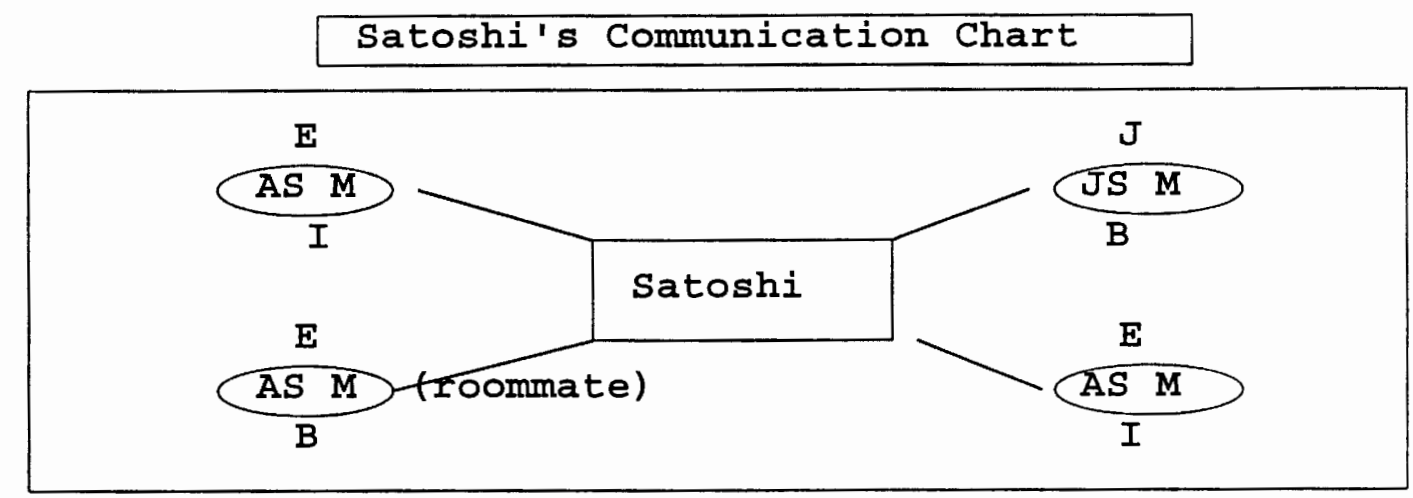

Legend

$$
\begin{array}{rlrl}
\mathrm{J} & =\text { Japanese } & & \mathbf{F}=\text { female } \\
\mathrm{E} & =\text { English } & \mathrm{M}=\text { male } \\
\mathrm{JS} & =\text { Japanese student } & \mathrm{B} & =\text { both initiate } \\
\mathrm{AS} & =\text { American student } & & \mathrm{I}=\text { Initiator }
\end{array}
$$

Figure 5 
I observed that the second male Japanese interviewee, Satoshi, was always the first Japanese student to speak up in class, to ask questions or make comments, and the Japanese student who spoke the most. Interestingly, Satoshi was only in the level two English class. His communication chart (see Figure 5) showed that he spoke to more American students than Japanese students.

Satoshi and his American roommate spoke English because the roommate was only in the beginning Japanese class. They, therefore, used English to discuss Japanese language, family, homework, and classes. With those Americans who were in the highest level Japanese class, Satoshi used both English and Japanese. Japanese was spoken when Satoshi was helping to teach the American students or sharing Japanese slang with them. English was spoken when they discussed Japanese culture, homework, women, American slang or when the Americans helped him with English pronunciation. There was only one Japanese student with whom Satoshi spoke primarily English and this was because the student had excellent English skills. 


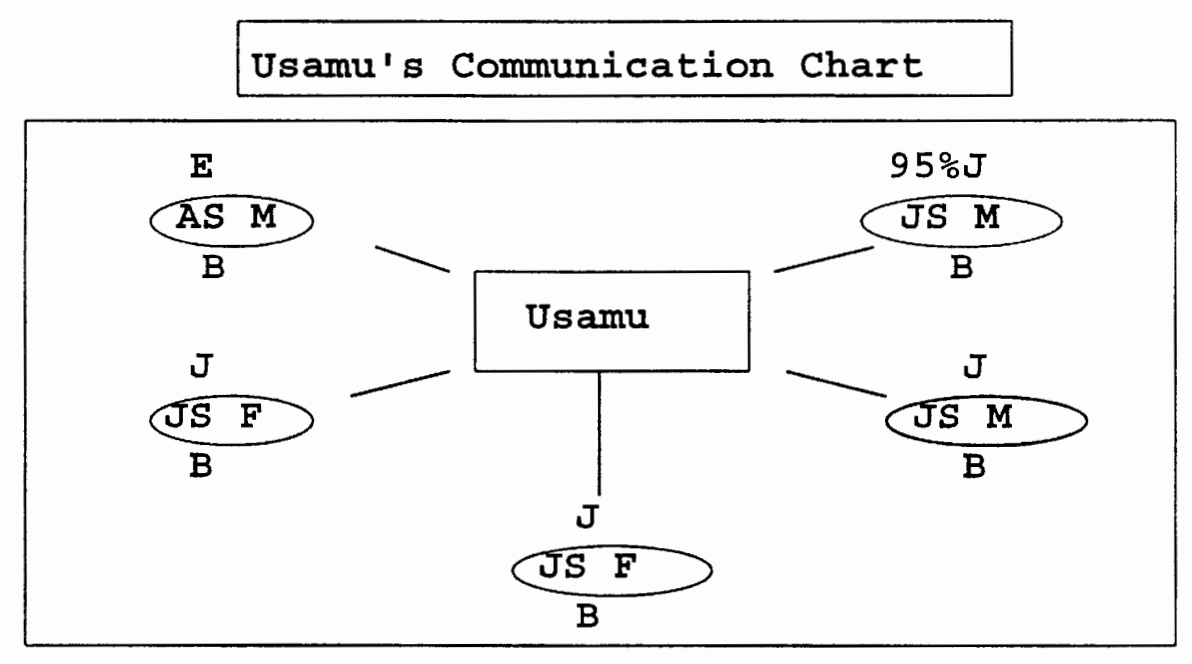

Legend

$\begin{array}{rlrl}\mathrm{J} & =\text { Japanese } & & \mathbf{F}=\text { female } \\ \mathbf{E} & =\text { English } & \mathbf{M}=\text { male } \\ \mathrm{JS} & =\text { Japanese student } & \mathrm{B} & =\text { both initiate } \\ \mathrm{AS} & =\text { American student } & & \mathrm{I}=\text { Initiator }\end{array}$

Figure 6 
However, they did switch to Japanese when discussion became serious or the topic was difficult or complicated. An interesting observation is that satoshi did not include his Japanese roommate on his communication chart. This illustrates the fact that it is not good to assume. I, for example, unconsciously assumed that all the Japanese students would include their Japanese roommates on their communication charts. I was incorrect, and I should have realized that just because people are from the same culture and are forced to live together does not mean they will like each other. There is always the possibility that satoshi forgot to put his name down but I doubt that happened since we spent a fair amount of time discussing the communication charts.

Satoshi indicated that there was equal initiation of conversations between him and his American roommate as well as between him and the Japanese students on his chart. Of the two Americas who had lived in Japan, they initiated contact with him the majority of the time. The last Japanese student to be interviewed, Usamu, was the most introverted of the six. On his communication 
chart, he indicated that most of his time was spent communicating with Japanese students (see Figure 6). The only American student on his chart was his roommate, and the only time they spoke Japanese together was when Usamu practiced phrases with him. In fact, his American roommate was the only person Usamu consistently spoke English with. His preference was to speak Japanese, and he virtually only communicated with the Japanese students. The exception was when he and both of his roommates were in conversation. During these occasions, he would speak English with the Japanese roommate for the benefit of their American roommate. In Usamu's perception, he used English only about five percent of the time and he felt that conversation was initiated an equal number of times by himself and the people on his chart. 
A Summary of the Communication Charts

of the Japanese students

\begin{tabular}{|c|c|c|c|c|c|c|c|}
\hline $\begin{array}{l}\text { Student } \\
\text { names }\end{array}$ & Yumiko & Satoko & Yoko & Koichi & Satoshi & Usamu & Total \\
\hline $\begin{array}{c}\text { Total \# } \\
\text { of } \\
\text { people } \\
\text { in the } \\
\text { Table }\end{array}$ & 7 & 5 & 16 & 7 & 4 & 5 & 44 \\
\hline $\begin{array}{c}\# \text { of } \\
\text { Japanese } \\
\text { student } \\
\text { contacts }\end{array}$ & 3 & 3 & 8 & 4 & 1 & 4 & 23 \\
\hline $\begin{array}{c}\# \text { of } \\
\text { American } \\
\text { student } \\
\text { contacts }\end{array}$ & 4 & 2 & 8 & 3 & 3 & 1 & 21 \\
\hline $\begin{array}{c}\# \text { of } \\
\text { contacts } \\
\text { in } \\
\text { Japanese }\end{array}$ & 4 & 4 & 9 & 6 & 1 & 4 & 28 \\
\hline $\begin{array}{c}\# \text { of } \\
\text { contacts } \\
\text { in } \\
\text { English }\end{array}$ & 4 & 2 & 7 & 3 & 3 & 1 & 20 \\
\hline $\begin{array}{c}\# \text { of } \\
\text { initia- } \\
\text { tors }\end{array}$ & 2 & 0 & 5 & 1 & 2 & 0 & 10 \\
\hline $\begin{array}{c}\# \text { of } \\
\text { equal } \\
\text { initia- } \\
\text { tions }\end{array}$ & 5 & 5 & 11 & 6 & 2 & 5 & 34 \\
\hline
\end{tabular}

Table 1 
The previous Table 1 is a summary of all the information that I gathered from the communication chart of the six Japanese students who were formally interviewed. The purpose of this table is to illustrate the patterns that presented themselves in the data. The totals are provided to be compared and contrasted with the other totals not as absolutes. It can be seen that there is only a slight difference between that number of Japanese students contacts and American student contacts. There is only a slightly larger difference between the number of contacts in Japanese and the numbers of contacts in English. Looking at the table it also becomes obvious that conversations between people were a result of equal initiations.

The following is a summary of the results of the six interviews. I spent up to two hours at least formally interviewing each of the six Japanese students. This time does not include the time I spent going back over my notes and checking them with the information on the tapes. Of the six Japanese students interviewed, only one student felt uncomfortable being tape recorded. In all 
six interviews the same basic eight questions were asked, though sometimes in different ways with different follow up questions. The questions were concerned primarily with the students' two content classes, literature and history/culture. There were also questions about time spent out of the classroom, but that data was supported more by my observations. The eight questions included not exclusively the following questions:

- Do you take notes in class? In English or Japanese?

- What do you write in your notes?

- Do you understand the lectures? What percent?

- What problems do you have in class?

- Which teachers can you understand more easily? Why?

- Is it helpful when the teachers use words or phrases in Japanese?

- Do you ever ask the teachers questions in class? After class? In their office hours?

- Do you sleep in class? Why?

- What strategies do you use to be understood or to understand others?

Of the six Japanese students, most of them asserted that they did take notes and took them in English with the exception of Satoko, who took about one tenth of her notes in Japanese. She wrote down words in Japanese when she did not know the English counterpart and used katakana 
when she did not know the spelling of a word. For Satoko, it was difficult to listen and take notes at the same time, and she felt that she could never get many notes down because she could not understand enough of the lectures. As a result, there was not much information in her notes, what was there having been directly copied from the board. She did take more notes here than in Japan, though.

Koichi said that he, too, was foiled in his attempt to take notes. He said that he either could not catch what the teacher was saying or simply did not understand the content of the class. In his notes he wrote down key words and tried to capture the flow of the lectures. For example in one instance he wrote "some $x$ of slavery in 1860". Yumiko wrote new vocabulary in katakana to be looked up later on, and Satoshi wrote down words he heard and what appeared to be the main point. Usamu and Yoko both said they wrote down words they heard and connections to those words.

When asked if they understood the lectures, there were varying degrees of comprehension beginning with 
Usamu, who declared he understood $90 \%$, and ending with Satoko, who said she understood about $30 \%$. Satoko claimed that she had difficulty understanding because the overabundance of English coupled with difficult vocabulary combined into an incomprehensible mishmash.

Satoshi stated he understood less than $50 \%$. He also had difficulty listening since the speech was too fast and the contractions were unfamiliar. Getting used to the normal conversation speed was difficult for him. He stated, for example, that he had learned to say, "Did you cut your hair?" Yet American students were much more likely to say, "Did you get a haircut?" The discrepancy confused him. Although he had problems with vocabulary he believed that had the teachers spoken slower, he might have understand more. Satoshi claimed that it was very helpful if he already knew the topic, such as an instance in the literature class where he had already read one of the books (in Japanese).

Yumiko and Yoko said they understood the general idea of the lectures but had difficulty listening because teachers spoke quickly and they could not discern words at 
times. Koichi declared that he understood about $50 \%-60 \%$ of the lectures and that it was both the language and his own laziness that affected this percentage.

The content classes had a Japanese teacher and an American teacher (both of whom taught in English), and it was interesting to find that the students differed on which teacher they understood better. Yumiko indicated that in the history class she understood the Japanese teacher, Mrs. Ito, more than the American teacher, Mr. Jensen, because the English was more like Japanese English and, consequently, easier to listen to. In addition, Yumiko had a background in Japanese history, so the topics that Mrs. Ito covered were familiar to her. Yumiko better understood the American teacher, Mr. Thomas, in the literature class because he spoke in a loud, clear voice and also because she had majored in Japanese literature. Satoko and Yoko both felt that the Japanese teachers were easier to understand because they spoke English with a familiar accent.

Koichi also felt that Mr. Thomas was easier to understand because he knew how to interest the students 
and he spoke slowly. In the history class, Koichi felt that Mrs. Ito spoke slowly enough and about familiar topics so he was better able to understand her. For Koichi, the moment he could not understand what the teacher was saying, the rest of the lecture was a wash. Satoshi did not feel there was much difference in his level of comprehension between the Japanese teachers and the American teachers. Usamu understood Mr. Thomas more in the literature class and suggested that professors could have helped the students by providing them with a list of the difficult vocabulary that would be used in the class. He felt this would have saved him a lot of time that he usually spent looking up words. The teachers did give out handouts outlining the lectures, but these were not helpful to him.

With exception of Mr. Jensen, instructors would occasionally throw in a word or phrase in Japanese. This occurred in both classes but more frequently in the literature class. Satoko, Yoko, Koichi, and Satoshi all felt that the bits of Japanese in class were very helpful. Yumiko, said that this was sometimes helpful, admitted 
that those token Japanese inclusions were the only parts of the lecture she could understand. Usamu, on the other hand, was not pleased with the fact that Japanese was used in class. Though he said it was helpful, he would have preferred the teachers stick to English only.

The students were asked if they asked questions and when, including in class, after class, and during teachers' office hours. Koichi stated that he never asked the teachers any questions, he simply relied on his friends to help him. Yumiko, Usamu and Yoko said that they asked about vocabulary in class once or twice. Satoko and Satoshi indicated that they only asked questions after class. Satoko only spoke to the Japanese Iiterature teacher, and her questions mainly focused on the topics of upcoming exams. In general, the teachers were not used as primary sources of information. Instead, students depended on friends to help them with comprehension.

Due to the amount of sleeping I observed in the classes I decided to question the Japanese students as to if they slept in class and why. Satoshi said that he 
really did not want to sleep in class but sometimes he was so tired from reading and staying up late the night before that he could not resist. He felt the readings were not hard but it took him a long time to read and he was behind schedule.

Usamu tried not to sleep but the Japanese literature teacher made him so sleepy by the way she spoke. Also when the room was dark for a video or movie or when the class was aftex lunch it was hard for him to resist the temptation to sleep.

Yumiko and Yoko only slept occasionally and only for short periods of time. They also mentioned the fact that they were usually up late studying so they felt very tired in class. Koichi indicated he feel asleep because he was sleeping a lot less in the U.S. than in Japan. He would stay up late studying, talking and sometimes drinking. Satoko was the only one who very rarely fell asleep. She said that she was trying very hard to understand and only fell asleep when she stayed up especially late the night before. 


\section{Strategies}

These students used a variety of strategies to be understood by others and to understand the classes and the American students. When a miscommunication occurred in a conversation between the Japanese and American students, the Japanese students said they were likely to repeat what they had said, look for another way to explain or say their idea, change their words, use gestures or different postures, or try to put emphasis on the important ideas. Usamu said that his inability to pronounce the letter "r" made it difficult for people to understand him so he tried very hard to pronounce "r" correctly. However, the "r" sound involved so much tongue movement that he was only able to get it approximately correct by focusing his concentration and speaking very slowly. It was not uncommon for me to observe instances when a Japanese student was having so much difficulty communicating that he/she would ask another Japanese student to say it instead.

When it came to understanding the lectures, many Japanese students said they asked other Japanese or 
American students for help in determining the main point of a lecture, the important parts of the reading materials, definitions of new vocabulary, homework and summaries. One Japanese student wrote a paper and asked four American students to read and edit it before he turned it in. Japanese students asked American students for help in class, after class and in the evenings when everyone was studying.

Satoshi said that when he was in class and did not understand, he would try to ask a question. Often he was apprehensive, however, he felt he only understood $50 \%$ of the lecture and, therefore, always wondered of his question would be correct. Too, as often happened, once he got up the nerve to ask, the teacher had already moved on to a new topic.

Yumiko, Yoko and others mentioned that their background in either literature or history helped them with comprehension. Yumiko and Yoko both had majored in Japanese literature, and Satoshi had read one of the literature books in Japanese and was able to follow the story in English. 


\section{Summary}

In summary, the opinions and perceptions elicited from the six formal interviews showed that, while some of the Japanese students asked the teachers for help, the majority of them relied on the American students for explanation of difficult materials and lectures. None of the six formally interviewed Japanese students ever went to any of the teachers' office hours. The Japanese students were also able to use a wide range of strategies to make themselves understood. Most of the Japanese students felt it was helpful when the teachers used words or phrases in Japanese in class. The interviewees reported varying levels of comprehension of the lectures, and most of the students tried to take notes. All of the Japanese students said they took notes in English and I observed a few words in Japanese along the margins. Various students also admitted to sleeping in class.

Inside the Formal Setting of the Classroom Weekdays started with language classes from 8:30 a.m. to 10:30 a.m. The American students took Japanese classes 
and the Japanese students took English classes. What students did after language class depended on the day. On Mondays, Wednesdays and Fridays language class was followed by two of three content classes: comparative literature, US-Asian history and culture, and US-Japanese economics.

The content classes were set up in a rotation, thus, the students had to check the weekly schedules (see Appendix A) that the RAs had handed out. It worked like this: if a student had one class after lunch, he/she would be done at 2:30 p.m.; if the student had two classes after lunch, the school day would not be finished until 4:30 p.m. On Tuesdays and Thursdays there were no content classes. Students spent a total of nineteen hours a week in class.

ESL classes

I went to each of the four English language classes, four times throughout the program for a total of 16 sessions, to see what the Japanese students were learning. Though there was a great deal of variation among the four 
ESL classes, there were also similarities. The following section will begin with a summary of a typical day in each of the four ESI classrooms followed by a presentation of the differences and similarities among the individual classes. A sample seating chart will be provided for each ESL class to aid in visualization.

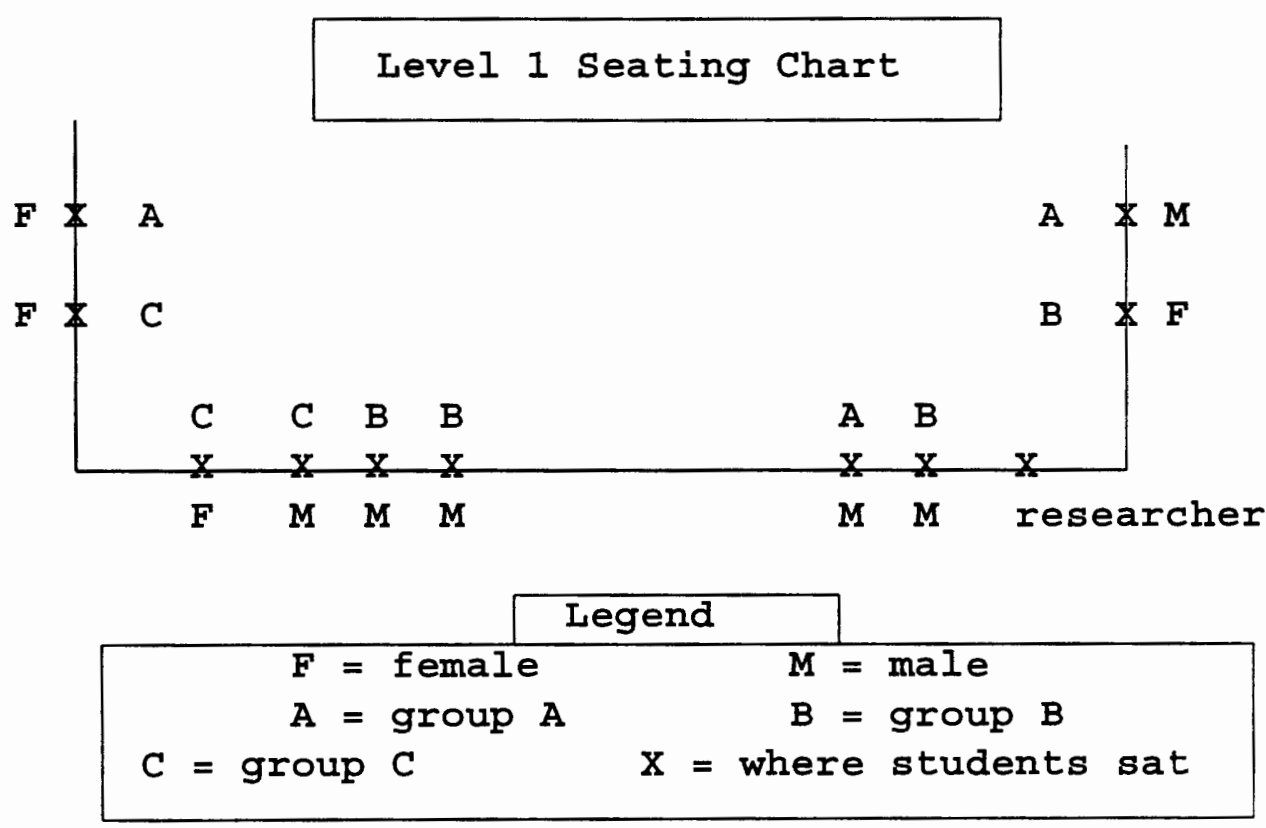

\section{Figure 7}

The Japanese students were divided into four levels of English capability, despite the fact that all of the students were, more or less, at equal levels. A few months before this exchange program started, the ESL 
teachers went to Japan and gave an orientation to the Japanese students. Those students who were chosen for the program had very similar English skills, and the teachers said they had a hard time dividing up the students. There were about 10 Japanese students in each English language class, with Level One designated the lowest and Level Four the highest.

Level one had 10 students (see Figure 7). At this level, the students did not speak English unless they were required to by the teacher, susan. For example, on one particular day the students were assigned to give in-class presentations in English. Susan gave them 30 minutes to prepare their presentations and make their overheads. The students, separated into either Group A, B, or C, (see Figure 7) spoke Japanese in planning their presentations, and Susan did not ask them to speak English.

The students then came back together to present. Group A (see Figure 7) consisted of two males and a female. Each student had a part in the presentation and they presented some good ideas, but it was hard for me to follow them at times. Group $A$ asked if the audience had 
any questions, but there were none. Susan commented on their voice level, gestures, posture, pronunciation, and content.

Group B consisted of three males and one female. The female was the easiest for me to understand, and she gave the explanation of the problem, background information and a summary of the situation. Once again, only susan had comments and questions. Susan and the males in the group had conflicting opinions, but the students were able to defend their position.

The last group to present, Group C, had two females and one male. The male did most of the talking. Susan said they had some constructive statements and good pronunciation, but it was hard to understand how the ideas were connected. I also observed that the content of their presentation seemed to jump around at times. I seemed that they had all written down their ideas and had not put them all together to form a cohesive presentation. The class ended, as usual, with the students writing in their journals about what they felt was important to study during the program. According to susan, most 
students indicated that they felt speaking practice was the most important.

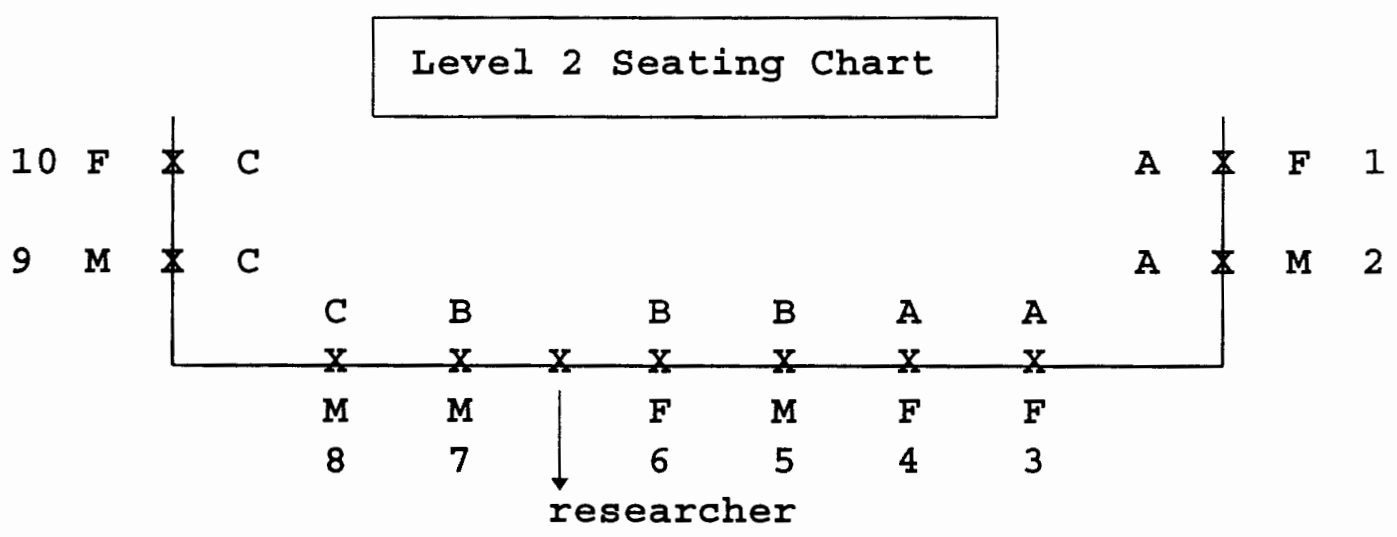

\begin{tabular}{|ll|}
\multicolumn{1}{c|}{ Legend } & \\
\hline $\mathrm{F}=$ female & $\mathrm{M}=$ male \\
$\mathrm{A}=$ group $\mathrm{A}$ & $\mathrm{B}=$ group $\mathrm{B}$ \\
$\mathrm{C}=$ group $\mathrm{C}$ & $\mathrm{X}=$ where students sat \\
\hline
\end{tabular}

Figure 8

Susan was the initiator of English conversations in the Level One ESL classroom. The students consistently spoke to each other in Japanese and only spoke English when Susan asked them to or when they gave their presentations. Susan suggested to me that perhaps the students did not consider themselves to be capable of 
learning English because they were in the lowest class level.

I observed that Level Two was different than Level One: there was almost no Japanese used in class and the teacher, Linda, could not get the students to stop talking. This class also had ten students. (see Figure 8) On one day, the students were going to discuss the topic of homeless people in the United States and Japan. They looked at a picture and had a class discussion. Then they broke into small groups and had an hour to discuss the topic and prepare a presentation of their ideas. In the group discussions, the students voluntarily spoke English to each other and only used an occasional word or phrase in Japanese.

Group A consisted of three females and one male. The male and the female in the middle (students 2 and 3 ) (see Figure 8) did most of the talking, while satoko (student 1) and the other female (student 4) were very shy and only spoke when they gave their part of the presentation. In Group B, student 5 gave the presentation, and student 10 gave the presentation for Group $C$. Outside of the 
presentations, students $2,3,6$ and 7 spoke the most and 8 and 10 spoke only a few times.

After each group gave their presentations they asked for questions. The other students asked so many questions that Linda had to stop them in order to give the other groups a chance to present. This phenomena was repeated after each presentation, and it occurred all in English.
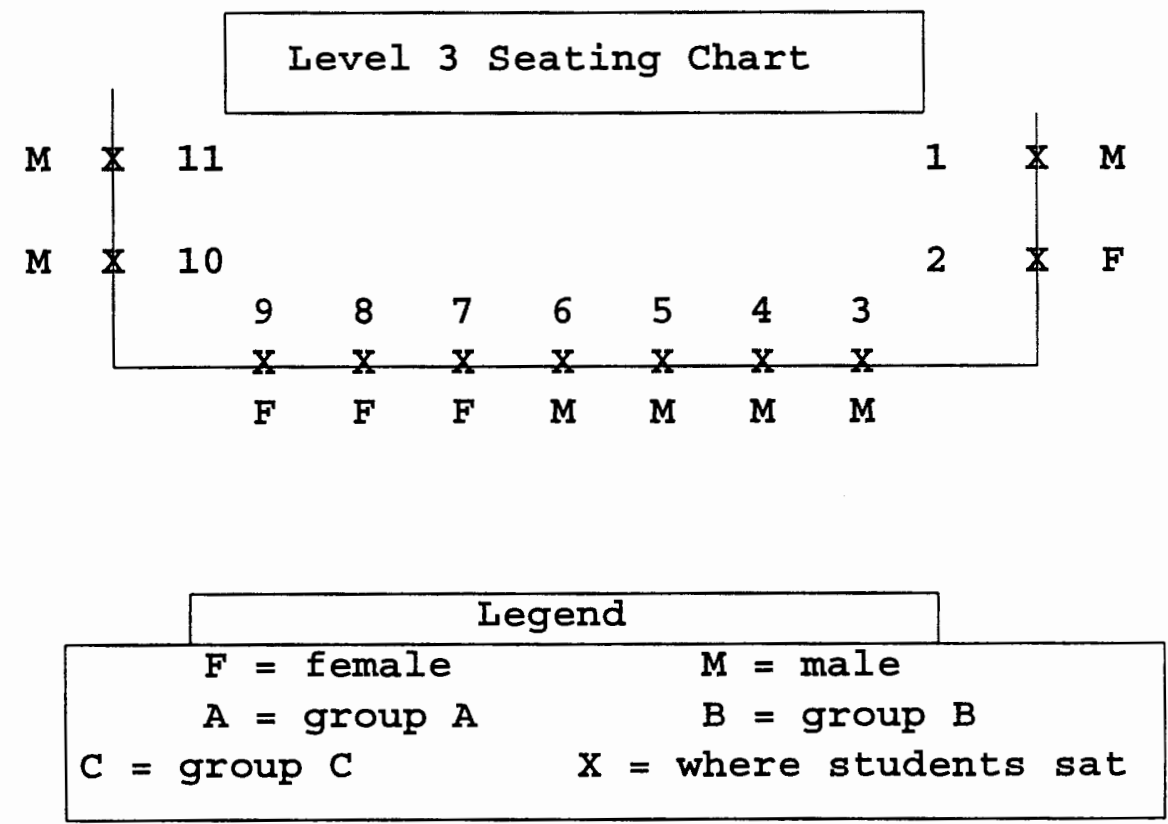

Figure 9

The students voluntarily commented and questioned each other without encouragement from the teacher. After the presentations, Linda talked about what they would be doing in the future. Basically the class was organized around the content classes. Since the students would have 
papers to turn in, Linda said that the thesis statements were due for the next class and that each student would have to present his/her thesis statement and a summary of their paper or Kyogen play in class. Linda said she was trying to teach the students general skills to help them understand the content classes.

In level three I observed that the students used English only to speak to the teacher, Cassandra. In general, Cassandra initiated contact with the students. They were usually slow to respond at first but would get more comfortable and eventually respond more readily to her questions. There were twelve students in the classroom but there were only three students who did almost all of the talking. Some students did not talk at all and others even fell asleep. (see Figure 9) On one particular day when I was in class, the following questions were written on the board for the students to answer in their journals: 1) How do you feel about your literature test or history paper? Satisfied? Dissatisfied? Why? 2) What do you need in your English class? Discussion, note taking, presenting, writing, 
or....? The students were given about 20 minutes to write in their journals. It took the students a few minutes to settle down and start writing. Cassandra asked them to be quiet and some of them asked her questions in English while the other continued speaking in Japanese. Cassandra then moved on and started a new activity by discussing some key words with the students. Then the students had a chance to read an article about a woman who was trying to get into an all male military academy. Cassandra asked questions on content. At first she had to call on the students by name but, little by little, the students started to volunteer answers.

Level 4 Seating Chart

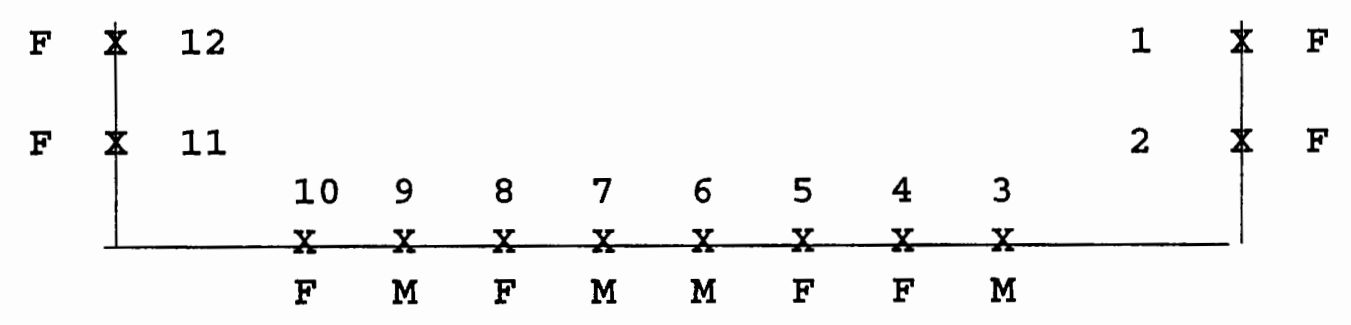

\begin{tabular}{|ll|}
\multicolumn{1}{c|}{ Legend } & \\
\hline $\mathrm{A}=$ female & $\mathrm{M}=$ male \\
$\mathrm{C}=$ group $\mathrm{A}$ & $\mathrm{B}=$ group $\mathrm{B}$ \\
& $\mathrm{X}=$ where students sat
\end{tabular}


In this class, the three students who did a majority of the talking were students 2,8 and 9. (see Figure 9) Students $1,3,5,7$, and 10 also commented a few times, and students 4,6 , and 11 never said anything. Also on this particular day three students feel asleep. Cassandra commented that she told the content teachers that they assigned too much homework. She felt that was the reason that they were always so tired in class.

Level Four was designated the most advanced, however the teacher, Anne, spoke the slowest and the most of all the ESI teachers (see Figure 10). In this class, the students spoke Japanese to each other and used English to speak to the teacher. Anne had to call on students; they were very reluctant to answer or participate in class. The teacher initiated contact with the students most of the time.

A typical day started with Anne asking each individual student, by name, about the status of his/her current paper. Anne talked about the consultation schedule where everyone would have a chance to talk to her individually and receive assistance on their papers. 
They moved on to grammar of quotations. Anne asked questions, but only a couple of students mumbled answers. The students were then divided up for group work and all spoke Japanese. When Anne asked them to speak English, they did for a few minutes before reverting back to Japanese again. Basically, the students did not speak up very much at all in class. There were some students who never even looked up at the teacher. Those who participated did so because of encouragement or because they were called on.

In summary, I found that there were similarities and differences among these four ESL classes. Excluding Level two, students spoke only English to their teachers most likely because their teachers did not speak Japanese. The students also spoke only Japanese amongst themselves. Though Anne did ask her students to speak English, Susan never said anything to her students about their use of Japanese. Cassandra only asked her students to settle down but did not ask them to speak English. Linda, on the other hand (Level two instructor), could not get her students to stop talking in English. 
Due to observations and casual conversations with the Japanese students and the teachers, I discovered that the ESL teachers had no choice but to structure their classes around the content courses. Their jobs, in effect, were reduced to merely reinforcing students' comprehension of what they were learning in the content classes.

Content Classes

As has been established earlier, on Mondays, Tuesdays and Fridays the students took two of the three possible content classes. There were a total of twelve classes for each of the content classes. I attended all twelve of the literature and the history/culture classes. Each class averaged 55 students with two teachers, an American teacher and a Japanese teacher from the Pacific Rim. In the literature class both teachers spoke Japanese. While in the history/culture class, the American teacher, Mr. Jensen, did not speak any Japanese. In most cases, the teachers rotated days to lecture. In the history class, Mr. Jensen spoke about issues in the United states, and the Japanese teacher, Mrs. Ito, spoke about issues in 
Japan. However, in the Iiterature class, the Japanese teacher, Mrs. Yamanaka, taught American literature and the American teacher, Mr. Thomas, taught Japanese literature.

In general, I observed very few opportunities to ask questions or make comments, especially in the history class. Teachers or speakers occasionally asked for questions or comments, but there was never enough time for the students to respond. The vocabulary and the topics of the history class were new for the Japanese students, and they did not have knowledge or previous experiences from which they could draw to help them in comprehension. In the literature class, the Japanese students said they had difficulty reading the books in English. It took one Japanese student fifteen minutes to read the first page of one book, and she still did not understand what she had read.

In the beginning, the students were fairly quiet in class and a vast majority of them paid attention. As the weeks progressed, more students started doing other things in class such as sleeping, talking, writing notes, or doing homework. Sleeping was the most popular activity, 
and many of the Japanese students frequently fell asleep in class. I was amazed at the number of students sleeping on a daily basis.

Despite the general similarities between the literature class and the history class, there are also specific issues to be addressed with regard to each class. The Iiterature class was in a classroom with the front-row students in a semi-circle and the rest of the students arranged in a haphazard manner behind them. On most days, the class spent half of the time together and half of the time divided into two smaller discussion groups headed by one of the teachers.

\section{Literature Class}

- Japanese Students

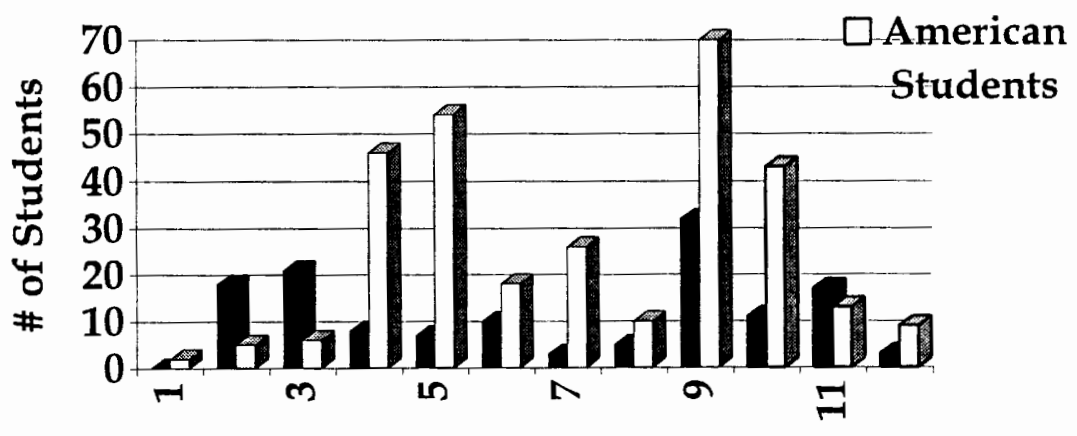

Days

Figure 11 
In the literature class I saw varying degrees of Japanese student participation. Figure 11 shows the number of instances when Japanese and American students participated in each of the twelve days of class according to my everyday observations to illustrate patterns that developed. I did not focus on individuals, if I had concentrated on individual production and a summary of individual utterances the data would have been to cumbersome and I would have not been able to take notes on the lectures in class. As can be seen in Figure 11 , American students spoke more than Japanese students. There are, however, a few exceptions. On days two and three, more Japanese students spoke up than American students due to the fact that there were Japanese guest speakers those days; the Japanese students were able to ask questions and make comments in Japanese. Discussions were always started by American students. Japanese males would chime in later and, finally, the Japanese females would join the conversation. Yoko was one of the more vocal of the Japanese females and even she was quiet in class. 
In one instance, the class had been divided into two smaller groups with one teacher in each group. The discussion that ensued involved the American students and the teacher. The teacher then specifically asked the Japanese students for their opinions and, when they still did not respond, the teacher asked them in Japanese. One male answered, followed by a female student who attempted to answer in English but switched to Japanese when no one could understand her. On another occasion, the Japanese teacher explained, in English, about an upcoming exam and switched to Japanese for the Japanese students.

\section{History/Culture Class}

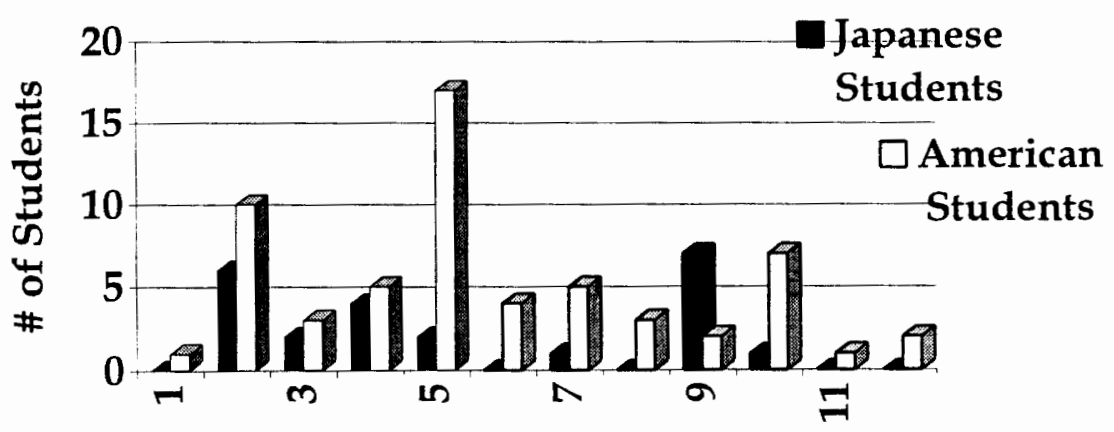

Days

Figure 12 
Unlike the literature class, the history/culture class was held that served to distance the students from the teachers. Consequently, there were even fewer opportunities to comment or ask questions of the teachers which can be seen in the much lower levels of students participation on Figure 12. Figure 12 gives a tally of the number instances of Japanese and American students who spoke up on each of the twelve days of class. The tallies are a result of my everyday observations in class. The topics covered included Indian fishing rights, the Japanese internment camps, the Japanese army's treatment of women, the images of the Japanese in America, and the images of the Americans in Japan.

Figures 11 and 12 show the disparity between the literature class and the history/culture class. In the literature class, the graph records a high of 70 students speaking on one day, contrasted with a high of only 17 students in the history/culture class and they had the same numbers of students overall.

There were many controversial issues brought up in the history/culture class, yet the vast wealth of opinions 
Student Participation:

Voluntary verses Non-voluntary Instances

in the Iiterature Class

Japanese Students

\begin{tabular}{|c|c|c|c|}
\hline Days & $\begin{array}{c}\text { Total number of } \\
\text { times students } \\
\text { speak up }\end{array}$ & $\begin{array}{c}\text { of voluntary } \\
\text { answers }\end{array}$ & $\begin{array}{c}\text { of non-voluntary } \\
\text { answers }\end{array}$ \\
\hline 1 & 0 & 0 & 0 \\
\hline 2 & 18 & 18 & 0 \\
\hline 3 & 21 & 21 & 0 \\
\hline 4 & 8 & 3 & 6 \\
\hline 5 & 7 & 1 & 6 \\
\hline 6 & 10 & 4 & 3 \\
\hline 7 & 3 & 0 & 2 \\
\hline 8 & 5 & 3 & 13 \\
\hline 9 & 32 & 19 & 2 \\
\hline 10 & 11 & 9 & 10 \\
\hline 11 & 17 & 7 & 0 \\
\hline 12 & 3 & 3 & 47 \\
\hline Total & 135 & 88 & \\
\hline
\end{tabular}

American Students

\begin{tabular}{|c|c|c|c|}
\hline Days & $\begin{array}{c}\text { Total number of } \\
\text { times students } \\
\text { speak up }\end{array}$ & $\begin{array}{c}\text { of voluntary } \\
\text { answers }\end{array}$ & $\begin{array}{c}\text { of non-voluntary } \\
\text { answers }\end{array}$ \\
\hline 1 & 2 & 2 & 0 \\
\hline 2 & 5 & 5 & 0 \\
\hline 3 & 6 & 6 & 0 \\
\hline 4 & 46 & 46 & 6 \\
\hline 5 & 54 & 48 & 2 \\
\hline 6 & 18 & 16 & 8 \\
\hline 7 & 26 & 18 & 0 \\
\hline 8 & 10 & 10 & 1 \\
\hline 9 & 70 & 69 & 2 \\
\hline 10 & 43 & 41 & 0 \\
\hline 11 & 13 & 13 & 0 \\
\hline 12 & 9 & 9 & 28 \\
\hline Total & 302 & 283 & \\
\hline
\end{tabular}

Table 2 
Student Participation:

Voluntary verses Non-voluntary Instances in the History/Culture Class

Japanese Students

\begin{tabular}{|c|c|c|c|}
\hline Days & $\begin{array}{c}\text { Total number of } \\
\text { times students } \\
\text { speak up }\end{array}$ & $\begin{array}{c}\text { Of voluntary } \\
\text { answers }\end{array}$ & $\begin{array}{c}\text { of non-voluntary } \\
\text { answers }\end{array}$ \\
\hline 1 & 0 & 0 & 0 \\
\hline 2 & 6 & 2 & 4 \\
\hline 3 & 2 & 2 & 0 \\
\hline 4 & 4 & 4 & 0 \\
\hline 5 & 2 & 2 & 0 \\
\hline 6 & 0 & 0 & 0 \\
\hline 7 & 1 & 1 & 0 \\
\hline 8 & 0 & 0 & 0 \\
\hline 9 & 7 & 7 & 0 \\
\hline 10 & 1 & 1 & 0 \\
\hline 11 & 0 & 0 & 0 \\
\hline 12 & 0 & 0 & 4 \\
\hline Total & 23 & 19 & 0 \\
\hline
\end{tabular}

\section{American Students}

\begin{tabular}{|c|c|c|c|}
\hline Days & $\begin{array}{c}\text { Total number of } \\
\text { times students } \\
\text { speak up }\end{array}$ & $\begin{array}{c}\text { of voluntary } \\
\text { answers }\end{array}$ & $\begin{array}{c}\text { of non-voluntary } \\
\text { answers }\end{array}$ \\
\hline 1 & 1 & 1 & 0 \\
\hline 2 & 10 & 10 & 0 \\
\hline 3 & 3 & 3 & 0 \\
\hline 4 & 5 & 5 & 0 \\
\hline 5 & 17 & 17 & 0 \\
\hline 6 & 4 & 4 & 0 \\
\hline 7 & 5 & 5 & 0 \\
\hline 8 & 3 & 3 & 0 \\
\hline 9 & 2 & 2 & 0 \\
\hline 10 & 7 & 7 & 0 \\
\hline 11 & 1 & 1 & 0 \\
\hline 12 & 2 & 2 & 0 \\
\hline Total & 60 & 60 & \\
\hline
\end{tabular}

Table 3 
was not utilized. When the Japanese students did speak up, it was to ask for clarification of an idea or vocabulary or for summaries of concepts. An extremely small number of Japanese students raised their hands in class to express/share their opinions.

On the third week of classes the history/culture teachers started to have study sessions in the dorms. There were two of these sessions and they lasted for three or four hours in the evenings. Mostly Japanese students sat in, and this more informal setting allowed them a chance to ask for clarification on many of the ideas and vocabulary that had been discussed in class.

Tables 2 and 3 show the number of times students spoke, both voluntarily and involuntarily in class. These numbers are a result of the tallying process that I used in class and are a accurate reflection of what took place. The involuntary instances were times when the teacher specifically called on a student, waited for and expected an answer. A vast majority of the involuntary answers were given by the Japanese students. In the classroom, generally only Japanese students were compelled to answer 
involuntarily; the American students volunteered answers and comments a majority of the time.

In summary, when Japanese teachers were lecturing, they occasionally included Japanese words or phrases or wrote characters on the board. The American teachers tried to speak slowly and write things on the board also. As the program progressed, there was a gradual increase in the number of Japanese students who spoke out in class. Many of the comments made to me by the Japanese students indicated that they were understanding a bit more as the program progressed. Some told me they would have liked to have understood more then they did. The observations and comments that I have made in this section were gathered in class and outside of class when I chatted with the Japanese students.

\section{Colloquiums}

There were a total of five colloquiums held once a week from seven to nine p.m. Professionals from the community came to talk about issues that had been brought up in the history/culture class. These colloquiums 
consisted of a lecture for the large group and then discussions in smaller groups with at least two teachers as facilitators. There were hardly any opportunities to ask questions or make comments. The only time questions were asked was when the class was divided into small groups of about ten students.

For the first colloquium, there were no comments or questions during the presentation. Only later, when the students were divided into small groups, did the American students volunteer information and opinions while the Japanese students remained extremely reluctant to speak up. When one Japanese student did speak, the rest of the group had a hard time understanding the student. The two teachers in the group tried to get the Japanese students involved, but they were unable to respond because they had not understood the speaker. At this point, the Japanese students had only been in the United States for six days, and they were still getting used to listening to English. The level of comprehension of the colloquiums increased only slightly so that, by the last colloquium, seven 
Japanese students spoke up voluntarily in the small groups I was in.

As the program progressed, sometimes very few students attended the colloquiums because they were in the dorm doing homework. During the colloquium, students were forced to interrupt the speaker if they had questions; no time was specifically designed for questioning or commenting. In the large group, the students initiated contact because, although the speakers did begin by asking for student participation, speakers never gave sufficient time for responses. Teachers who attended the colloquiums participated the most. I believe this was due to their lack of fear of interrupting the speaker to throw out an idea, question, or a comment. The teachers were on equal levels with the speakers, making it more appropriate for them to interrupt to add their thoughts and questions. In most cases, students in the small groups were reluctant to speak up, and many would only do so when they were directly asked a question by the facilitators. Yet when the Japanese students were asked directly, they did have answers and opinions and were able to organize their 
ideas and express them to the group. During one of the colloquiums, the small groups were required to give presentations to the large group and share ideas that had been generated. The Japanese students were required to give the presentations. The Japanese students were able to talk in English and make themselves understood. Most of the presenters used notes in their presentations. 
CHAPTER V

\section{DISCUSSION AND CONCLUSION}

\section{Discussion}

In this case study I examined in depth an unusual intercultural learning program in order to explore language and culture learning which occurred for the Japanese participants. In order to gather data, I was a student and went through the same process as all of the other students. Throughout the program, I recorded my observations. In addition to my observations, I also collected data from casual conversations with the Japanese students and from formal interviews with six Japanese students, the American history/culture teacher and all four of the ESI teachers. As a case study researcher I simply observed, "...the characteristics of an individual unit - a child, a clique, a class, a school, or a community" (Nunan, 1992, p.77). This technique resulted 
in a deep probe and analysis of the phenomena that constituted the life of the subject or the community. The results that are gathered can be generalized to include a wider community (Nunan, 1992).

I will discuss the results of my observations, casual conversations and formal interviews in relation to the guiding questions that I proposed in Chapter I and in relation to other issues that presented themselves during the course of the program. I will also mention the limitations and the implications of this case study for the program.

At first I was mainly concerned with the language use of the Japanese students. The first guiding question is concerned with when the Japanese students used English and who was involved. The second guiding question is concerned with the times when the Japanese students use Japanese and whether more or less Japanese was used as the program advanced. As I have indicated in Chapter IV, I found that in general the Japanese students outside the formal setting of the classroom used Japanese when talking to other Japanese students. If there were a group of 
Japanese and American students together, then the Japanese students would use a combination of English and Japanese. At the end of the program I did not witness as great a change in the amount of English used by the Japanese students as I had expected and hoped for. More Japanese students were speaking English and more American students were willing to try to speak Japanese but with such a highly integrated program I expected a much more noticeable difference.

I also looked at who initiated contact with whom. The data from the formal interviews indicated that a majority of the Japanese students felt that contact was initiated an equal number of times by Americans and by Japanese (see Figure 7, p. 109). The communication charts also indicated that the Japanese students felt that some of the American students initiated contact with them the majority of the time.

Outside of the classroom the Japanese students employed a variety of strategies to make themselves understood. They said they would repeat what they had said, look for other ways to explain or say their idea, 
change the words they were using, use gestures or different postures or try to put emphasis on important points. I also observed instances when one Japanese student would ask another to explain his/her idea in English or when Japanese students would use their dictionaries to try to find appropriate English words.

I feel that the Japanese students were very resourceful despite the lack of support from the program. I feel that it would have been very beneficial to the students to have been able to talk about differences that we were encountering and ways we were dealing with those issues. Explicit training to help the students understand the processes they were going through was never given. The students experienced differences but never received any aid from the program in comprehending those differences.

Bennett (1986) states that developmental models should be organized around the concept of "difference" and should allow students to experience "difference" and then provide strategies to aid in comprehending the 
"differences". The only strategies that were used were provided by the students themselves.

This concept of differences is central in the field of intercultural communication. In a well structured program, students move towards an increasing awareness and expand their understanding as they pass through stages on the way to developing an understanding of other cultures. They begin with ethnocentrism where their culture is central and move towards ethnorelativism where they realize that their culture is not necessarily central to others (Bennett, 1986).

From the communication charts, of the Japanese students I interviewed, it appears that there was a fair amount of communication between the Japanese and the American students. The question is, was this a result of good program planning or was this simply the result of a strong desire to learn and the fact that all of the students were living in such close proximity?

Actually there were only a few activities outside the classrooms that were aimed at Japanese and American culture and language. At one point the Japanese students 
were given a questionnaire to be used to elicit opinions and ideas from the American students. For my Japanese class we were given only one assignment to ask questions of the Japanese students. A group of Japanese students would meet with the ESL teachers outside of class in the cafeteria. This group formed because of a request made by one of the Japanese students. I believe that the amount of communication between the Japanese students and the American students was due to the fact that the students were in contact with each other for a majority of the time everyday. From what I observed there really was not any actual facilitating of cross-cultural contact by teachers, administrators and residential assistants in the program.

Before we started our classes we were all required to participate in the outdoor wilderness trip. The students handbook says, "The outdoor wilderness trip encourages U.S. and Japanese students to interact and to become more familiar with one another through a shared experience" (NWPR pamphlet) This appears to be an attempt by the administrators to force the students to be relaxed and familiar with each other. I do feel that friendships were 
formed but never were any cultural issues brought up, and we were never given a chance to really talk to each other and express our feelings in a structured environment with trained cross-cuitural facilitators. Also for the three days that the outdoor wilderness trip lasted, I only saw the third of the group in which I was placed. As a result, I only had a chance to bond with one third of the group. Perhaps it would have been better to have the outdoor wilderness trip at the end of the program or at least to have it last longer so that students could have a chance to change groups and bond with more of the participants in the program.

Chapter I also mentions guiding questions that deal with language use inside of the formal structure of the classrooms. In three of the four ESL classes the Japanese students only used English to talk to the teachers or to give presentations'. The rest of the time they used Japanese. The exception was the fourth class, Linda's level two ESL class, where the students voluntarily used English in class. The same was true in the content classes: in class, English was used with the teachers and 
Japanese was used between Japanese students. Since Japanese teachers were in the content classes, some of the Japanese students asked questions in Japanese during class or after class.

There were guiding questions concerned with determining who initiated more conversations. In class students had to initiate contact more than half of the time. The teachers did ask for questions but many times they did not allow time for answers. Many of the Japanese students had trouble understanding the topics in the content classes, so this was a factor that interfered with the amount of questions and comments in class. Figures 11 and 12 (p. 120 and 121) show the number of times students spoke up in the literature and history/culture classes.

There were also guiding questions dealing with the strategies that Japanese students used inside and outside the classroom. The Japanese students used many strategies in class to aid in comprehension. The most commonly used method to understand lectures and readings was for Japanese students to ask other Japanese or American students for help. The Japanese students I formally 
interviewed said they took notes in class and attempted to keep up with the readings, but they still had many questions, and they relied on the other students to explain and clarify things for them. I believe that the lack of background knowledge was a factor contributing to the Japanese students' lack of comprehension in class. A few of the Japanese students that I formally interviewed also commented that their lack of knowledge of certain subjects (for example, Indian fishing rights) made comprehension all that much more difficult.

I am inclined to think that the Japanese students would have understood a lot more if the teachers had given them a chance to ask questions and had covered fewer topics. In my interviews with the ESL teachers I found that they concurred. This would have enabled the assigned topics to be covered more thoroughly in detail. Also, fewer topics would have given the Japanese students time to understand and not fall so far behind.

The content class teachers, for example, appeared to possess a wealth of knowledge on the particular topics that they were talking about. However, their approaches 
were not especially successful. This lack of ability to share may have been due to the language difficulties and the Japanese students lack of familiarity of some of the topics. For example 20 points were possible on the first literature test (in-class essay); the Japanese students averaged 14 while the American students averaged 18. All the students were given the questions a few days before the test. The Japanese students were not very pleased with their scores. They had worked so hard preparing for the test by writing out 2 - 3 page answers for each of the possible questions but they still were unable to perform as highly as they would have liked.

The previous information concerning the language difficulties of the Japanese students was gathered through observations of and casual conversations with students. Besides looking at the opinions and comments of the Japanese students I also felt it necessary to get a different point-of-view by interviewing all four of the ESL teachers. They provided insights and suggestions that helped point out issues that affected the communication of Japanese students in this program. 
Since the ESL teachers' offices were all in the same room, they were in constant contact. They shared with me that they had decided to concentrate on verbal communication in their classrooms because time to teach the students writing was limited. The ESL teachers were also available to the students on a one-on-one basis. Much more communication amongst the ESL teachers existed then between the ESL teachers and the content teachers. More communication between the ESL and the content teachers may have aided the students by causing the content classes to be focused on the needs of the students concerning their English proficiency.

All of the Japanese students had received high scores on the TOEFL exam and yet the majority of them could not understand the materials presented in the content classes. The ESI teachers spent all their time trying to help the students understand the content courses.

In early theories, language proficiency was equated with knowledge of grammar. More recent theories note that other kinds of knowledge are involved in language proficiency. Mohan (1986) believes that language learning 
should take place not only in the language classroom but also in content classes. He explains that using foreign language in content classes increases the language proficiency by giving it context for use. The language and content classes could reinforce each other, thereby giving the students more useful information and a forum to apply their new-gained knowledge.

There are certain steps Mohan suggests that can be taken to help students learn language that will be useful to them. An organizing framework should be developed that provides language and thinking skills that apply across curricula. This framework should help students develop skills that will allow them to connect what they learn in classes and also learn how to understand independently of others. Students should definitely be helped to improve communication in the subject matter at hand. Mohan (1986) emphasizes the fact that the teacher should try to find strategies that will help the students develop the thinking skills that they will need to be successful language learners. One suggestion is content-based instruction. 
The level one ESI teacher believed that it would be much better if the program was longer. She suggested eight weeks with one whole week for the outdoor wilderness trip and seven weeks for classes. This would be two weeks longer than the current program length. She also felt that the classes could be much more logically organized. For example students could have a content class then a corresponding language class and then another content class and another language class for a total of four classes a day. The content teachers and the language teachers would have to work together to help the students as much as possible.

I believe that the lack of communication between the ESI teachers and the content teachers resulted in problems for the students. For example, some miscommunications on the requirements for the papers for the history class occurred. The directions said approximately five pages. The ESL teachers told their Japanese students that it would be acceptable if they only wrote three to four pages. The students in Level one had never written papers, and some had never typed, so the teacher felt it 
was going to be difficult for them. However, when the assignment for the second paper was handed out the Japanese teacher made it very clear to the Japanese students in Japanese that this time she expected them to write five pages. The Japanese students were upset because the ESI teachers had told them that three to four would be sufficient.

During the program many people were complaining about the plethora of things to do. For example, there was never a lack of homework. Besides the three inch, three ring binder full of readings, students were also assigned to read handouts, additional books, papers, and to take tests; and in the literature class, we wrote and performed our own plays. Besides the large amount of homework, students were required to participate in various activities. The activities included: field trips, meetings, dinners and parties. All of this equaled an overwhelming amount of information to absorb. Many felt overwhelmed with all the information. The Japanese students especially were upset by the amount of homework and activities they were required to do because it gave 
them little time to converse with the American students and learn about the language and culture in the United States. Even ESL teachers were upset that their students had too much to do. As a result of the overload, the ESI teachers had the almost impossible job of bringing up the slack.

The Japanese students consistently indicated that they were eager to have speaking practice. Effective program planning consisting of a needs assessment of the NWPR program may have located this particular desire of the Japanese students and they could have been given more activities that promoted communication (Nunan, 1991). For example the Japanese students were given only one activity in which they were required to ask the American students questions. American students were asked how they would typically behave in a formal classroom setting. More of these activities should have been planned in order to aid the students in sharing their languages, cultures and opinions. People also need to recognize their own culturally-based values, feelings and attitudes and should 
be able to communicate them and learn the logic of other cultural systems (Byrd, 1993; Paige, 1993; Pusch, 1979).

\section{Additional Pertinent Issues}

Besides the issues that the guiding questions were concerned with there were other aspects of the program that could not be ignored. The history of cross-cultural orientation suggests that practitioners have been far too willing to experiment with new program ideas and have, as a result, neglected to identify any conceptual and theoretical foundations. As I read over the information regarding the NWPR program it became apparent that the practitioners felt they had created an unique program with students living together in constant contact, but they do not fully utilize what they have created.

Though the NWPR summer program claims to be a highly innovative venture it was developed by administrators and directors who had limited knowledge of intercultural training theory and who also never participated in the program they created. Many cross-cultural programs bring two groups of students together from different cultures to 
learn a new language and culture. To make the NWPR program different the students' constantly close proximity, as opposed to living in separate host families, should be used to facilitate greater learning.

The literature in Chapter II shows some of the important parts of an intercultural exchange program that lead to a successful program. Many methods can be used to promote cross cultural learning. These activities include: role plays, contrast cultural training, simulation games, critical incidents, the cultural assimilator, and case studies. In order to create a successful cross-cultural program administrators should ask themselves, "What method of language study works abroad?" The method that works is one that incorporates what the foreign setting has to offer in the way of instances, practices and evaluations of the local environments (Kauffmann et al, 1992).

Nieto (1992) reminds us that situations have similarities but also unique challenges, and people must be taught or shown how to ask questions rather than being left to make assumptions. The students in the program 
could have generated misconceptions or stereotypes about each other. No structure guided them. In cross-cultural contact, it is important to avoid stereotypes and attempt to differentiate among members of other cultures (Triandis, 1994).

Ethnocentrism, using one's own culture as a standard for judging other cultures, can have an affect on the quality of intercultural contact. Appropriate training combined with contact between groups, can result in the more accurate stereotypes being formed (Triandis, 1994). Students in cross-cultural exchange programs have been given a chance to participate actively in the language process and to discover through real life incidents the impact of cultural differences and similarities and the consequences, long lasting friendships, misunderstandings and miscommunications that could result. Program administrators should be aware of the transitional experiences that students go through from contact, to disintegration, to reintegration, to autonomy, to independence. Adler (1975) believes that the transitional experience is "a movement from a state of low 
self and cultural awareness to a state of high self and cultural awareness" (p. 15). Adamson (1993) states that in order for students to succeed in main stream courses, they need a general proficiency in English plus background knowledge of the content material and effective study skills.

With regard to the NWPR program, all the students were in the program to meet people from other cultures. The process was slow. The Japanese students were eager simply for the chance to come to the United states. A lot of time was spent planning the places they would visit after the program ended and before they went home. I found that the vast majority of the students, Japanese and American, thoroughly enjoyed the cross-cultural contact and many were sad when it was over. A year later most of the students including myself are still in contact via a special e-mail mailing list. Many of the American students have gone to Japan to visit and study and many of the Japanese students are planning on coming to the United states to study. 
In the NWPR pamphlet advertising this program it says this is a, "six week summer program of Japanese language and comparative culture study." The NWPR pamphlet for the American students says:

The program is designed for undergraduates beginning or continuing their study of Japanese language and culture, students interested in intercultural and international issues and students planning to study or work in Japan. It is an excellent opportunity to begin Japanese language study and gain exposure to Japanese culture through daily interactions with Japanese students in and outside the classroom. (p. 1)

The NWPR pamphlet mentions that past participants felt the intercultural living was "one of the most memorable and successful elements of the summer program." Students live in an intercultural residence hall with Japanese students providing a unique opportunity for language and cultural learning.

The Student Bulletin says that:

The goal of the NWPR summer program is to enhance the understanding of the interplay of the Japanese and American societies of everyone involved in the program through a jointly designed curriculum team-taught by $N W$ and Pacific Rim faculty. Information gathered from an assessment of the summer program will be used in continued planning... (p. 3) 
As can be seen, the organizers strove to gather the opinions and suggestions of the student participants in their evaluation process. At the beginning, middle, and end of the program, multi-page questionnaires were handed out to the participants (see Appendix C). These evaluations asked about the classes there were never any questions dealing with any cross-cultural issues.

The NWPR pamphlet states that, "With both Japanese students and U.S. students participating, the [content] classes are designed to confront issues of cross cultural learning." Very little information is presented about Japanese culture and issues that would be helpful for us to know. In retrospect I would have liked to have learned some useful cultural aspects about Japanese and also some areas of possible culture conflict.

The program did provide us with an opportunity to listen to and to question former NWPR students, but since this intercultural experience was new to us, we did not know what questions to ask. Now, as I look back on the program, I am sure that I would be able to ask many useful questions. The program should have based the interaction 
between us and the former NWPR students on problems that arose in past years to aid us in avoiding or at least being aware of those areas in the hope that we would be able to deal with them more effectively.

\section{Suggestions}

Through the process of data collection and analysis I have found my case study was only able to cover a portion of the information that was presented and that could be studied. I recommend that a more diachronic study be conducted. I was only able to see one summer and was not made aware of recurrent problems and difficulties. A study that lasts over a few summers would be able to provide useful information.

It would also be appropriate for the program to conduct a summative evaluation study. This self study could be used to find out what worked and what did not. With the assistance of professionals in intercultural training and learning, the NWPR program could form a list of the questions that would need to be asked to promote intercultural sensitivity. 
Conclusion

This program was created after the realization that there is $a$, "...need to create a program which challenges not just students, but faculty to think beyond the bounds of their own culture and develop a joint perspective in issues of importance" (students Bulletin, p. 3).

There are so many ways that the NWPR program could have introduced and helped the students with the crosscultural experiences. They had evaluations, the bi-weekly Shinbun and weekly meetings and yet none of these activities dealt with any cross-cultural aspects. Perhaps, I realize that even though we are from different cultures and different countries, we have as many similarities as differences. I also realize that I was nervous about meeting the Japanese students but in the end I found out that they are just people like I am, struggling to do their best. Many friendships were forged in the course of the outdoor program. People are always asking each other questions up to the very end of the program. 
The initial avoidance might have been perpetuated by several factors. First, the American students were together for three days before the Japanese students arrived, and they had already started to form friendships. Also, there were fewer Americans then Japanese, by a ratio of nearly 2 to 1 . Iastly the Japanese students all came from the same Pacific Rim university, many knew each other, and they had participated in their own orientation activities before leaving for the USA. Opportunities for friendships and bonding were present within each group before they came into contact. People spoke to each other, but it took the entire six week program to produce friendships, some of which are still maintained today.

If learners are not achieving the goals and objectives that the program sets, the evaluation should help determine where it fails and why. In the end, the evaluation should also provide ideas as to what can be done to remedy any problems or shortcomings. It is, however, important to remember that an evaluation is not simply a process of obtaining information; it also involves making decisions. Therefore, it can be said that 
the researcher who conducts a program evaluation does not only have to assemble information but also has the job of interpreting that information and making value judgments. The purpose of evaluations is to identify shortcomings in information gathering procedures, so that next time something different will be done to obtain better results. The Japanese students used English to communicate with people who did not speak Japanese a vast majority of the time. They used English with their American teachers and American classmates. They were, however, most likely to use Japanese among themselves. This did change a bit through the course of the program and there was more language sharing at the end of the program. Conversations were initiated by all of the students on an equal basis. The Japanese students employed a wide variety of strategies to communicate and attempt to correct miscommunications.

As a participant observer I was able to become a part of this program and experience it as a student. I feel that I was able to formulate very authentic conclusions due to my first hand experience and the fact that I 
formally interviewed students and teachers and included that information along with my observations. 


\section{REFERENCES}

Adamson, H. D. (1993). Academic competence: Theory and classroom practice: Preparing ESL students for content courses. NY, Longman.

Adler, P. S. (1975). The transitional experience: An alternative view of culture shock. Journal of Humanistic Psychology, 15, 13-23.

Bachman, L. \& Savignon, S. J. (1986). The evaluation of communicative language proficiency: A critique of the ACFI oral interview. Modern Language Journal, 70, 380-90. Bennett, M. J. (1986). Towards ethnorelativism: A developmental model of intercultural sensitivity. In $M$. Paige (ED.), Cross-cultural orientation: New conceptualizations and applications (pp. 27-69). Lanham, MD: University Press of America. Bochner, S. (1982). Culture in contact: studies in cross-cultural interaction. NY: Pergamon Press. 
Brislin, R. W. (1981). Cross-cultural encounters, face-to-face. NY: Pergamon Press Inc.

Byrd, M. (1993). The intercultural communication book.

Canale, M. (1985). A theory of strategy-oriented language development (Report No. FL 015 976). Arlington, VA: Proceedings of a Conference in Issues in English Language Development for Minority Language Education. (ERIC Document Reproduction Service No. ED 273 147)

De Mente, B. (1987). Made in Japan: The methods, motivation and culture of the Japanese and the influence on US business and all Americans. IL: Passport books.

Hall, E. T. (1959). The silent language. Garden, City, NY: Doubleday \& Company.

Jorgensen, D. L. (1989) . Participant observation: A methodology for human studies. Newbury Park, Cali: SAGE Pub.

Kauffmann, N. L., Martin, J. N., Weaver, H D and Weaver, J. (1992) . Students abroad: Strangers at home. Education for a global society. Yarmouth, Maine: Intercultural Press. 
Kim, Y. Y. (1988). Communication and cross-cultural adaptation: An integrative theory. Philadelphia, PA: Multimatters.

Koester, J. \& Lustig, M. W. (1991). Communication curricula in the multicultural university. Communication Education, 40, 250-54.

Kondo, T. (1987). Karuchah shokku no shinniri: Ibunka to tsukiau tameni [Psychology of culture shock: To deal with other cultures]. Osaka, Japan: Sohgensha.

Kramsch, C. (1982). Interaction in the classroom: Negotiated roles in meanings (Report No. FL 013 544). New York, NY: Annual meeting of the American Council on the Teaching of Foreign Languages. (ERIC Document Reproduction Service No. ED 227 681)

Kramsch, C. (1986). Proficiency to interactional competence. Modern Language Journal, 70, 366-72.

Kramsch, C. (1987). Socialization and literacy in a foreign language: Learning through interaction. Theory into Practice, 26, 243-50.

Kramsch, C. (1989). New directions in the teaching of language and culture (Report No. FL 018 694).: NFL 
Occasional Papers. (ERIC Document Reproduction Service No. ED $320 \quad 440)$

Martin, J. N. (1986). The relationship between student sojourner perceptions of intercultural competencies and previous sojourn experience. (Report No. CS 505522). Chicago, IL: (ERIC Document Reproduction Service No. ED 280 089)

Martin, J. N. (1989). Predeparture orientation: Preparing college sojourners for intercultural interaction. Communication Education, 38, 249-58. Mohan, B. A. (1986). Language and content. Reading, Mass., Addison-Wesley Pub.

Nieto, s. (1992). Affirming diversity; The sociopolitical context of multicultural education. NY: Longman.

Nunan, D. (1991). Issues in language programme evaluation in the 1990s. Singapore: SEAMEO Regional Language Centre. Nunan, D. (1992). Research methods in language learning. NY: Cambridge University Press. 
NWPR pamphlet, (N.D.). Unpublished. General information regarding the NWPR program.

Paige, M. (ED.). (1986). Cross-cultural orientation: New conceptualizations and applications. Lanham, MD: University Press of America.

Paige, M. (1993). Education for the intercultural experience. Yarmouth, Maine: Intercultural Press.

Pusch, M. D. (ED.). (1979) . Multicultural education: A cross cultural training approach. La Grand Park, Ill: Intercultural Network.

Spradley, J P (1979). The ethnographic interview. NY: Holt, Rinehart and winston.

Spradley, J. P. (1980) . Participant-observation. NY: Holt, Rinehart and Winston.

Student Bulletin, (N.D.). Unpublished. Handed out to all of the students in the NWPR program.

Swain, M. (1988). Manipulating and complementing content teaching to maximize second language learning. TESL Canada Journal, $6,68-83$.

Triandis, H. L. (1994) . Culture and social behavior. NY: McGraw Hill Inc.. 
APPENDIX A

THE 1995 NWPR SUMMER

PROGRAM CALENDAR 


\section{MASTER CALENDAR \#1}

Tuesday. July 18,1995

\begin{tabular}{|c|c|c|}
\hline $\begin{array}{l}1: 00- \\
2: 30 \mathrm{pm}\end{array}$ & $\begin{array}{l}\text { Odell Hall opens for U.S. program } \\
\text { participants. Resident Assistants (RAs) } \\
\text { are on duty. Keys and ID cards available } \\
\text { in Odell Hall lounge. }\end{array}$ & Odell Hall \\
\hline $\begin{array}{l}3: 30-- \\
5: 00 \mathrm{pm}\end{array}$ & $\begin{array}{l}\text { Orientation } \\
\text {-Introductions } \\
\text { - Program history, goals } \\
\text { - Review of calendar/schedule } \\
\text { - Nuts \& Bolts } \\
\text { - Registration }\end{array}$ & Odell Lounge \\
\hline $5: 00 \mathrm{pm}$ & $\begin{array}{l}\text { Tours of the Lewis \& Clark campus in } \\
\text { small groups. }\end{array}$ & Odell Lounge \\
\hline $6: 00 \mathrm{pm}$ & Dinner & Fields Dining Room \\
\hline $7: 00 \mathrm{pm}$ & $\begin{array}{l}\text { Orientation } \\
\text {-Intercultural living: rewards and } \\
\text { challenges. Student panel discussion. }\end{array}$ & Odell Lounge \\
\hline
\end{tabular}

Wednesday.July 19.1995

\begin{tabular}{|c|c|c|}
\hline $\begin{array}{l}10: 00 \\
12: 00 \text { Noon }\end{array}$ & $\begin{array}{l}\text { Pre-program classes: Economics } \\
\text { and history preview (O'Bannon } \\
\text { and Biolsi) }\end{array}$ & Edmonds 10 \\
\hline 12:00 Noon & Lunch & Fields Dining Room \\
\hline $\begin{array}{l}1: 30- \\
3: 30 \mathrm{pm}\end{array}$ & Japanese language placement test & Edmonds 10 \\
\hline $5: 30 \mathrm{pm}$ & Dinner & Fields Dining Room \\
\hline $6: 30 \mathrm{pm}$ & Film: Tampopo & Olin 301 \\
\hline
\end{tabular}

Thursday.July 20

9:00 am --

Japanese language interviews

BPA 104 (Group

12:00 Noon

Individual interviews:

Olin 102

Olin 103

Olin 204

12:00 Noon

Lunch

Fields Dining Room 
2:00 --

$5: 00 \mathrm{pm}$

Eriday.July 21

10:15 am

12:00 Noon

1:30 pm

$3: 30 \mathrm{pm}$

Afternoon

5:30 pm

7:30 pm
Pre-program classes: Intro to Japan and culture preview (Kominz)

BPB 104

Fields Dining Room

Odell Dorm Lounge - Campus regulations

-Internet (e-mail)

-Mail

-Assessment Questionnaire

Orientation for Waseda students

Individual meetings with students (as required)

Dinner

Choice of activities:

-Sleep

- Karaoke (Downtown)

-Video

-Shuttles to Fred Meyer

-TBA

Meet/Odell Front

Odell Lounge

Meet/Odell Front

Meet/Odell Front
Juniper

Fields Dining Room

Saturday. July 22

$\begin{array}{cl}\begin{array}{cl}11: 00 \mathrm{am}-- \\ 12: 00 \mathrm{Noon}\end{array} & \begin{array}{l}\text { Continuing Orientation } \\ \text { (Pictures, College Outdoor, roommates) }\end{array} \\ \begin{array}{l}\text { 2:00 -- } \\ \text { 4:00 pm }\end{array} & \text { College Outdoor Orientation } \\ \begin{array}{l}\text { 3:30 -- } \\ 5: 30 \mathrm{pm}\end{array} & \begin{array}{l}\text { Meeting: Oregon Joint Program Committee } \\ \text { members and '95 summer faculty }\end{array} \\ 5: 30 \mathrm{pm} & \text { Opening Dinner } \\ & \begin{array}{l}\text { Speakers: Michael Mooney, } \\ \text { Tsumoru Ushiyama. Toast by }\end{array} \\ & \text { Consul Takayoshi Ito }\end{array}$

Tamarack Lounge

Gymnasium (main floor)

Thaxter 3

Manor House Patio Trailroom in case of rain. 
Sunday. July 23

Wilderness trip begins for students

9:00 am --

4:00 pm

Optional faculty/staff/administrative trip to view the rock-climbing wilderness trip

Contact staff

(Limited seats available)

Monday. July 24

10:00 --

11:00 am

11:00 am --

12:00 noon

1:00 pm

Tuesday. July 25

$8: 45$ am

9:00 -

$11: 30$ am

12:00 Noon

$1: 00--$

4:00 pm
Wilderness trip continues for students

Faculty orientation to L\&C library

Computer Training for Faculty

Faculty orientation to the L\&C campus (Optional)

Wildemess trip continues for students

Continental breakfast (optional)

Faculty Meeting

Tentative agenda

Opening remarks

Summer visitors from Waseda

Pre- \& post program questionnaires

Program assessment

Planning 1996

Program schedule

Colloquia planning

Grading policy

Dorm arrangement

Extra-curricular activities

Lunch for faculty (on your own)

Planning time for faculty groups

(Japanese language, English language, US/Japan Economies, US/Japan History

\& Culture, Comparative Literature groups)
Library Circulation Desk

Throckmorton

Macintosh lab

Juniper

Throckmorton 7B

Throckmorton 7B

Juniper Offices

Wednesday.July 26

$\begin{array}{cr}\text { 8:30 -- } & \text { Japanese 1 } \\ \text { 10:20 am } & \text { Japanese 2 } \\ & \text { Japanese 3 } \\ & \text { Japanese 4 }\end{array}$
Albany 120
BPB 104
Thaxter 3
Throckmorton 5 
English 1

English 2

English 3

English 4

10:30 -11:50 am

$1: 00$

2:20 pm

2:30 --

3:50 pm

7:00 --

9:00 pm

Thursday July 27

8:30 --

$10: 20 \mathrm{am}$

10:30 am-

$12: 30 \mathrm{pm}$

5:00 --

$6: 00 \mathrm{pm}$

6:30 p.m.
Comparative Literature (video)

U.S./Asian History

U.S. / Japan Economies

Colloquium Introduction

Speaker: President Mooney

Discussion breakout rooms:

Japanese 1

Japanese 2

Japanese 3

Japanese 4

English 1

English 2

English 3

English 4

Computer training for students

(See Odell bulletin board for your group and time)

Group A

(10:30 am)

Group B

(11:45 am)

Group C

(11:45 am)

Linen Exchange

Film: Double Suicide
Throckmorton 7B

Evans 29

Edmonds 10

Olin 305

Edmonds 10

Olin 301

Edmonds 10

Olin 301

Olin 102

Olin 103

Olin 306

Olin 309

Olin 305

Albany 120

BPB 104

Thaxter 3

Throckmorton 5

Throckmorton 7B

Evans 29

Edmonds 10

Olin 305
Odell computer lab

Odell computer lab

Throckmorton lab

Odell Lounge

Olin 301

Eriday. July 28

8:30 --

10:20 am
Japanese 1

Japanese 2
Albany 120

BPB 104 
Japanese 3

Japanese 4

English 1

English 2

English 3

English 4

$10: 30$

11:50 am

1:00 --

2:20 pm

$$
\text { 2:30-- }
$$

$4: 30 \mathrm{pm}$

6:30 pm

Saturday. July 29

9:00 pm

Sunday. July 30

6:15 pm

7:00 pm

Monday. July 31

$$
\begin{aligned}
& \text { 8:30 -- } \\
& \text { 10:20 am }
\end{aligned}
$$

$10: 30$

$11: 50$ am

English 2

English 3

English 4
U.S. / Japan Economies

Comparative Literature: Guest speakers, Jonah Salz and Akira Shigeyama

U.S / Asian History

Volleyball Game: Faculty/Staff vs. Students

Party for U.S. students and Japanese language teachers

Free

Optional (Japanese) film: A Taxing Woman

Odell Lounge

Front of Odell

World Trade Center 25 SW Salmon

Portland, OR
(Michael Griggs 725-5389)
Thaxter 3

Throckmorton 5

Throckmorton 7B

Evans 29

Edmonds 10

Olin 305

Edmonds 10

TBA (Probably

Black Box Theater but not yet confirmed)

Olin 301

Juniper Sand Court

Meet/Odell Front
BPB 137

BPB 104

Gate House Throckmorton 5

Throckmorton 7B

Evans 29

Edmonds 10

Olin 305

Olin 301

U.S./Asian History 


\begin{tabular}{|c|c|c|}
\hline 12:00 Noon & Faculty/Staff Meeting & Juniper Loung \\
\hline $\begin{array}{l}1: 00- \\
2: 20 \mathrm{pm}\end{array}$ & Japan/US Economies & Edmonds 10 \\
\hline 2:30 -- & $\begin{array}{l}\text { Comparative Literature: Guest speakers, } \\
\text { Issey Ogata and Yuzo Morita }\end{array}$ & Edmonds 10 \\
\hline
\end{tabular}

Tuesday August 1

\begin{tabular}{|c|c|c|c|}
\hline \multirow[t]{2}{*}{$\begin{array}{l}8: 30-- \\
10: 20 \mathrm{am}\end{array}$} & $\begin{array}{l}\text { Japanese } 1 \\
\text { Japanese } 2 \\
\text { Japanese } 3 \\
\text { Japanese } 4\end{array}$ & $\begin{array}{l}\text { (L1) } \\
\text { (L2) }\end{array}$ & $\begin{array}{l}\text { BPB } 137 \\
\text { BPB } 104 \\
\text { Gate House } \\
\text { Throckmorton } 5\end{array}$ \\
\hline & \multicolumn{2}{|l|}{$\begin{array}{l}\text { English } 1 \\
\text { English } 2 \\
\text { English } 3 \\
\text { English } 4\end{array}$} & $\begin{array}{l}\text { Throckmorton 7B } \\
\text { Evans } 29 \\
\text { Edmonds } 10 \\
\text { Olin } 305\end{array}$ \\
\hline $1: 00 \mathrm{pm}$ & \multicolumn{2}{|c|}{ Japan Day Preparation (students) } & Tamarack Lounge \\
\hline $3: 00 \mathrm{pm}$ & \multicolumn{2}{|l|}{ Japan Day } & Tamarack Lounge \\
\hline $5: 00 \mathrm{pm}$ & \multicolumn{2}{|c|}{$\begin{array}{l}\text { Picnic for students, faculty, staff and } \\
\text { families }\end{array}$} & $\begin{array}{l}\text { On lawn between } \\
\text { Templeton and } \\
\text { Manor House }\end{array}$ \\
\hline
\end{tabular}

Wednesday. August 2

$\begin{array}{cll}\begin{array}{c}\text { 8:30 -- } \\ \text { 10:20 am }\end{array} & \begin{array}{l}\text { Japanese 1 } \\ \text { Japanese 2 } \\ \text { Japanese 3 } \\ \text { Japanese 4 }\end{array} & \begin{array}{l}\text { BPB 137 } \\ \text { BPB 104 } \\ \text { Gate House } \\ \text { Throckmorton 5 }\end{array} \\ & \begin{array}{l}\text { English 1 } \\ \text { English 2 } \\ \text { English 3 } \\ \text { English 4 }\end{array} & \begin{array}{l}\text { Throckmorton 7B } \\ \text { Evans 29 } \\ \text { Edmonds 10 } \\ \text { Olin 305 }\end{array} \\ & \text { Comparative Literature } & \text { Edmonds 10 } \\ \text { 10:30 -- } & \text { ESL/theme faculty meeting } & \\ 11: 50 \text { am } & \text { U.S./Asian History } & \text { Juniper Lounge } \\ 12: 00 \mathrm{Noon} & & \text { Olin 301 } \\ 1: 00-- & & \\ 2: 20 \mathrm{pm} & & \end{array}$


NO US / JAPAN ECONOMIES CLASS --

FIELD TRIP TOMORROW

Thursday August 3

\begin{tabular}{|c|c|c|}
\hline $\begin{array}{l}8: 30-- \\
10: 20 \text { am }\end{array}$ & $\begin{array}{l}\text { Japanese } 1 \\
\text { Japanese } 2 \\
\text { Japanese } 3 \\
\text { Japanese } 4\end{array}$ & $\begin{array}{l}\text { BPB } 137 \\
\text { BPB } 104 \\
\text { Gate House } \\
\text { Throckmorton } 5\end{array}$ \\
\hline & $\begin{array}{l}\text { English } 1 \\
\text { English } 2 \\
\text { English } 3 \\
\text { English } 4\end{array}$ & $\begin{array}{l}\text { Throckmorton 7B } \\
\text { Evans } 29 \\
\text { Edmonds } 10 \\
\text { Olin } 305\end{array}$ \\
\hline 1:00 pm & $\begin{array}{l}\text { U.S. / Japan Economies } \\
\text { (field trip to Ft. Vancouver Plywood) }\end{array}$ & $\begin{array}{l}\text { Meet in front of } \\
\text { Odell Dorm }\end{array}$ \\
\hline $\begin{array}{l}5: 00-- \\
6: 00 \mathrm{pm}\end{array}$ & Linen Exchange & Odell Lounge \\
\hline $\begin{array}{l}7: 00-- \\
9: 00 \mathrm{pm}\end{array}$ & $\begin{array}{l}\text { Colloquium: Japanese-American } \\
\text { Internment. *Speakers Dr. Homer } \\
\text { Yasui and Mrs. Susie Sakai }\end{array}$ & Olin 301 \\
\hline
\end{tabular}

Eriday. August 4

\begin{tabular}{|c|c|c|}
\hline $\begin{array}{l}8: 30-- \\
10: 20 \mathrm{am}\end{array}$ & $\begin{array}{l}\text { Japanese } 1 \\
\text { Japanese } 2 \\
\text { Japanese } 3 \\
\text { Japanese } 4\end{array}$ & $\begin{array}{l}\text { BPB } 137 \\
\text { BPB } 104 \\
\text { Gate House } \\
\text { Throckmorton } 5\end{array}$ \\
\hline & $\begin{array}{l}\text { English } 1 \\
\text { English } 2 \\
\text { English } 3 \\
\text { English } 4\end{array}$ & $\begin{array}{l}\text { Throckmorton 7B } \\
\text { Evans } 29 \\
\text { Edmonds } 10 \\
\text { Olin } 305\end{array}$ \\
\hline $\begin{array}{l}10: 30-- \\
11: 50 \mathrm{am}\end{array}$ & U.S. / Japan Economies & Edmonds 10 \\
\hline $\begin{array}{l}1: 00-- \\
2: 20 \mathrm{pm}\end{array}$ & Comparative Literature & Edmonds 10 \\
\hline $\begin{array}{l}2: 30-- \\
3: 50 \mathrm{pm}\end{array}$ & $\begin{array}{l}\text { U.S / Asian History, Guest Speaker, } \\
\text { Georgia Owens, Asst. Director of } \\
\text { Affirmative Action at PSU }\end{array}$ & Olin 301 \\
\hline p.m. & Sports & TBA \\
\hline
\end{tabular}


Saturday August 5

8:30 am

Sunday_Algust 6

Free

Monday, August 7

8:30 --
$10: 20$ am

10:30 --

11:50 am

12:00 Noon

$1: 00$--

2:20 pm

2:30 --

3:50 pm

Tuesday August 8

8:00 am
All-day field trip to Warm Springs Indian Reservation

BPB 137

BPB 104

Gate House

Throckmorton 5

English 1

English 2

English 3

English 4

U.S.JAsian History

Faculty/Staff Meeting

Japan/US Economies

Comparative Literature

Edmonds 9

Evans 29

Edmonds 10

Olin 305

Olin 301

Juniper Lounge

Edmonds 10

Edmonds 10

Meet in front of Odell Dorm

Wednesday. August 9

$$
\begin{aligned}
& \text { 8:30 -- } \\
& \text { 10:20 am }
\end{aligned}
$$

$10: 30$
Japanese 1

Japanese 2

Japanese 3

Japanese 4

English 1

English 2

English 3

English 4

Comparative Literature
BPB 137

BPB 104

Gate House

Throckmorton 5

Edmonds 9

Evans 29

Edmonds 10

Olin 305

Edmonds 10 
$11: 50$ am

12:00 Noon

1:00 --

2:20 pm

2:30 --

3:50 pm

6:30 pm

Thursday August 10
ESL/theme faculty meeting

U.S.Asian History

U.S. / Japan Economies

Film: Sister Carrie

(Optional viewing for those who missed it earlier)
Juniper Lounge

Olin 301

Edmonds 10

Odell Lounge

$\begin{array}{cll}\text { 8:30 -- } & \begin{array}{l}\text { Japanese 1 } \\ \text { Japanese 2 } \\ \text { Japanese 3 } \\ \text { Japanese 4 }\end{array} \\ & \text { (L2) } \\ & \begin{array}{l}\text { English 1 } \\ \text { English 2 } \\ \text { English 3 } \\ \text { English 4 }\end{array} \\ & \begin{array}{l}\text { U.S. / Japan Economies } \\ \text { field trip/migrant camp }\end{array} \\ \text { 10:45 am } & \text { Linen Exchange } \\ \text { 5:00 -- } & \text { 6:00 pm } & \text { Colloquium: Immigration and } \\ 7: 00-- & \text { Crossing Borders. Speaker is } \\ 9: 00 \mathrm{pm} & \text { Larry Klineman }\end{array}$

Discussion breakout rooms:
BPB 137

BPB 104

Gate House

Throckmorton 5

Edmonds 9

Evans 29

Edmonds 10

Olin 305

Meet in front of Odell Dorm

Odell Lounge

Olin 301

Olin 102

Olin 103

Olin 305

Olin 306

Olin 309

Eriday. August 11

$$
\begin{aligned}
& \text { 8:30 -- } \\
& 10: 20 \text { am }
\end{aligned}
$$

Japanese 1

Japanese 2

Japanese 3

Japanese 4

(L2)

English 1

English 2

English 3

English 4
BPB 137

BPB 104

Gate House Throckmorton 5

Edmonds 9

Evans 29

Edmonds 10

Olin 305 
10:30 --

11:50 am

1:00 --

2:20 pm

2:30 --

$3: 50 \mathrm{pm}$

p.m.

Saturday. August 12

9:00 pm

Sunday. August 13

$9.00 \mathrm{pm}$
Comparative Literature

U.S./Asian History

U.S. / Japan Economies

Sports

Free

Optional (U.S.) film: TBA

Free

Optional (Japanese) film: A Taxing

Woman Returns
Edmonds 10

Olin 301

Edmonds 10

TBA

Odell Lounge

Odell Lounge 
Monday August 14

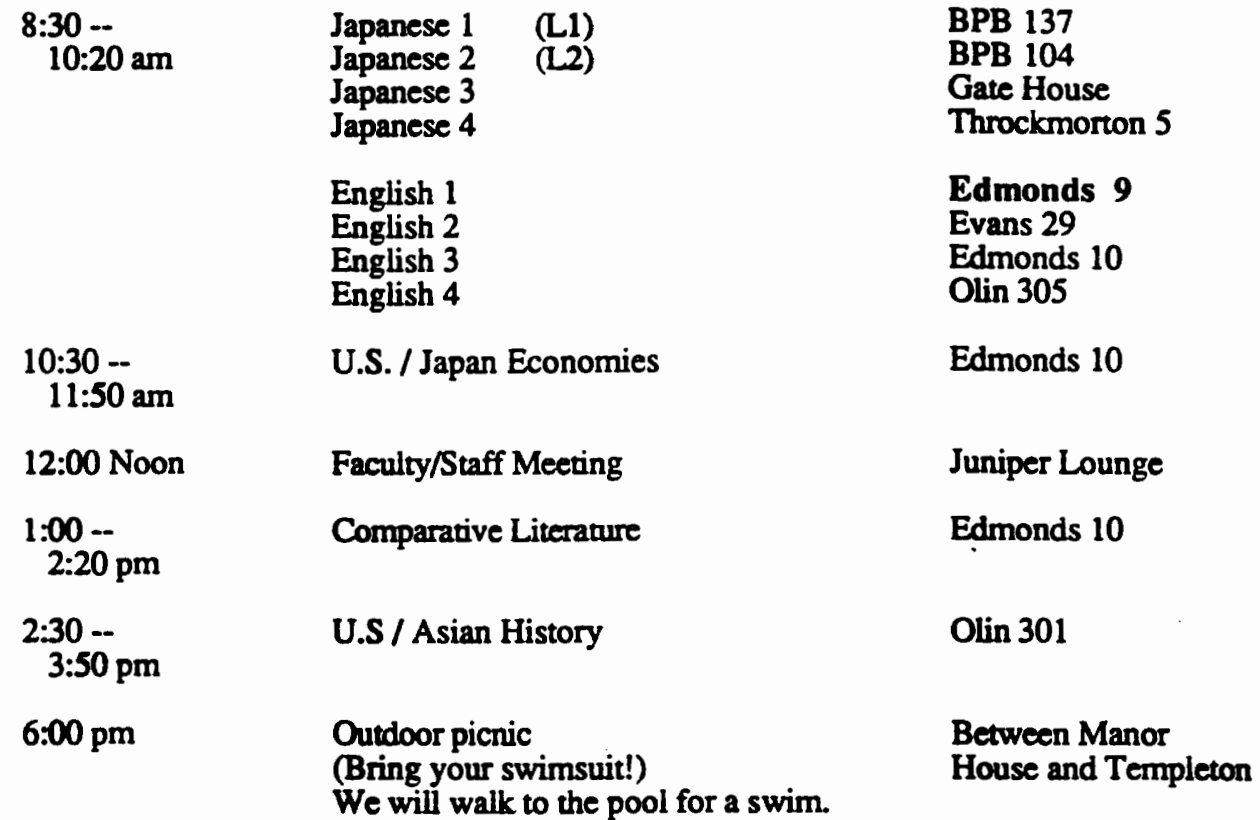

Tuesday. August 15

\begin{tabular}{|c|c|c|c|}
\hline \multirow[t]{2}{*}{$\begin{array}{l}8: 30 \text {-- } \\
10: 20 \text { am }\end{array}$} & $\begin{array}{l}\text { Japanese } 1 \\
\text { Japanese } 2 \\
\text { Japanese } 3 \\
\text { Japanese } 4\end{array}$ & $\begin{array}{l}\text { (L1) } \\
\text { (L2) }\end{array}$ & $\begin{array}{l}\text { BPB } 137 \\
\text { BPB } 104 \\
\text { Gate House } \\
\text { Throckmorton } 5\end{array}$ \\
\hline & \multicolumn{2}{|l|}{$\begin{array}{l}\text { English } 1 \\
\text { English } 2 \\
\text { English } 3 \\
\text { English } 4\end{array}$} & $\begin{array}{l}\text { Edmonds } 9 \\
\text { Evans } 29 \\
\text { Edmonds } 10 \\
\text { Olin } 305\end{array}$ \\
\hline $12: 30 \mathrm{pm}$ & \multicolumn{2}{|c|}{$\begin{array}{l}\text { Field trip: Japanese Gardens/for } \\
\text { students studying Japanese language }\end{array}$} & $\begin{array}{l}\text { Meet in front of } \\
\text { Odell Dorm }\end{array}$ \\
\hline 6:30 pm & \multicolumn{2}{|c|}{ Film: Nine to Five } & Olin 301 \\
\hline
\end{tabular}

Wednesday. August 16 


\begin{tabular}{|c|c|c|}
\hline \multirow[t]{2}{*}{$\begin{array}{l}8: 30 \ldots \\
10: 20 \text { am }\end{array}$} & $\begin{array}{l}\text { Japanese } 1 \\
\text { Japanese } 2 \\
\text { Japanese } 3 \\
\text { Japanese } 4\end{array}$ & $\begin{array}{l}\text { BPB } 137 \\
\text { BPB } 104 \\
\text { Gate House } \\
\text { Throckmorton } 5\end{array}$ \\
\hline & $\begin{array}{l}\text { English } 1 \\
\text { English } 2 \\
\text { English } 3 \\
\text { English } 4\end{array}$ & $\begin{array}{l}\text { Edmonds } 9 \\
\text { Evans } 29 \\
\text { Edmonds } 10 \\
\text { Olin } 305\end{array}$ \\
\hline $\begin{array}{l}10: 30-- \\
11: 50 \mathrm{am}\end{array}$ & Comparative Literature & Edmonds 10 \\
\hline 12:00 Noon & ESL/theme faculty meeting & Juniper Lounge \\
\hline $\begin{array}{l}1: 00 \ldots \\
2: 20 \mathrm{pm}\end{array}$ & U.S./Asian History & Olin 301 \\
\hline
\end{tabular}

\section{Thursday, August 17}

\begin{tabular}{|c|c|c|}
\hline $\begin{array}{l}8: 30-- \\
10: 20 \mathrm{am}\end{array}$ & $\begin{array}{l}\text { Japanese } 1 \\
\text { Japanese } 2 \\
\text { Japanese } 3 \\
\text { Japanese } 4\end{array}$ & $\begin{array}{l}\text { BPB } 137 \\
\text { BPB } 104 \\
\text { Gate House } \\
\text { Throckmorton } 5\end{array}$ \\
\hline & $\begin{array}{l}\text { English } 1 \\
\text { English } 2 \\
\text { English } 3 \\
\text { English } 4\end{array}$ & $\begin{array}{l}\text { Edmonds } 9 \\
\text { Evans } 29 \\
\text { Edmonds } 10 \\
\text { Olin } 305\end{array}$ \\
\hline $1: 30 \mathrm{pm}$ & $\begin{array}{l}\text { U.S. / Japan Economies } \\
\text { (field trip to Pendleton Woolen } \\
\text { Mills) }\end{array}$ & $\begin{array}{l}\text { Meet in front of } \\
\text { Odell Dorm }\end{array}$ \\
\hline $\begin{array}{l}5: 00-- \\
6: 00 \mathrm{pm}\end{array}$ & Linen exchange & Odell Lounge \\
\hline \multirow[t]{2}{*}{$\begin{array}{l}\text { 7:00 -- } \\
\text { 9:00 pm }\end{array}$} & $\begin{array}{l}\text { Colloquium: Gender and Race } \\
\text { in the Workplace. Speaker: } \\
\text { Georgia Owens }\end{array}$ & Olin 301 \\
\hline & Discussion breakout rooms: & $\begin{array}{l}\text { Olin } 102 \\
\text { Olin } 103 \\
\text { Olin } 305 \\
\text { Olin } 306 \\
\text { Olin } 309\end{array}$ \\
\hline
\end{tabular}

Eriday August 18 


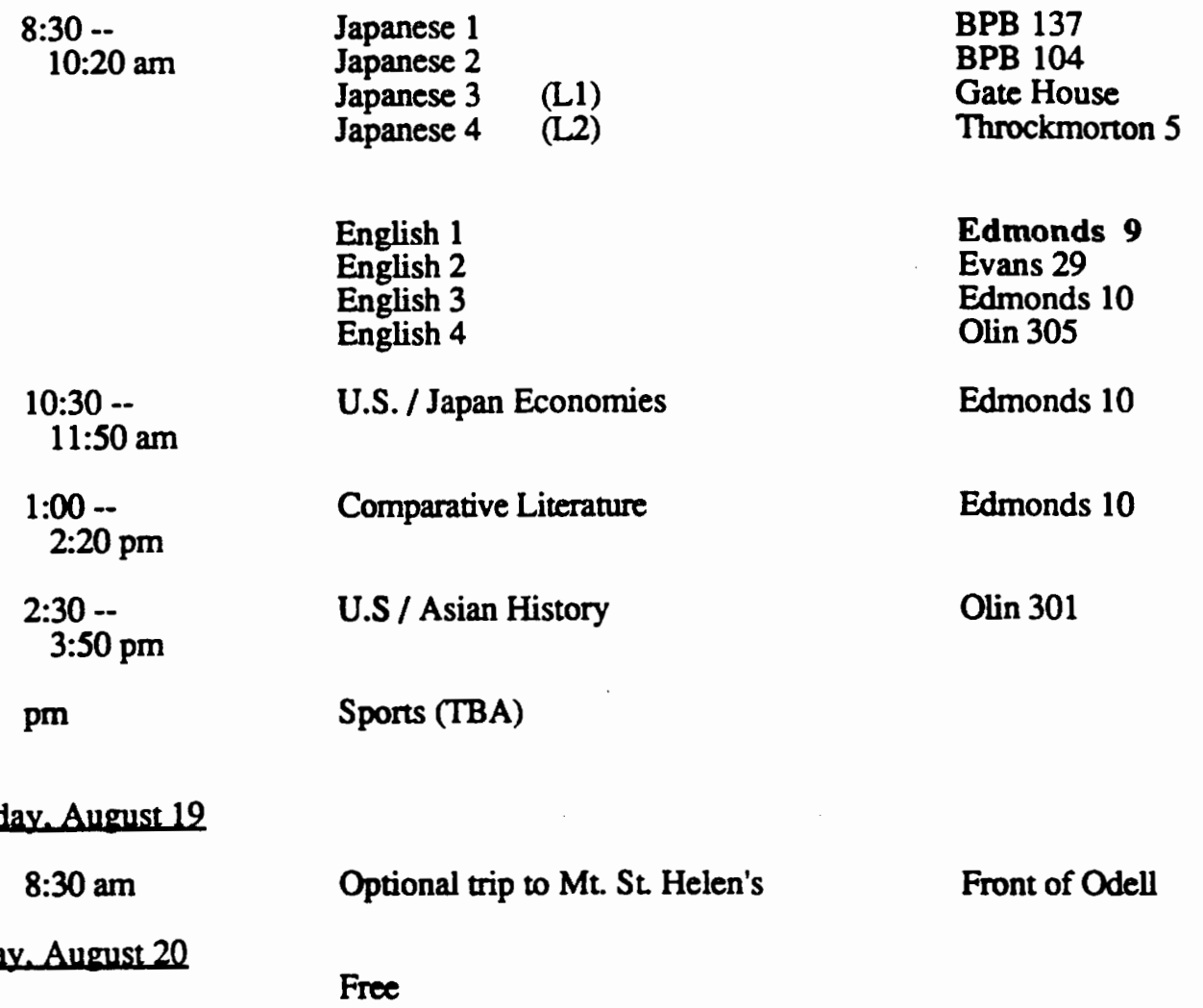


Monday. August 21

\begin{tabular}{|c|c|c|}
\hline \multirow[t]{2}{*}{$\begin{array}{l}8: 30 \text {.. } \\
10: 20 \text { am }\end{array}$} & $\begin{array}{l}\text { Japanese } 1 \\
\text { Japanese } 2 \\
\text { Japanese } 3 \\
\text { Japanese } 4\end{array}$ & $\begin{array}{l}\text { BPB } 137 \\
\text { BPB } 104 \\
\text { Gate House } \\
\text { Throckmorton } 5\end{array}$ \\
\hline & $\begin{array}{l}\text { English } 1 \\
\text { English } 2 \\
\text { English } 3 \\
\text { English } 4\end{array}$ & $\begin{array}{l}\text { Edmonds } 9 \\
\text { Evans } 29 \\
\text { Edmonds } 10 \\
\text { Olin } 305\end{array}$ \\
\hline $\begin{array}{l}10: 30-- \\
11: 50 \mathrm{am}\end{array}$ & U.S.Asian History & Olin 301 \\
\hline 12:00 Noon & Faculty/Staff Meeting & Juniper Lounge \\
\hline $1: 00--2: 20 \mathrm{pm}$ & U.S. / Japan Economies & Edmonds 10 \\
\hline $2: 30-3: 50 \mathrm{pm}$ & Comparative Literature & Edmonds 10 \\
\hline \multirow{2}{*}{$\begin{array}{l}\text { 7:00 -- } \\
9: 00 \mathrm{pm}\end{array}$} & Colloquium: What is an Ideal Society? & Olin 301 \\
\hline & Discussion breakout rooms: & $\begin{array}{l}\text { Olin } 102 \\
\text { Olin } 103 \\
\text { Olin } 305 \\
\text { Olin } 306 \\
\text { Olin } 309\end{array}$ \\
\hline
\end{tabular}

Tuesday. August 22

\begin{tabular}{|c|c|c|c|}
\hline \multirow[t]{2}{*}{$\begin{array}{l}8: 30- \\
10: 20 \text { am }\end{array}$} & $\begin{array}{l}\text { Japanese } 1 \\
\text { Japanese } 2 \\
\text { Japanese } 3 \\
\text { Japanese } 4\end{array}$ & $\begin{array}{l}\text { (L1) } \\
(\mathrm{L} 2)\end{array}$ & $\begin{array}{l}\text { BPB } 137 \\
\text { BPB } 104 \\
\text { Gate House } \\
\text { Throckmorton } 5\end{array}$ \\
\hline & \multicolumn{2}{|l|}{$\begin{array}{l}\text { English } 1 \\
\text { English } 2 \\
\text { English } 3 \\
\text { English } 4\end{array}$} & $\begin{array}{l}\text { Edmonds } 9 \\
\text { Evans } 29 \\
\text { Edmonds } 10 \\
\text { Olin } 305\end{array}$ \\
\hline Afternoon & \multicolumn{2}{|c|}{$\begin{array}{l}\text { Blackbox reserved for practice } \\
\text { for lit class students }\end{array}$} & Blackbox Theatre \\
\hline $7: 00 \mathrm{pm}$ & \multicolumn{2}{|c|}{$\begin{array}{l}\text { Film: Tootsie (Only for students who } \\
\text { have not seen the film previously). }\end{array}$} & Odell Lounge \\
\hline
\end{tabular}


Wednesday. August 23

\begin{tabular}{|c|c|c|}
\hline $\begin{array}{l}8: 30-- \\
10: 20 \text { am }\end{array}$ & $\begin{array}{l}\text { Japanese } 1 \\
\text { Japanese } 2 \\
\text { Japanese } 3 \\
\text { Japanese } 4\end{array}$ & $\begin{array}{l}\text { BPB } 137 \\
\text { BPB } 104 \\
\text { Gate House } \\
\text { Throckmorton } 5\end{array}$ \\
\hline & $\begin{array}{l}\text { English } 1 \\
\text { English } 2 \\
\text { English } 3 \\
\text { English } 4\end{array}$ & $\begin{array}{l}\text { Edmonds } 9 \\
\text { Evans } 29 \\
\text { Edmonds } 10 \\
\text { Olin } 305\end{array}$ \\
\hline $\begin{array}{l}10: 30-. \\
11: 50 \mathrm{am}\end{array}$ & U.S. / Japan Economies & Edmonds 10 \\
\hline 12:00 Noon & ESL/theme faculty meeting & Juniper Lounge \\
\hline $\begin{array}{l}1: 00-- \\
2: 20 \mathrm{pm}\end{array}$ & Comparative Literature & Edmonds 10 \\
\hline $\begin{array}{l}2: 30-- \\
3: 50 \mathrm{pm}\end{array}$ & U.S./Asian History & Olin 301 \\
\hline $\begin{array}{l}\text { 6:00 pm -- } \\
12: 00 \text { midnight }\end{array}$ & $\begin{array}{l}\text { Dress rehearsal for the Comparative } \\
\text { Literature class plays }\end{array}$ & Black Box Theatre \\
\hline
\end{tabular}

Thursday. August 24

$\begin{array}{cl}\text { 8:30 -- } & \begin{array}{l}\text { Japanese 1 } \\ \text { Japanese 2 } \\ \text { Japanese 3 } \\ \text { Japanese 4 }\end{array} \\ & \begin{array}{l}\text { English 1 } \\ \text { English 2 } \\ \text { English 3 } \\ \text { English 4 }\end{array} \\ & \begin{array}{l}\text { Comparative Literature } \\ \text { (Plays performed) All students and } \\ \text { staff are welcome! }\end{array} \\ \text { 1:30 -- } & \text { Linen exchange } \\ \text { 5:30 pm } & \\ \text { 6:00 pm } & \text { Blackbox reserved for practice } \\ \text { pm } & \end{array}$

BPB 137

BPB 104

Gate House

Throckmorton 5

Edmonds 9

Evans 29

Edmonds 10

Olin 305

Black Box Theater

Odell Lounge

Black Box Theater 
Eriday August 25

$\begin{array}{cl}\text { 8:30 -- } & \begin{array}{l}\text { Japanese 1 } \\ \text { Japanese 2 } \\ \text { Japanese 3 } \\ \text { Japanese 4 }\end{array} \\ & \begin{array}{l}\text { English 1 } \\ \text { English 2 } \\ \text { English 3 } \\ \text { English 4 }\end{array} \\ & \text { U.S./Asian History } \\ \text { 10:30 -- } & \\ 11: 50 \text { am } & \\ & \\ 1: 00 ~-- & \text { Japan/US Economies } \\ \text { ??? pm } & \text { (Student presentations) All students and } \\ & \text { staff are welcome! }\end{array}$

Saturday. August 26

$6: 30 \mathrm{pm}$

Sunday, August 27

Program ends

U.S. Students depart before lunch

9:45 am

2:00 pm

Monday, August 28

10:00 am
Assessment meeting for faculty and staff

JPC Meeting
Waseda students board bus for airport
BPB 137

BPB 104

Gate House

Throckmorton 5

Edmonds 9

Evans 29

Edmonds 10

Olin 305

Olin 301

Olin 301
Thayer/Templeton

Thayer/Templeton

Waseda students leave 
APPENDIX B

THE ALMOST DAILY

SHINBUN 


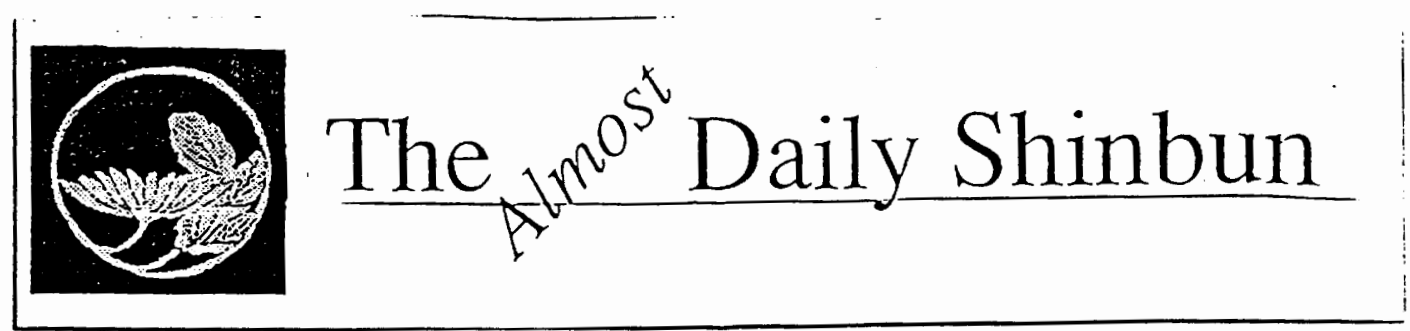

Issue 1

\section{WELCOME TO THE PROGRAM!}

Welcome to the Oregon/Waseda Summer Program! It is great to have you participate in the program and all of the staff and faculty members look forward to working with you during the next five weeks. We hope you will have a great time while you are in Portland this summer.

For those of you new to Portiand and to the Lewis \& Clark College campus, we offer a special weicome. This is a beautiful area of the country and we urge you to take every opportunity to enjoy the Pacific Northwest.

The Oregon/Waseda Summer Program promises to be a great success this year. We expect to enroll 45 students from Waseda University in Tokyo, 1 student from the University of Bonn, Germany where Waseda has an institute, and 26 students from U.S. universities.

A special weicome to all of you!

\section{IMPORTANT: ROOM CHANGE FOR TONIGHT'S MOVIE}

We have already made our first schedule/room change! Tonight's movie, Tampopo, will be shown in the Odell Dormitory Lounge instead of Olin 301. The movie starts at 6:30 p.m. We changed the room because the Olin classroom seats 90 students and is too large for a group of 27 students. Also, it is a long walk to Olin in this heat!

Oregon/Waseda Summer Program

\section{JAPANESE LANGUAGE PROGRAM INSTALLED IN COMPUTER LAB!}

As requested at yesterday's orientation session, the Japanese language (kanji) program has been installed on several of the computers in the Odell Computer Lab (basement lab). We asked Information Technology to install the program on some but not all of the computers since it requires a lot of memory and slows down the machines. The computers with the kanji program are labeled.

The Odell computer lab will be open at the beginning of the academic program. In the meantime, you may use the computer clusters in Odell and Stewart dorms at any time (open 24 hours a day). To enter the computer clusters, please ask one of the RAs for the door combination.

\section{E-MAIL IS COMING!}

We are working on the e-mail guest accounts and will have them in the next day or so. You will be able to access the accounts through both the Odell Computer Lab (basement) or the computer clusters in Odell and Stewar. To use e-mail in the clusters, you will need a special e-mail disk that will be placed in the room by tomorrow afternoon.

\section{YOUR MORNING NEWS}

The Almost Daily Shinbun is your news source for the Oregon/Waseda Summer Program. It is published on an irregular basis and disuributed directly to your rooms. It was a great success during past years' programs and helped a great deal with communication. 
Please read it carefully as it often contains important information on schedule changes.

Students are welcome to write for the Almost Daily Shinbun. If you have an announcement or would like to write an article, please submit it to any member of the staff. If you would like to write an article in Japanese, that is great too.

\section{FACIIITIES}

While living on the Lewis \& Clark College campus this summer, we invite you to use any campus facilities that are open. This includes the library, the gym, the indoor and outdoor pools, the weight room in the gymnasium. tennis courts, etc. Your temporary program I.D. will permit your use of all facilities.

In Odell Hall please feel free to use the lounge TV and VCR. A kitchen is next to the lounge and you may use that for late preparing night snacks (just clean up after yourself). In the basement you will find study rooms. laundry facilities, recreational facilities, and a computer lab.

\section{IMPORTANT NUMBERS}

You should have received a "wallet size" card with emergency telephone numbers. If you did not receive that card, please contact one of the R.A.s or the program staff.

\section{WHAT'S MY TELEPHONE NUMBER?}

If friends and family would like to call you during the program, they may do so by calling directly to the telephone in your room. Your telephone should have the number written on it. The area code for Portland is (503) and the prefix for Lewis \& Clark is 768 . Your number then will be (503) 768-XXXX (your extension). Those of you receiving calls from overseas should be sure to tell callers that the "Country Code" for the U.S. is " 1. "

You might also want to tell your friends that the Lewis \& Clark College switchboard number is (503) 7687855. That telephone is answered during business hours only.

Oregon/Waseda Summer Program

\section{INTERNATIONAL TELEPHONE CALLS}

You can make long distance and international calls from the telephone in your room if you have your own telephone card (MCI, AT\&T, etc.) or if you purchase a "Pre-Paid Telephone Card" from Lewis \& Clark's telephone service provider. The cards can be purchased from the Lewis \& Clark Bookstore in increments of $\$ 50.00$ and will permit calls to be made from any touch-tone telephone in the United States. The cards offer reasonable rates and can be used after the program ends.

\section{WHAT'S MY ADDRESS?}

Please tell your friends to write you care of the following address: (Your name), c/o Oregon/Waseda Summer Program, Campus Box 185, Lewis \& Clark College, Portland. Oregon 97219. U.S.A. Your mail will be delivered to your room every day except Sunday.

\section{CHANGE YOUR SHEETS!}

The summer program provides linen service while you are on campus. Erich Paesch is the "Conference Manager" for Odell Hall and will help with the exchange of sheets and towels each Thursday (beginning next week). The system worked well last year and so we will try it again.

On Thursday aftemoon between 5:00 and 6:00 (just before dinner), take your used linens to Odell Lounge. Erich will be there to give you clean sheets and towels in exchange, or he will simply leave them there for you to pick up. 


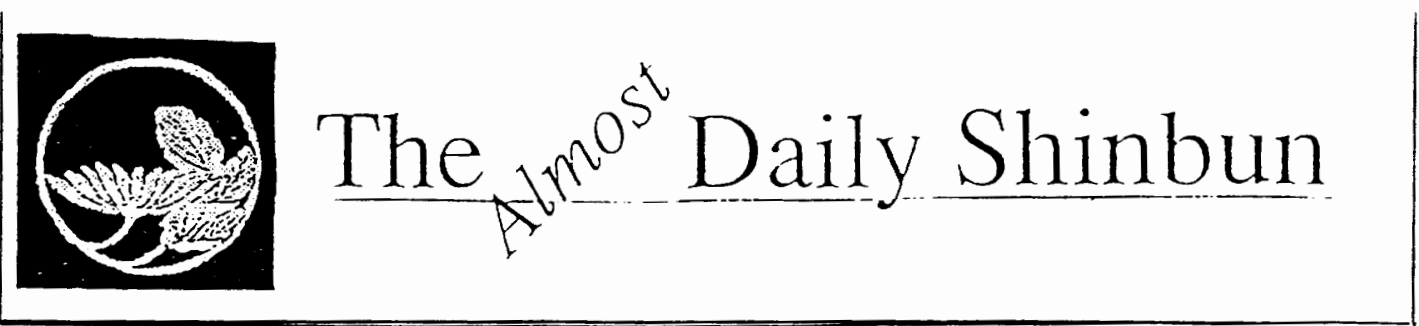

Issue 2

July 26,1995

\section{WELCOME BACK!}

Welcome back to the soft beds and hot showers of Odell Dorm! According to all reports received so far. everyone made it back from safely and in good humor from their outdoor wildemess experience. Everyone seemed a little tired this morning. but most described the experience as "great" or "perfect." We are glad that you had a good time and that you are back safely.

Lisa Galbraith, the organizer of the trips, called this morning to repor that you were a great group of students. She particularly appreciated your cooperation and enthusiasm and what she called "your graciousness."

In a few days, the staff will distribute a brief questionnaire about the wildemess experience. Lisa hopes that you will complete it so that she can continue to improve the program next year.

\section{NEW SCHEDULE PUBLISHED}

All students and faculty should have received a new (yellow) schedule that was distributed last night. Please make sure that you discard any old schedules and use the new, yellow one. We will publish new schedules as the program coninues to make sure that all items are up to date.

\section{TONIGHT'S COLLOQUIA}

Please remember tonight's first colloquia. It is a required part of the program and all students and stafi should plan to attend. The meeting will be in Olin 301 at 7:00 pm. Tonight's speaker will be Dr. Michael Mooney, President of Lewis \& Clark College.

\section{REGISTRATION DEADLINE SET! DON'T WAIT!}

Please note that the last day to change your class regisuration and/or choice of grading system is $4: 30 \mathrm{pm}$ on Friday, July 28. After that time, you may not change classes or grading systems.

Also, note that the U.S./A sian History and Culturc class is full and students will not be pernitted to add that class. Students who would like to drop the U.S./ Asian History and Culture class and add either U.S./ Japan Economies or Comparative Literature may do so.

All U.S. students are currently signed up to receive letter grades (A, B, C, D, etc.). If you prefer to register for CR/NC (credit/no credit), please inform Bill Griesar or Greg Caldwell in writing before the Friday deadline.

\section{COMPUTER TRAINING TOMORROW!}

Please remember that computer training is scheduled for tomorrow, Thursday, July 27 . This is an important session and we ask that all students attend. Even if you are familiar with Macintosh computers and your own institution's computer network, you will be able to use this training session. And, if you are a "computer expert" already, perhaps you could help those at the session who are less familiar with the system.

Students have been divided into three groups-A.B, and C. Please look on the main bulletin board at Odell Dorm for your group assignment. Then, pay special attention to the schedule and place because each group meets at a different time and different place. (See the new, yellow schedule). 


\section{E-MAIL}

Waseda students who applied for e-mail accounts eariier this week should now have the accounts in hand. If not. please let one of the staff members know.

\section{REACH OUT AND TOUCH SOMEONE!}

This year for the first time, the Oregon/Waseda Summer Program students have access to voice mail. It can be a very helpful communication tool. Would you please make sure that you have set up the voice mail service in your room. If you have any difficulty in setting up the system. please check with one of the R.A.s.

\section{VOLLEYBALL CHALLENGE!}

The facuity and staff would like to challenge the students to a volleyball game this coming Friday, July 28th. at 4:30 p.m. on the sand court beside Juniper Dorm. Last year the faculty and staff won-badly! Not much competition from the students!

This year promises to be a repeat of last year. With faculty players such as "Bionic Biolsi" "Spiker Spak," "Hard Hitting Hoshino" and "Dale the Deliverer," the offense should carry the faculty through. Be there-if you dare!

\section{PARTY PARTY PARTY}

Following the volleyball game, the Japanese language faculty have scheduled a part for the students in their classes. Transportation to the Waseda faculty apartments downtown will be provided.

\section{ISSEY OGATA PERFORMANCE}

On Sunday evening students from the Comparative Literature class will attend the performance by Issey Ogata at the World Trade Center. Because of space and budget considerations. only those students in the comparative literature class will be provided with tickets. However, if other students would like to atend and pay the $\$ 12$ fee, we can arrange for them to attend as well. Please let Kenji or Greg know as soon as possible. Call X7308.

Oregon/Waseda Summer Program

\section{JAPAN DAY PREPARATION}

Thursday, July 27, a group of about ten Waseda students will meet with the Japanese professors to prepare for the upcoming Japan Day celebration. The meeting will be at 12:30 pm in the Odell Dorm lounge. Students participating in the meeting should furst get their lunches and take their trays out of the cafeteria and walk over to the Odell Dorm lounge. Tabies will be set up in the lounge so that you can have a luncheon meeting.

\section{PLEASE LOCK OFFICE WINDOWS}

We ask that faculty members please make sure that their windows are tightly closed and locked when out of their offices and when they leave at the end of the day. There are obvious security concerns.

The windows in the building do not fit well and even though a window may appear to be closed, it may not be locked. Please check to see that the window is securely fastened and/or that there is a wooden block securing the window. Thank you.

\section{TAXI FARE}

If you need a taxi to or from Lewis \& Clark College campus, you can call the following:

Broadway Cab: 227-1234

Rose City Cab: $282-7707$

Portland Taxi: $256-5400$

The cost of a taxi between Lewis \& Clark and downtown Portland should be approximately $\$ 12$ total. Be sure that the driver uses the meter. Riders usually give a tip to the driver. A $10 \%$ tip should be sufficient.

\section{CHANGE YOUR SHEETS!}

The summer program provides linen service while you are on campus. Erich Paesch is the "Conference Manager" for Odell Hall and will help with the exchange of sheets and towels each Thursday in Odell Lounge between 5:00 and 6:00 pm. 


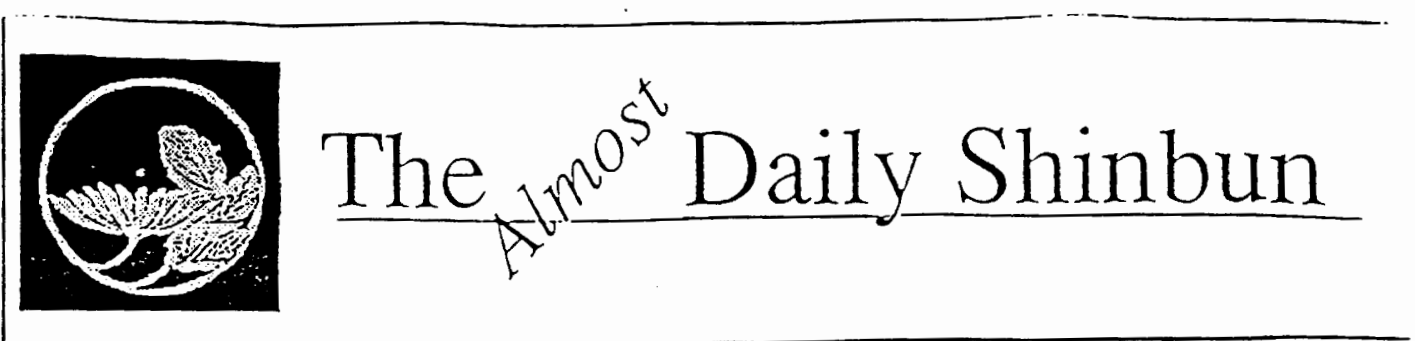

Issue 3

YOLLEYBALL GAME-A TIE!

Though the students surged to a quick lead in the studendfaculty volleyball game on Friday, the faculty managed to pull themselves together and win the lasi two games. That evened the serics of four games at two to two and brings up the prospect for a championship game later this summer.

In the first two games on Friday, the students seemed unstoppable and the faculty seemed a bit bewildered. In an interview after the garne, Kenji Shibata suggested that the faculty team was simply short handed. Bionic Biolsi was on the sidelines cheering, out of action with a bad back. Spiker Spak was on leave on Friday afternoon, too, which further hurn the faculty team. And, one of the strong defensive members of the team, Shoko Tsuzuki, was unable to participate until game 3 because of several students" "urgent" requests. (Was that a plot?).

Those interviewed after the game seemed to enjoy it, and all are looking forward to the final, ultimate game later this surmmer!

\section{USE THE GREEN SCHEDULE}

A new, green colored scheduled was distributed to the sudents and faculty on Sunday evening. Please make sure that you throw away any old schedules and follow the new, green schedule.

The weekly change of schedules is necessary as faculty members make changes in their syliabi, as bus schedules change, and as unexpected events arise. But, it will all work as long as we are all using the same, green schedule!

Oregon/Waseda Summer Program
July 31, 1995

\section{SUYOBI WHA NIHONGO WO HANASHIMASHO}

It has been suggested that Wednesciay be "Speak Japanese" day for tic remainder of the program. Since our classes are all in English and the U.S. students would enjoy more practice in Japanesc, the faculty has agreed that we should encourage the use of Japanese on Wednesdays. This does not mean that you have to speak Japanese (I can't). But, you should feel free to use it throughout the day. This might mean more lunch and dinner conversations in Japanese, a few questions in class in Japanese, and so forth. Let's ty it and see how it goes!

\section{A TAXING WOMAN ARRIVES}

The video A Taxing Woman arrived in the mail this morning-two days late! As a consequence, we substituted The Funeral instead. Since A Taxing Woman is now in our possession, we will show it tonight (Monday) at 9:00 pm in Odell Lounge. It is an optional video and just for fun. If you have not seen this comedy, you will enjoy it!

\section{TAKE THE BUS!}

A number of program participants have been asking the R.A.s to take them on errands to Fred Meyer, the post office, etc. The program staff does not provide "taxi services" or "bus services" for students. If you want to go downtown or to Fred Meyer, please plan to take the Tri-Met Bus or a taxi. Please do not ask the staff members to take you on errands. 
However, we want to encourage groups of students to get off campus and we will try to provide transportation (vans) when it is for a good purpose and at a convenient time. The criteria we use are: (1) if a van is available from the Campus Safety Office; (2) if an R.A. or approved drivers is availabie to drive; (3) if the request is made well ahead of time so that arrangements can be made; (4) if the request is made by an integrated group of 10 or more participants; (5) if the activity is culturally enriching in some way.

Remember that a group of four or five students can take a taxi to and from downtown for about $\$ 10$ total. That way, each student would have to pay only $\$ 2-\$ 3$ each.

And, obviously, we will do what we can to help students in emergencies.

\section{PROGRAM LIBRARY}

The Oregon/Waseda Summer Program has a "library" on the second floor of Odell Hall. The room number is Odell 20.

There are a number of reference books available in the program library for student use. A list of reference books has been posted on the program library door. There are dictionaries as well books on Japanese language and culture. Videos are also available. Please check out books and videos through any of the RAs. Each has a key to the program library.

\section{RUMOR CONTROL}

Bumor. If you lose your key, the staff will immediately get you another one for free!

Eact: You will have to wait two days and pay $\$ 25.00$ for a lost key charge.

Bumor: The Oregon/Waseda students were in the Stewart Lounge using marijuana-according to a person atcending a conference. He knows because he smelled it!

Eact: None of the program participants was using marijuana. Some of the Japanese students were burning "Okyu," a Japanese herbal medicine used for tired muscles! It may smell strange, but it was definiteiy not marijuana.

Bumor: Greg Caldwell was not able to climb to the top of the rock climb during the wilderness program.

Eact: I made it all the way to the top after a very brief, temporary set back! 


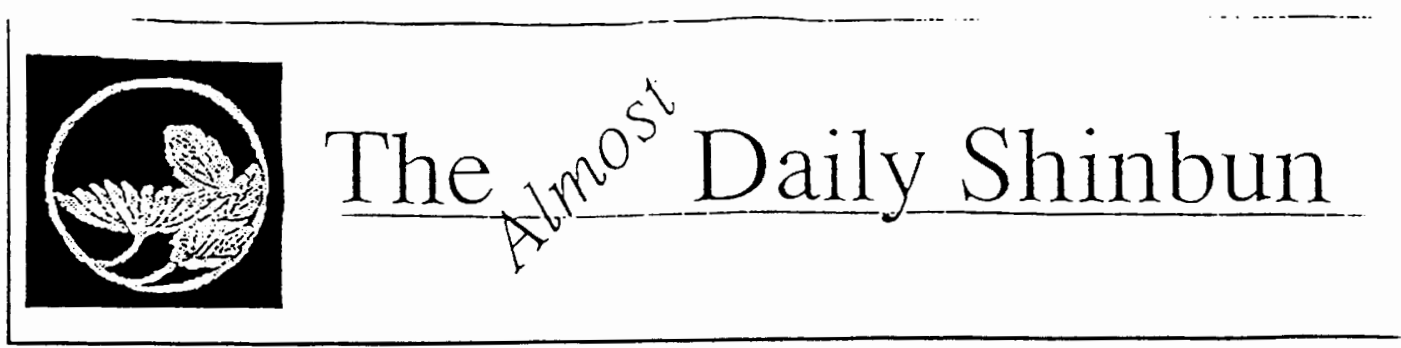

Issue 4

August 1, 1995

\section{IMPORTANT CHANGE! LITERATURE CLASS FILM TONIGHT!}

Sister Carrie, the film, will be shown tonight at 6:30 pm in Olin 301 for students enrolled in the Comparative Literature course. The film will be discussed in the literature class and is required for students in that class. Other students are welcomed to attend as well.

The film was originaily scheduled for later in the program but Professors Kominz and Ohkoso felt that it needed to be moved ahead to better accommodate the pace of the class.

Please make a note of the change and attend the film tonight at 6:30.

\section{“GRADUATION" CERTIFICATES - A CHECK}

We are in the process of preparing certificates for students who successfully complete the Oregon/ Waseda Summer Program. We want to be sure that your name is listed as you want it on the certificate and that the spelling is correct.

Please check the list that will soon be placed on the bulletin board near the Odell Hall entrance. Make sure that your name is listed correctly. Make any changes on the sheet. All changes should be made by next Monday, August 7.

\section{LET'S DANCE}

The International Students at lewis \& Clark (ISLC) is sponsoring a dance on Friday night, August 4 from 8:30 pm to midnight in Tammarack Lounge (site of Japan Day). The ISLC invites the Oregon/Waseda Summer Program participants to stop by and dance.

There will be soft drinks and a few snacks. There is a $\$ 2.00$ cover charge per student. It may be a good way to let off some steam and get to know some other students at Lewis \& Clark.

\section{HOME PAGE FOR OREGON/WASEDA SUMMER PROGRAM}

With (lots of) help from Toshi Abe, the staff is in the process of setting up a world wide web home page for the summer program. In just a few hours. Toshi has organized a home page with pictures of the wilderness trip and with sections on facuity, dorms, and student life.

Thank you, Toshi, for all of your help! You are a computer genius. 


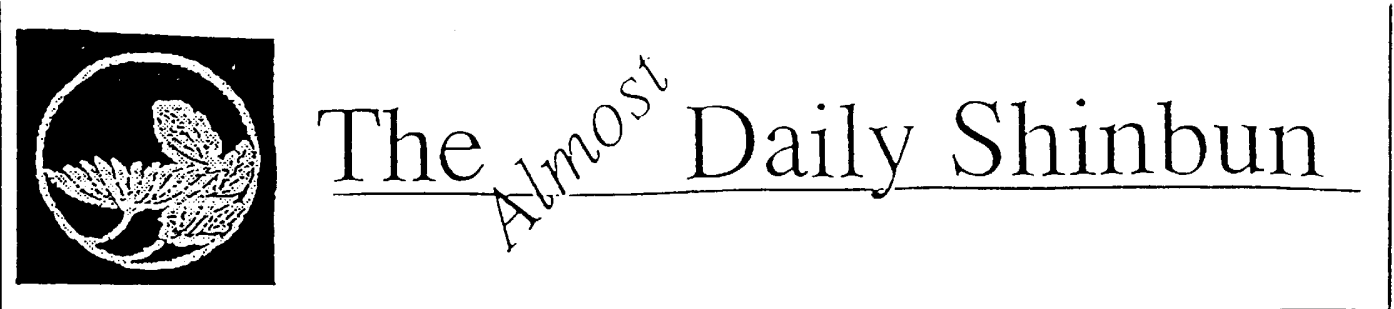

Issue 5

August 9, 1995

\section{QUESTIONNAIRE RESULTS: A MEETING!}

Thank you for taking time on the bus yesterday to complete the questionnaire that we distributed. The results were interesting and helpful. The faculty and staff appreciate your comments.

The results of the questionnaire suggested that some of you (about $50 \%$ ) would like to discuss the program in an open forum or meeting. The faculty and staff have agreed to meet with interested students tomorrow night (Thursday, August 10) before the colloquium.

The purpose of the meeting will be to let you talk about how you view the program and to make suggestions that can help improve the program-either this year or in the future. Kenji Shibata and Greg Caldwell will serve as moderators. Faculty members will also attend to hear what you have to say and to answer any questions.

Hope to see you Thursday, August 10, at 6:00 pm in Olin 301 , just before the colloquium.

\section{COMPUTER LAB OPEN}

The Odell Dorm computer lab will open this week. Lesley Parker, RA, will post a schedule for the lab tomorrow. We have had several requests from students to open the lab. So, someone must be studying!

\section{BASEBALL, ANYONE?}

Professor O'Bannon has been hard at work planning a trip to Seatule for all of you baseball nuts, (excuse me, fans). On Sunday, August 20 in Seattle, the Mariners play Boston (I am told Boston is \# I at this point) and an exciting trip is planned.

The trip is being arranged through Professor O'Bannon's friend, Pete Ward. Pete is a Lewis \& Clark graduate who played professionally for both Chicago and the Yankees. Pete would enjoy accompanying a group of students to see the game in Seattle. Tentatively, you would leave by train around 7:00 am on Sunday, August 20th, go to the baseball game in the Kingdom (next to the station) and then travel back to Portland the same day by train.

Cost of the trip will be $\$ 75$ and will include the transportation costs and tickets to the game.

If you are interested, please sign up on the board at Odell Dorm by Friday.

\section{OFFICE HOURS}

Professor Ohkoso would like to inform students of her office hours. Please stop by and see her:

Fri. $8 / 11 \quad 4-5 \mathrm{pm}$
Mon. $8 / 14 \quad 4-5 \mathrm{pm}$
Wed. $8 / 23 \quad 4-5 \mathrm{pm}$. 


\section{VOLLEYBALL REMATCH}

How about a volleyball re-match between the students and the faculty/staff! We will see you at the Juniper volleyball court at 4:30 pm on Friday, August 12.

The faculty/staff team has added a few people to its line-up. So look out!

\section{TOOTSIE IS DEAD!}

It appears that just about everyone has seen the film Tootsie, originally scheduled for the last week of the program. Therefore, we have been asked to cancel the showing of that film as a "group" activity.

For those few students who may not have seen Tootsie, it will be available for viewing in the Odell Dorm lounge on Tuesday evening, August 22nd.

\section{REMEMBER THURSDAY}

Remember that you should change your sheets tomorrow! 


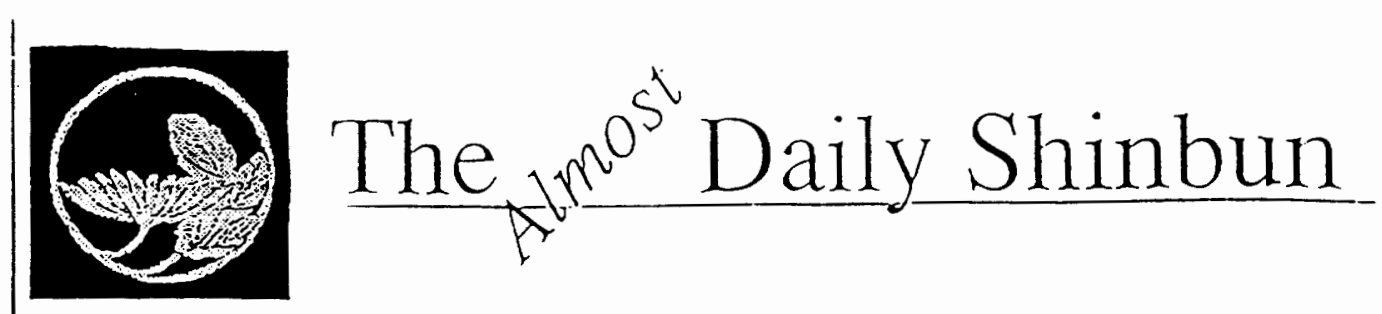

Issue 6

August 15, 1995

\section{YOU HAD BETTER READ THIS!}

It appears that many of you are not reading the Almost Daily Shinbun.. It is to your advantage to at least skim it quickly each time it is published as it contains important announcements. If you don't read this edition, you may not eat tomorrow!

\section{PLEASE KEEP YOUR DOORS LOCKED!}

The RAs report finding many dorm rooms open and no students in the rooms. Please make sure that you lock your doors when you are out of the room. Usually, the RAs close and lock doors in rooms that are vacant.

\section{CHECK YOUR NAME FOR THE CERTIFICATE}

We are getring the "graduation" certificates ready for the closing dinner/ceremony. We want to be sure that your name appears as you want it on the certificate. Please check the list that is on the Odell bulletin board to make sure that your name is spelled correctly and that it is the exact name you want on the certificate. We will take the list down and send it to the calligrapher on Wednesday. So, please check the list today.

\section{NEW SCHEDULE}

A new schedule was published and distributed yesterday. Please make sure that you have a copy. If not, please contact an RA or one of the staff members.

Oregon/Waseda Summer Program
NEW MEAL SCHEDULE

For the next ten days Waseda program students will be the only students served by Bon Appetit in the cafeteria. For this reason. Bon Appetit has asked that we shorten the meal hours to make it more convenient for them and less costly to operate the cafeteria.

The new meal hours are:

Breakfast: 7:30 - 8:30

Lunch: $12: 00-1: 00$

Dinner: $5: 00-6: 00$

\section{COMPUTER NEEDS}

Many students have indicated that there is a need to open the Odell computer lab (basement) for longer hours during the last two weeks of the program. Lesley Parker, RA. is in charge of the Odell lab and she will do what she can to assist you. If you have recommendations for times, please let Lesley know. But, remember to be reasonable. It will not be possible for the RAs to monitor the computer lab twenty-four hours each day.

Lesley is aiso working to make sure that the computer clusters in Odell, Stewart and Akin are up and running for the next two weeks.

If you run out of paper or there is a problem with a computer, please let Lesley know. Just slip a note under her door if she is not in. 


\section{DIRTY DISHES ARE NOT “COOL!”}

The housecleaning staff has reported that the Odell kitchen is a mess. Evidently, students are leaving dirty pots, pans and dishes around the kitchen.

We have instructed the housecleaning staff to confiscate any dirty dishes left in kitchen. They will not be replaced. So, if you want to use the kitchen facilities, please make sure that you clean up after yourself. Thank you for your cooperation.

\section{SAFE AND RESTFUL SLEEP, SLEEP, SLEEP!}

Some of you are not getting enough sleep. It is evident from the bags under the eyes, the nodding heads in class, and the soaring emotional level. We are now in the fifth week of the program and, like last year, this is a time of high frustration and low energy.

The faculty and staff are aware of this and are taking some steps to help you out. You can help yourself out as well by taking care of yourself. You need more rest and you need to eat well and exercise sufficiently.

Let's try on both sides to realize this situation and take steps to control it. OK? Thanks.

\section{INTERESTED IN BEING AN R.A. NEXT YEAR???}

If you are a participant in this year's program and would be interested in being an R.A. in next year's program, please contact Greg Caldwell. R.A.

recruiment will not start until well into next year, but Greg will make a note of your interest and contact you when the positions are announced.

\section{RUMOR CONTROL!}

Bumor: The Econ field trip scheduled for Thursday is cancelled.

Tnuth: The Econ field trip to Pendleton scheduled for Thursday is still scheduled for Thursday. But, the Econ field trip for next Monday has been cancelled. 
APPENDIX C

EVALUATIONS 


\section{HOW IS THE PROGRAM GOING?}

We are now in the middle of the summer program and it is time to hear from you. We want to know how the program is going from the students' point of view. Please take five minutes to make comments.

Dead line: END OF FIELD TRIP TOMORROW

I am a (check one) ___ Japanese student __ US student

1. Tell us your language class level and comment on the class.

(Example: What are the most/least useful activities? What do you most enjoy/dislike doing? Do you understand the instructions? Is the pace/speed of the class appropriale?)

2. Check two theme classes: Please comment on the classes:

Comparative Literature

US/Asian History/Culture

US/Japan Economies

3. Do you understand the basic technical terms (for example. "affirmative action." "discrimination," ) used in the courses?

4. Do you have any suggestions of ways that we could help you understand and enjoy the courses more?

5. Would you like to have a group meeting with students and faculty to discuss the program?

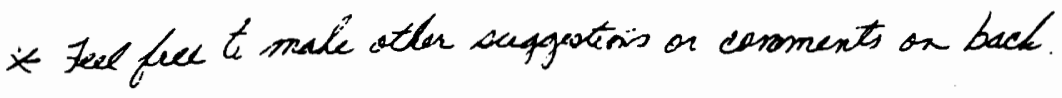




\section{U.S. and International Students' End-Program Questionnaire}

You will remember completing a pre-program questionnaire during the first week of the program. We realize that you are very busy studying for examinations, writing your final paper and preparing for your departure. Please take a few minutes to complete this endprogram questionnaire and return it to the program staff or resident assistants by Friday, August 25 .

Your cooperation will be greately appreciated.

Name:

(Optional)

1. How important was the interdisciplinary, thematic approach of academic course to you?(Check one)

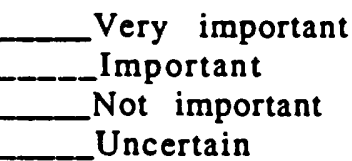

2. How important was the theme, "Japanese and American

Secieties: Equality and Inequality" to you?(Check one)

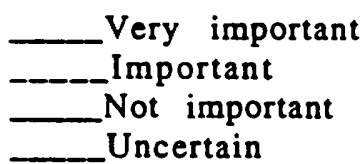

3. What did you think about the colloquium approach ? 
4. What did you think about the course selection system (choosing two classes out of three offered)?

I liked it

I did not like it

Reason/comments:

5. Please identify your Japanese Language class level.
Level
2
3

The amount of homework was (circle one)

Too little Appropriate Too much

6. How was the amount of homework assigned in the theme classes ? (circle according to your classes)
a. Literature
Too little
Appropriate Too much
b. History/Culture
Too little
Appropriate Too much
c. Economics
Too little
Appropriate Too much

7. How was the amount of office hours ? (circle one)
Insufficient
Appropriate

8. What did you think about the balance of class hours of

Japanese language and theme classes?(check one)

Appropriate balance

Japanese language and theme classes should be evenly balanced.

There should be more Japanese language classes than theme classes.

There should be more theme classes than Japanese language classes.

Uncertain 
9. What did you think about the focus of the program?(Check one)

The integrated, theme approach with adjunct Japanese is appropriate.

More attention should be given to the theme.

More attention should be given to Japanese.

More attention should be given to extracurricular and special activities. Uncertain.

Other(please specify)

10. What do you think was most important to your participation in class discussions?(Rank the following from 1 to 7 , with 1 indicating the most important factor.)

Knowledge about and understanding of the theme.

Knowledge about and understanding of the United States.

Knowledge about and understanding of Japan.

Open, positive attitude.

Communication skills.

English language proficiency of Japanese Students.

Other (Please specify)

11. What were the most challenging aspects of this program? (Rank from 1 to 7 , with 1 the most challenging.)

Theme classes.

Japanese langage classes.

Living with Japanese roommates.

Experiencing a new culture.

Making new friends.

Extracurricular activities

Other (Please specify) 
12. What were the most enjeyable aspects of this program? (Rank from 1 to 7 , with 1 the most enjoyable.)

Theme classes.

Japanese language classes.

Living with Japanese roommates.

Experiencing a new culture.

Making new friends.

Extracurricular activities

Other (Please specify)

13. What word best describes your general impression of the program content ? (Please specify)

14. Do you think participation in this program will be helpful to your present and/or future academic study plan?

_ Yes

No

Uncertain

15. Do you have any other comments and/or suggestions about the summer program?

16. Did the program meet your academic expectations? (Please circle)

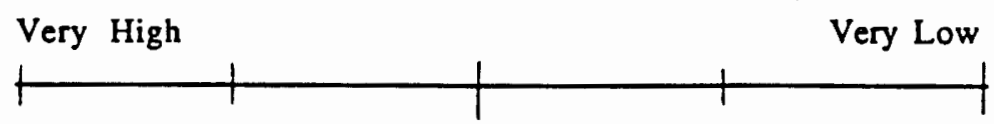

Comments: 
17. Did the program meet your cultural expectations? (Please circle)

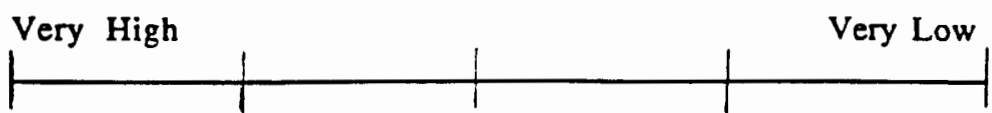

Comments:

18. Do you think the pre-program was effective?

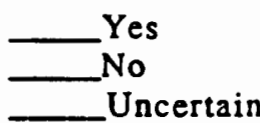

19. Do you think the pre-program for the theme courses should be held next summer?

\begin{tabular}{l} 
Yes \\
\hline No \\
\hline Uncertain
\end{tabular}

If "Yes",

A) When do you think the pre-program should begin?

B) How many days should the pre-program last?

C) How many class hours should there be?

D) Do you have any ideas on how the pre-program classes should be taught?

If "No", why not? 
20. Do you think Japanese language classes should be included in the pre-program?

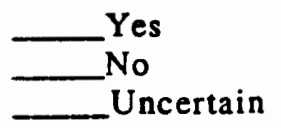

If "Yes",

A) When do you think Japanese classes in the preprogram should begin?

B) How many days should the Japanese classes in the pre-program last?

C) How many class hours for Japanese classes should be there in the pre-program?

D) Do you have any ideas on how the Japanese classes should be taught?

If "No", why not?

21. If you were a planning the information session held on your home campus advertising the summer program, how would you plan it? 
22. If you were planning the orientation of the summer program, how would you plan it?

23. Do you have any comments and/or suggestions about the preprogram of the summer program?

24. Based on your experience, what statement below best reflects your thought about the cost of the program? (Check one)

Too expensive

Expensive but worthwhile

Not too expensive

Unexpectedly low Uncertain

25. Do you think Waseda University should develop longer international education programs similar to this summer program?

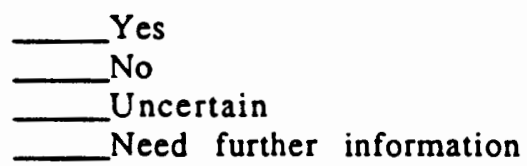

If "Yes" or "No" or"Need further info.", why?

26. If Waseda were to create a new international education program, what would be the ideal length of time? (Rank from 1 to 4 , with 1 the most appropriate.)

5 or 6 weeks

1 term

1 year

Other (please specify.) 
27. If Waseda should develop a long-term program of international study similar to the summer program, would you like to participate?

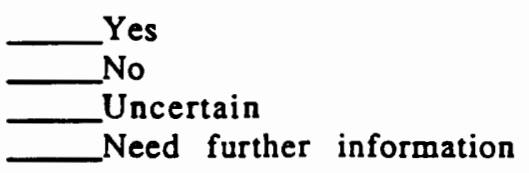

Thank you very much for your cooperation!

Please remember to return your completed questionnare to the program staff or resident assistants by Friday, August 25. 
APPENDIX D

TALLY NOTES 


$$
\text { - } 2+8-16 \text { Discusin grage wJT }
$$

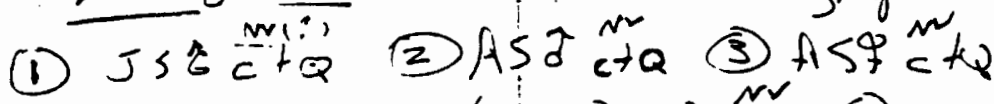

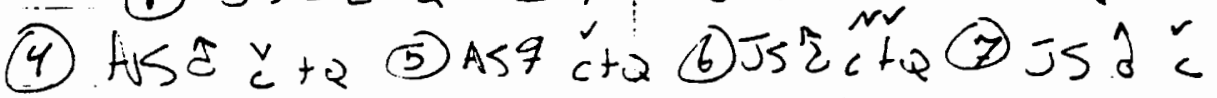

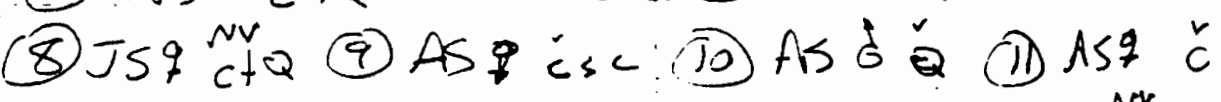

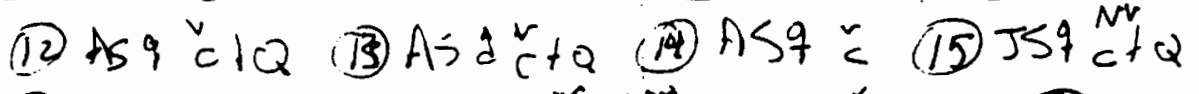

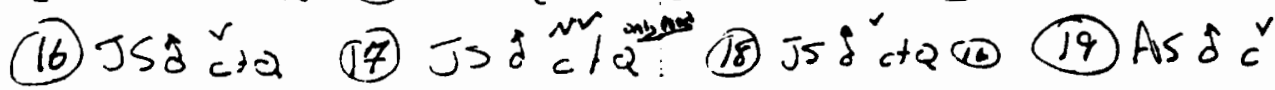

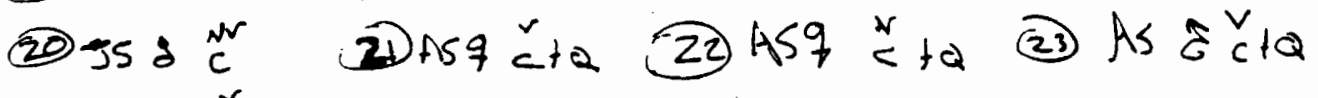

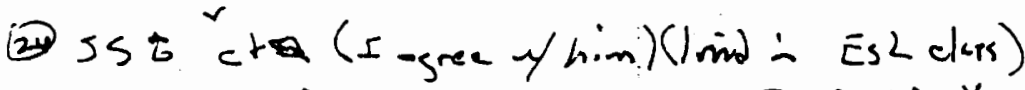

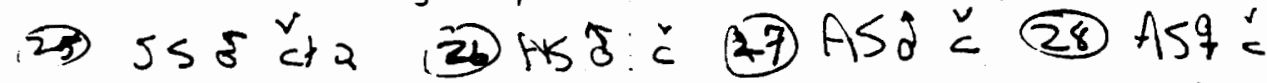

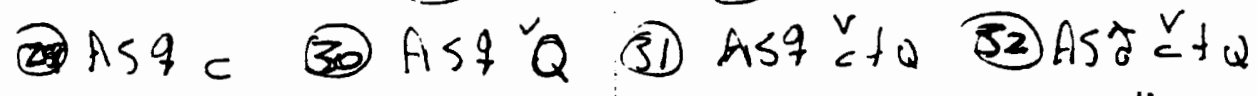

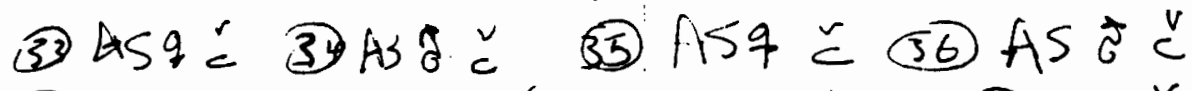

(DAS

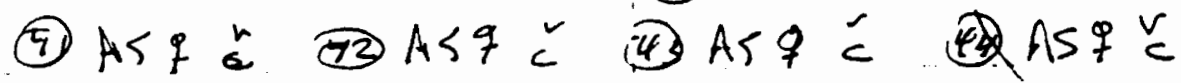

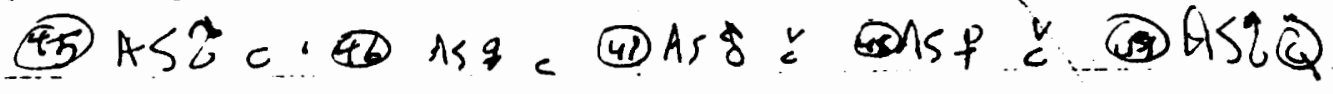

(50)ASi ${ }^{\circ}$ (31)

52

T. will go to dom, to talle to stud, 